\title{
Role of Blood Pressure Management in Stroke Prevention: A Systematic Review and Network Meta-Analysis of 93 Randomized Controlled Trials
}

\author{
Xiao-Ling Zhong, ${ }^{\mathrm{a}, *}$ Yi Dong, ${ }^{\mathrm{b}, *}$ Wei Xu, ${ }^{\mathrm{c}}$ Yu-Yuan Huang, ${ }^{\mathrm{b}}$ Hui-Fu Wang, ${ }^{\mathrm{c}}$ Tian-Song Zhang, ${ }^{\mathrm{d}}$ Li Sun, ${ }^{\mathrm{a}}$ \\ Lan Tan, ${ }^{\mathrm{c}}$ Qiang Dong, ${ }^{\mathrm{b}}$ Jin-Tai Yu ${ }^{\mathrm{b}}$ \\ ${ }^{a}$ Department of Neurology, Qingdao Central Hospital, Qingdao University, Qingdao, China \\ ${ }^{b}$ Department of Neurology and Institute of Neurology, Huashan Hospital, Shanghai Medical College, Fudan University, Shanghai, China \\ 'Department of Neurology, Qingdao Municipal Hospital, Qingdao University, Qingdao, China \\ 'Department of Chinese Traditional Medicine, Jing'an District Center Hospital of Shanghai, Fudan University, Shanghai, China
}

Background and Purpose The present study aimed to compare the efficacy and tolerability of different blood pressure (BP)-lowering strategies.

Methods Randomized controlled trials that compared various antihypertensive treatments and stroke outcomes were included. Eligible trials were categorized into three scenarios: single or combination antihypertensive agents against placebos; single or combination agents against other agents; and different BP-lowering targets. The primary efficacy outcome was the risk reduction pertaining to strokes. The tolerability outcome was the withdrawal of drugs, owing to drug-related side effects (PROSPERO registration number CRD42018118454 [20/12/2018]).

Results The present study included 93 trials (average follow-up duration, 3.3 years). In the pairwise analysis, angiotensin-converting enzyme inhibitors (ACEis) and beta-blockers (BBs) were inferior to calcium channel blockers (CCBs) (odds ratio [OR], 1.123; 95\% confidence interval [CI], 1.008 to 1.252) $(\mathrm{OR}, 1.261 ; 95 \% \mathrm{Cl}, 1.116$ to 1.425$)$ for stroke prevention, $\mathrm{BB}$ was inferior to angiotensin II receptor blockers (ARB) $(\mathrm{OR}, 1.361 ; 95 \% \mathrm{Cl}, 1.142$ to 1.622$)$, and diuretics were superior to $\mathrm{ACEi}$ $(\mathrm{OR}, 0.871 ; 95 \% \mathrm{Cl}, 0.771$ to 0.984$)$. The combination of $A C E i+C C B$ was superior to $A C E i+d i u r e t i c$ $(\mathrm{OR}, 0.892 ; 95 \% \mathrm{Cl}, 0.823$ to 0.966$)$. The network meta-analysis confirmed that diuretics were superior to $\mathrm{BB}(\mathrm{OR}, 1.34 ; 95 \% \mathrm{Cl}, 1.11$ to 1.58$)$, $\mathrm{ACEi}+$ diuretic $(\mathrm{OR}, 1.47 ; 95 \% \mathrm{Cl}, 1.02$ to 2.08$), \mathrm{BB}+\mathrm{C}-$ $\mathrm{CB}(\mathrm{OR}, 2.05 ; 95 \% \mathrm{Cl}, 1.05$ to 3.79$)$, and renin inhibitors $(\mathrm{OR}, 1.87 ; 95 \% \mathrm{Cl}, 1.25$ to 2.75$)$ for stroke prevention. Regarding the tolerability profile, the pairwise analysis revealed that ACEi was inferior to CCB and less tolerable, compared to the other treatments.

Conclusions Monotherapy using diuretics, $\mathrm{CCB}$, or $\mathrm{ARB}$, and their combinations could be employed as first-line treatments for stroke prevention in terms of efficacy and tolerability.

Keywords Antihypertensive agents; Stroke; Meta-analysis
Correspondence: Jin-Tai Yu Department of Neurology and Institute of Neurology, Huashan Hospital, Shanghai Medical College, Fudan University, 12th Wulumuqi Zhong Road, Shanghai 200040, China Tel: $+86-21-52888160$ Fax: +86-21-62483421

E-mail: jintai_yu@fudan.edu.cn https://orcid.org/0000-0002-76860547

Co-correspondence: Qiang Dong Department of Neurology and Institute of Neurology, Huashan Hospital, Shanghai Medical College, Fudan University, 12th Wulumuqi Zhong Road, Shanghai 200040, China Tel: $+86-21-52888160$

Fax: +86-21-62483421 E-mail:dong_qiang@fudan.edu.cn https://orcid.org/0000-0002-43872461

Co-correspondence: Lan Tan Department of Neurology, Qingdao Municipal Hospital, Qingdao University, Qingdao 266071, China

Tel: +86-21-52888160

Fax: +86-21-62483421

E-mail: dr.tanlan@163.com https://orcid.org/0000-0002-87597588

Received: July 4, 2020

Revised: October 8, 2020

Accepted: October 14, 2020

* These authors contributed equally to the manuscript as first author. 


\section{Introduction}

Stroke is a leading cause of morbidity and mortality across the globe. In 2017, stroke was the second most frequent cause of death, after ischemic heart disease, and caused 6.2 million deaths worldwide. ${ }^{1}$ Moreover, hypertension is a leading cause of stroke and the significance of blood pressure (BP) lowering in stroke prevention is already established in literature. ${ }^{2}$ Considering the high prevalence of stroke, achievement of the most appropriate or ideal BP could have a significant impact on public health.

A recent meta-analysis reported that the reduction in systolic blood pressure (SBP) by $10 \mathrm{~mm} \mathrm{Hg}$ was associated with a $27 \%$ reduction in the risk associated with stroke. ${ }^{3}$ Moreover, the magnitude of reduction in BP was linearly associated with the extent of risk reduction pertaining to recurrent strokes. ${ }^{4} \mathrm{~A}$ systematic review of the 2017 American College of Cardiology (ACC)/American Heart Association (AHA)/American Academy of Physician Assistants (AAPA)/Association of Black Cardiologists $(A B C) / A m e r i c a n$ College of Preventive Medicine (ACPM)/American Geriatrics Society (AGS)/American Pharmacists Association (APhA)/American Society of Hematology (ASH)/American Society for Preventive Cardiology (ASPC)/National Medical Association (NMA)/Preventive Cardiovascular Nurses Association (PCNA) guidelines for the prevention, detection, evaluation, and management of high BP in adults (the 2017 high BP guidelines) has recommended intensive BP-lowering treatments (to a target of below $130 \mathrm{~mm} \mathrm{Hg}$ ) other than the standard antihypertensive therapies. ${ }^{5}$ However, despite the well-established and widespread use of BP-lowering agents for the prevention of stroke, the most appropriate treatments pertaining to various populations are still under debate. A meta-analysis published in 2016 demonstrated that calcium channel blockers (CCBs) were superior to other drugs for the prevention of stroke in the general population. ${ }^{3}$ A systematic review of the 2017 high BP guidelines employed network meta-analysis and reported that thiazides and thiazide-like diuretics (THZs) were associated with a significantly lower risk of stroke in patients with hypertension. ${ }^{5}$ Another meta-analysis reported that CCBs were at least as effective as the other first-line antihypertensive agents in the management of hypertensive patients with a previous history of stroke. ${ }^{6}$ Nevertheless, previous meta-analyses have rarely involved the comprehensive analysis of the most appropriate antihypertensive agents for different target populations. Moreover, previous meta-analyses did not consider the tolerability and safety profiles pertaining to the antihypertensive strategies. Furthermore, combined antihypertensive strategies were recommended by several guidelines, in order to achieve better BP control and to slow the progression of hypertension. However, previous studies provided limited evidence on the efficacy of combined antihypertensive therapies in stroke prevention.

Traditional meta-analysis could only compare the treatments assessed in the same study, whereas network meta-analysis could compare multiple treatments from different studies through common comparators. Consequently, several treatments could be ranked. ${ }^{7.8}$ Hence, the present study performed a network meta-analysis to compare the efficacy and tolerability profiles of both single and combined antihypertensive strategies for stroke prevention in different populations.

\section{Methods}

\section{Search strategy and selection criteria}

The present meta-analysis adhered to the preferred reporting items for systematic reviews and meta-analysis PRISMA) statement $^{9}$ and the PRISMA network meta-analysis extension statement. ${ }^{10}$ The current study used an existing strategy ${ }^{11}$ with additional items, such as cerebrovascular disorders, stroke, brain infarction, cerebral infarction, brain ischemia, cerebral hemorrhage, or intracranial hemorrhage, in order to identify the relevant trials from the Pubmed database, published during the time period from January 1, 1966 to December 1, 2018. The detailed search terms are provided in Appendix 1. The present study restricted the search to randomized controlled trials (RCTs) alone without any language restrictions. The Cochrane Collaboration database was also searched. Furthermore, in order to identify eligible studies, the present study performed a manual inspection of the reference list pertaining to the studies included in the review. Subsequently, a manual examination was performed to ascertain whether each trial reported stroke as a primary or secondary outcome. Studies that fulfilled the following criteria were included in the current meta-analysis: (1) RCTs; (2) greater than 1,000 patient-years of follow-up in each study group; (3) trials that reported stroke as the primary or secondary outcome; and (4) trials that used antihypertensive drugs for indications other than the management of hypertension such as proteinuria. Eligible trials were extracted and categorized into three scenarios: single, or a combination antihypertensive agents against placebos, single, or combination agents against others, and different BP-lowering targets. Trials that documented the presence of baseline comorbidities were not excluded.

\section{Data extraction and quality assessment}

The literature search, data extraction, and quality assessment were performed independently by two researchers (X.L.Z. and Y.D.). In case of disagreements, consensus was achieved through 
the referral to a third reviewer (J.T.Y.). Data were extracted into specially designed Excel sheets that listed the baseline characteristics pertaining to each group, which is provided in Supplementary Table 1.

The primary efficacy outcome was measured by the incidence of stroke. Outcomes of interest were all-cause mortality, cardiovascular-related deaths, all strokes (fatal or nonfatal), fatal or disabling stroke, ischemic stroke, and hemorrhagic stroke by groups. The tolerability outcome was measured by the withdrawal, owing to drug-related side effects.

The quality of each study was critically appraised by the two researchers who performed the literature review, on the basis of a 7-point tool, in order to assess the risk of bias using the Cochrane Collaboration tool. ${ }^{12}$

\section{Statistical analysis}

The present study performed the meta-analysis in two steps. First, a traditional meta-analysis was performed to clarify the effects of antihypertensive agents on the odds ratio (OR) of various outcomes. Second, a pairwise and network analysis was performed to compare the efficacy and tolerability of all antihypertensive agents in stroke prevention.

\section{Effects of BP-lowering for various outcomes}

In this step, the present study combined the trials involving antihypertensive agents versus placebos and higher versus lower BP-lowering targets, and performed a traditional meta-analysis. The OR was estimated from the number of events and participants pertaining to each outcome in each trial and pooled results with the Mantel-Haenszel and Hartung-Knapp adjustment for random effects models. The magnitude of the statistical heterogeneity among the studies was assessed using the standard Cochrane chi-square test. Subgroup analyses were stratified by age, history of stroke, cardiovascular disease, diabetes mellitus, baseline SBP levels, and achieved SBP level. Publication bias was evaluated both graphically using a funnel plot and using the Egger statistical test for funnel plot asymmetry, ${ }_{1}^{13}$ if a minimum of 10 studies were available for each outcome. A leave-one-out sensitivity analysis was performed to determine whether any one study had a disproportionately large impact on the pooled $\mathrm{OR}$.

\section{Pairwise and network analysis of BP-lowering agents for stroke prevention}

In this step, the current study included all the eligible trials and performed the pairwise and network meta-analysis. The primary outcome was measured as all types of stroke reduction and the tolerability outcome was assessed by the incidence of drug withdrawal, owing to drug-related side effects. First, a pairwise meta-analysis was performed with a random effects model to analyze direct treatment comparisons. Heterogeneity was assessed using the $\mathrm{I}^{2}$ metric. Second, the present study analyzed the pooled data pertaining to all BP-lowering treatments with random effects models within a Bayesian framework in OpenBUGS (http://openbugs.net). ${ }^{14}$ The details pertaining to the OpenBUGS codes that were used in the study are shown in Appendix 2. A valid network meta-analysis will satisfy the assumption of transitivity. Differences between the direct and indirect comparisons could suggest that the transitivity assumption might not hold. The present study assessed the evidence consistency in the networks in two ways. One was the nodesplit approach to contrast direct evidence with indirect evidence from the entire network on each node. ${ }^{15-17}$ The other was the design-by-treatment interaction model that provided a single inference, using the chi-square test, regarding the plausibility of assuming consistency throughout the entire network. ${ }^{18}$ The surface under the cumulative ranking curve (SUCRA) and rankograms were used to provide a hierarchy of the regimens. ${ }^{19}$ The two-dimensional plots and clustering methods were conducted to obtain meaningful groups of the treatments..$^{20}$ In addition, the current study assessed the small study effects using comparison adjusted funnel plot symmetr..$^{20}$

\section{Sensitivity analyses}

In order to examine the generalizability of the findings, the present study assessed for the effects of different trials and participant characteristics on the outcomes of sensitivity analyses by restricting the analyses to studies with the following design characteristics: hypertensive participants, no heart failure, published in or after 2000, and duration of follow-up of more than 3 years. The present study performed the subgroup analyses, in accordance with the age, history of stroke, history of diabetes, and baseline SBP. More details about the statistical analysis are shown in Supplementary methods.

Traditional meta-analyses were performed using $R$ version 3.4.1 (R Foundation for Statistical Computing, Vienna, Austria) and network meta-analyses were performed using OpenBUGS 3.2.3 and STATA 14.0 (StataCorp., College Station, TX, USA).

\section{Results}

In the present study, a total of 93 RCTs met the inclusion criteria, which enrolled 504,613 participants with an average follow-up period of 3.3 years and provided sufficient data to be included in the traditional or network meta-analysis (Figure 1). Among the aforementioned studies, 66 were deemed to be tri- 
als pertaining to the lowering of BP (52 compared a single BP-lowering agent against a placebo; 14 compared different BP-lowering targets) and they were included in the analysis to explore the association between the BP-lowering treatments and various outcomes. Among the 64 studies, 44 focused on patients above the age of 60 years. Four studies involved participants without any prior history of stroke and five studies included participants with a previous history of stroke. A total of 82 trials with 14 different BP-lowering strategies were included to compare the efficacy of the treatments. Six drug classes, alone or in combination, were compared with each other or the

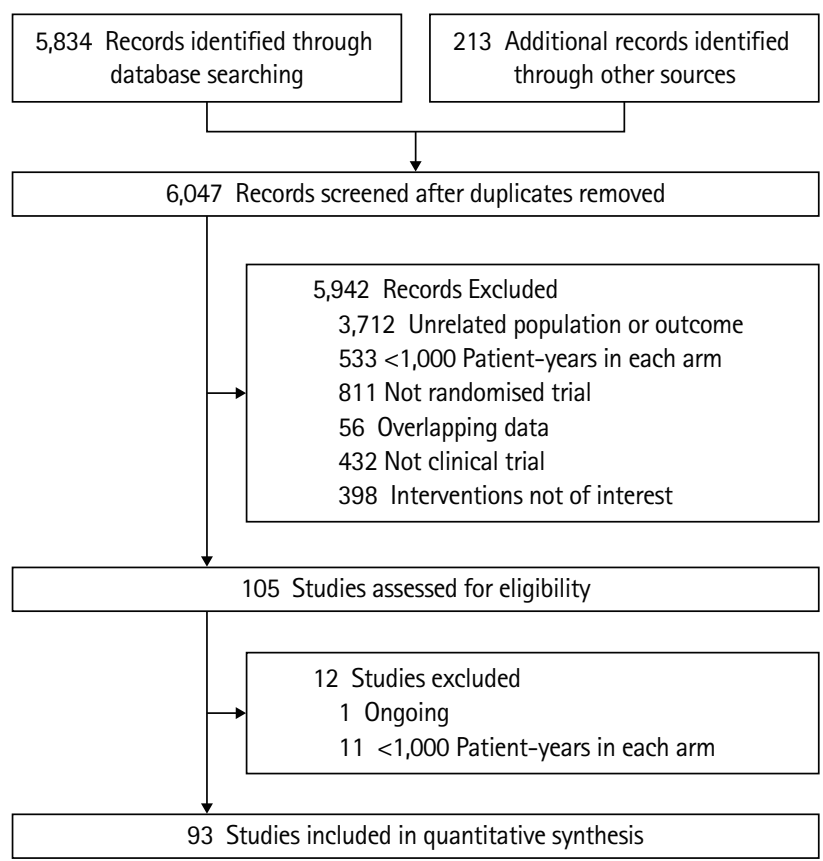

Figure 1. Flow diagram depicting the study selection. placebos. Among the 82 studies, five studies focused on participants without any prior history of stroke, whereas seven studies included patients with a previous history of stroke. Among the studies, 60 trials were published after 2000 and 42 studies focused on participants with hypertension. The present study included 22 trials that reported the events pertaining to drug-related side effects and withdrawal, in order to compare the tolerability of the treatments. In the current study, 36 trials compared different BP-lowering agents against each other and nine of them were included in both the analyses. Among them, five trials compared the BP-lowering agents to placebos and four trials compared the different BP-lowering targets with different antihypertensive agents.

Regarding the quality of the studies, 88 trials were judged to be at a low risk of bias; the risk of bias was unclear in three trials and two trials were deemed to be at a high risk of bias. The baseline characteristics and summary of risk bias assessment of the trials are shown in Supplementary Table 1 and Supplementary Figure 1.

\section{Meta-analysis of the association between BP-lowering treatment and various outcomes}

The significance of SBP reduction pertaining to various outcomes is shown in Figure 2. BP-lowering treatment was associated with a significant risk reduction in all strokes $(O R, 0.79$; 95\% confidence interval [CI], 0.74 to 0.85 ). Consistently, the reduction in BP was associated with a reduction in all-cause mortality, cardiovascular-related death, fatal or disabling stroke, ischemic stroke, and hemorrhagic stroke. The 0 statistics and $\mathrm{I}^{2}$ metrics indicated that the heterogeneity pertaining to all the concerned outcomes was moderate (Supplementary Figures 2-7).
No. of studies

$\begin{array}{lrrrrr} & & \text { Events } & \text { Participants } & \text { Events } & \text { Participants } \\ \text { Stroke } & 66 & 5,264 & 166,416 & 6,173 & 158,396 \\ \text { Ischemic stroke } & 6 & 1,606 & 24,268 & 1,805 & 24,288 \\ \text { Hemorrhagic stroke } & 6 & 177 & 24,268 & 247 & 24,288 \\ \text { Fatal or disabling stroke } & 18 & 448 & 43,087 & 637 & 42,928 \\ \text { Ml } & 55 & 4,138 & 135,816 & 4,383 & 127,822 \\ \text { Cardiovascular death } & 52 & 6,384 & 152,222 & 6,939 & 144,674 \\ \text { All cause death } & 56 & 11,326 & 155,586 & 11,779 & 148,155\end{array}$

OR $(95 \% \mathrm{Cl})$

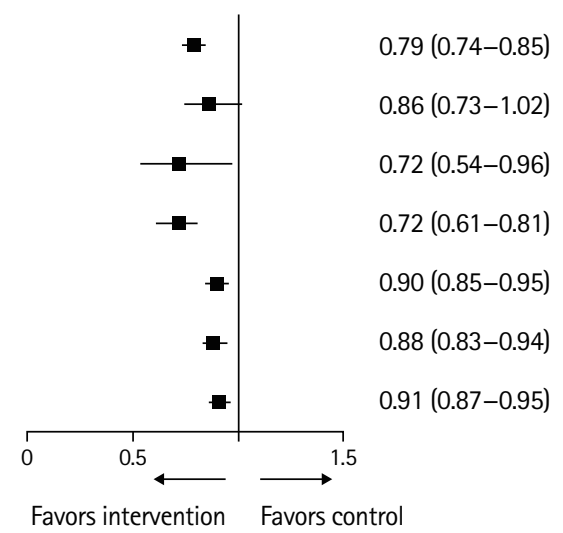

Figure 2. Significance of systolic blood pressure reduction pertaining to multiple outcomes. $\mathrm{OR}$, odds ratio; $\mathrm{Cl}$, confidence interval; $\mathrm{Ml}$, myocardial infarction. 
The association between BP reduction and stroke prevention, categorized according to the different study characteristics, is shown in Figure 3. The results of the subgroup analyses were generally concurrent with the main analyses, which showed a significant association between the stroke incidence and BP-lowering treatments. However, among the patients with

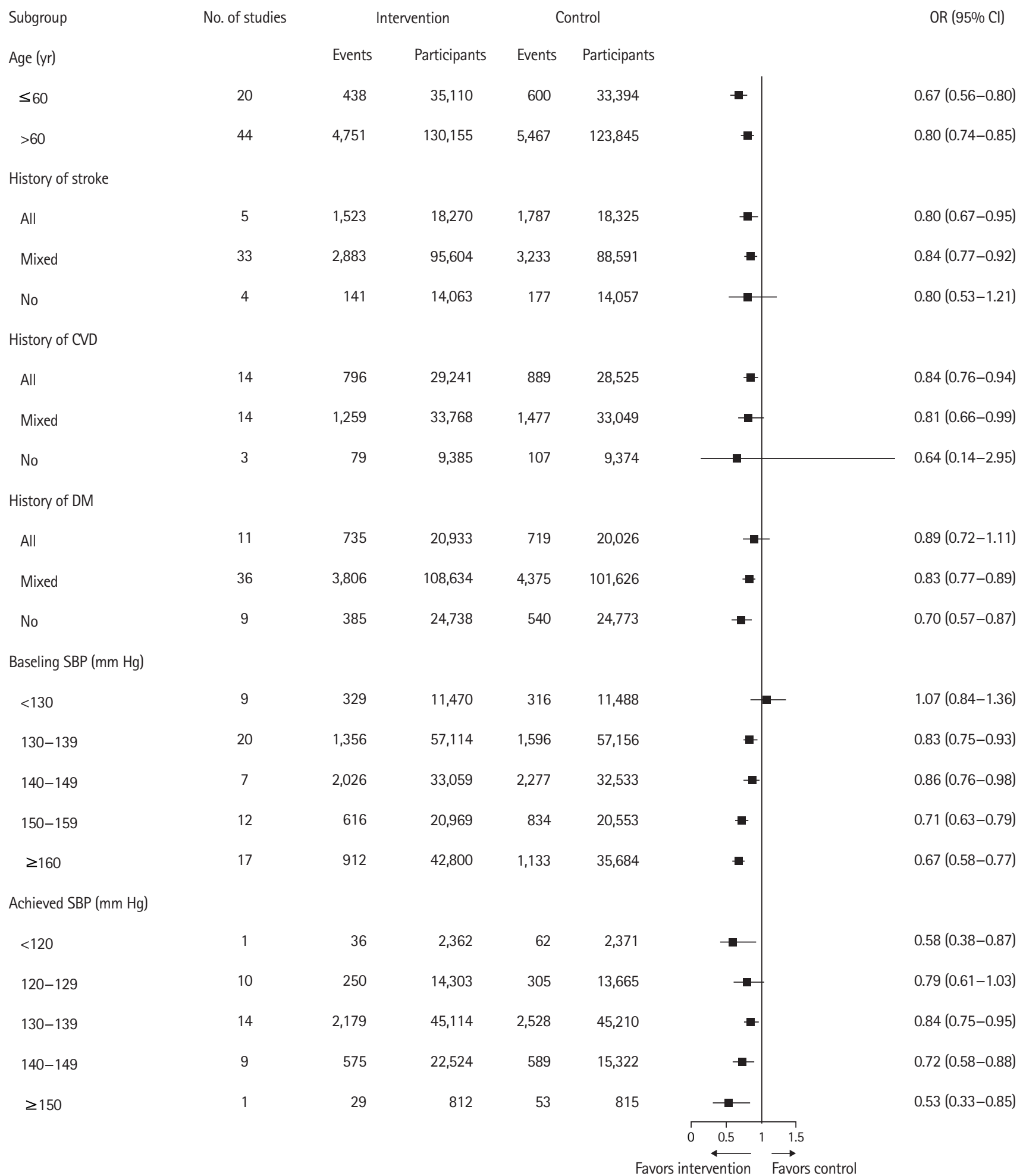

Figure 3. Association of blood pressure lowering and stroke prevention, categorized in accordance with the multiple study characteristics. $\mathrm{OR}$, odds ratio; $\mathrm{Cl}$, confidence interval; CVD, cardiovascular disease; DM, diabetes mellitus; SBP, systolic blood pressure. 
baseline SBP below $130 \mathrm{~mm} \mathrm{Hg}$, there was no significant association between the stroke incidence and BP-lowering treatments (OR, 1.07; $95 \% \mathrm{Cl}, 0.84$ to 1.36$)$. The present study observed a trend of increased benefits that could be gained with the increase in baseline SBP. Moreover, BP-lowering treatments were associated with a low risk of stroke at all target levels of SBP, except for the levels of 120 to $129 \mathrm{~mm} \mathrm{Hg}$. The present analyses showed a potential benefit pertaining to the association between BP reduction and stroke prevention in patients without a previous history of stroke. However, the results were not statistically significant $(\mathrm{OR}, 0.80 ; 95 \% \mathrm{Cl}, 0.53$ to 1.21$)$. Heterogeneity pertaining to the subgroups, measured using $\mathrm{I}^{2}$, is demonstrated in the subgroup plots in Supplementary Figures 8-13.

The possibility of publication bias was analyzed using Funnel-plot-based methods, which showed statistical significance pertaining to the outcomes of stroke and all-cause mortality (Egger's test, $P=0.03$ and $P=0.02$, respectively). The Duval and Tweedie trim and fill procedure suggested little changes in the $\mathrm{OR}$ and $95 \% \mathrm{Cl}$ after the adjustment $(\mathrm{OR}, 0.82 ; 95 \% \mathrm{Cl}, 0.80$ to 0.88 ) for stroke and $(\mathrm{OR}, 0.94 ; 95 \% \mathrm{Cl}, 0.90$ to 0.97$)$ all-cause mortality (Supplementary Figures 14-21).

A leave-one-out sensitivity analysis was performed and the pooled OR slightly varied from the original analysis (ranging from 0.91 to 0.92 for all-cause mortality; 0.88 to 0.89 for cardiovascular-related death; 0.79 to 0.80 for all stroke subtypes; 0.69 to 0.72 for fatal or disabling stroke; 0.83 to 0.89 for ischemic stroke; and 0.67 to 0.81 for hemorrhagic stroke) (Supplementary Figures 22-27). Hence, the effect of any one study on the overall summary estimates remained low.

\section{Comparison of different BP-lowering treatments using pairwise and network meta-analysis}

A total of 82 studies were included in the BP-lowering treatment comparison. Pairwise and network meta-analyses were performed to analyze the efficacy and tolerability as outcomes. Networks of eligible comparisons for efficacy and tolerability are presented in Figure 4, showing predominantly pairwise comparisons of agents with $\mathrm{CCB}$, angiotensin II receptor blocker (ARB), angiotensin-converting enzyme inhibitor (ACEi), or placebo. Thirty pairwise treatment comparisons had direct evidence pertaining to efficacy and 11 pairwise treatment comparisons had direct evidence pertaining to tolerability.

\section{Pairwise meta-analysis}

The results of the pairwise meta-analysis for efficacy and tolerability profiles were summarized in Supplementary Table 2. Among the monotherapies, CCB and diuretics were associated
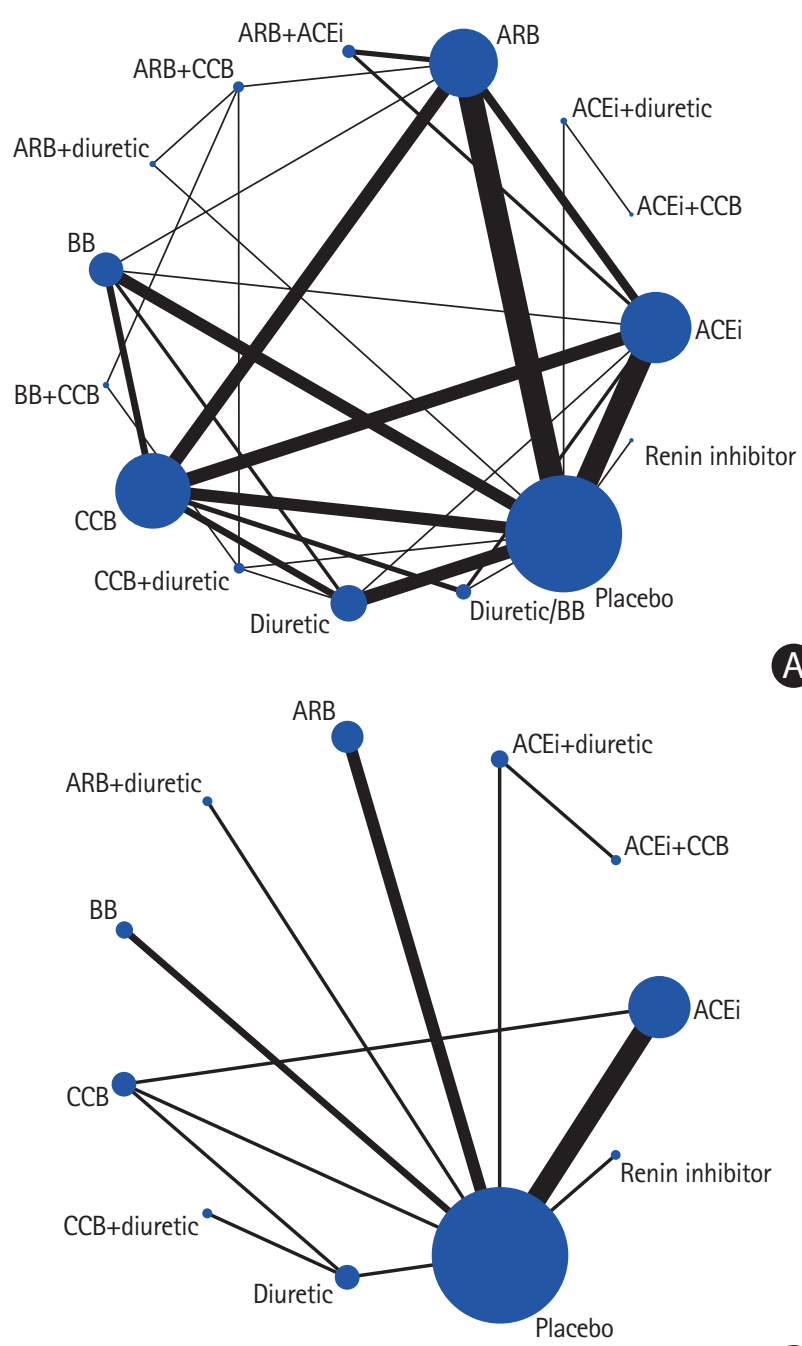

B

Figure 4. (A) Network of the studies included in the review with the available direct comparisons regarding efficacy. (B) Network of the studies included in the review with the available direct comparisons regarding tolerability. The width of the lines and the size of the nodes are proportional to the number of studies compared in each pair of treatments and the total sample size pertaining to each treatment, respectively. ARB, angiotensin II receptor blocker; $A C E i$, angiotensin-converting enzyme inhibitor; $C C B$, calcium channel blocker; BB, beta-blocker.

with a reduced incidence of about one-third of strokes, while beta-blockers (BBs) and ACEis were associated with a risk reduction of $19 \%$ and $8 \%$, respectively. Among the combination treatments, the combination of $\mathrm{CCB}+\mathrm{THZ}$ was associated with a $30 \%$ reduction in stroke risk, compared to the placebo. An assessment of the comparative efficacy of different strategies revealed that $A C E i$ and $B B$ were inferior to $C C B$ (ACEi vs. CCB [OR, $1.123 ; 95 \% \mathrm{Cl}, 1.008$ to 1.252 ], BB vs. CCB [OR, $1.261 ; 95 \% \mathrm{Cl}$, 1.116 to 1.425$]), B B$ was inferior to $A R B(O R, 1.361 ; 95 \% \mathrm{Cl}$, 1.142 to 1.622$)$, and diuretics were superior to $A C E i(O R, 0.871$; $95 \% \mathrm{Cl}, 0.771$ to 0.984$)$. Regarding the tolerability profile of 
Efficacy in stroke prevention

\begin{tabular}{|c|c|c|c|c|c|c|c|c|c|c|c|c|c|c|}
\hline Placebo & $\begin{array}{c}0.74 \\
(0.67-0.82) \\
\end{array}$ & $\frac{0.81}{(0.73-0.89)}$ & $\frac{0.81}{(0.73-0.90)}$ & $\frac{0.68}{(0.59-0.77)}$ & $\begin{array}{c}0.90 \\
(0.78-1.03) \\
\end{array}$ & $\begin{array}{c}0.99 \\
(0.71-1.37) \\
\end{array}$ & $\begin{array}{c}0.71 \\
0.53-0.94) \\
\end{array}$ & $\begin{array}{c}0.78 \\
(0.54-1.07) \\
\end{array}$ & $\frac{0.79}{(0.65-0.94)}$ & $\begin{array}{c}0.78 \\
(0.63-0.96) \\
\end{array}$ & $\begin{array}{c}0.72 \\
(0.47-1.05) \\
\end{array}$ & $\begin{array}{c}0.84 \\
(0.50-1.34) \\
\end{array}$ & $\begin{array}{c}1.38 \\
(0.72-2.53) \\
\end{array}$ & $\begin{array}{c}1.26 \\
(0.85-1.79) \\
\end{array}$ \\
\hline $\begin{array}{c}1.43 \\
(0.53-3.09) \\
\end{array}$ & CCB & $\begin{array}{c}1.09 \\
(0.97-1.22) \\
\end{array}$ & $\begin{array}{c}1.09 \\
(0.97-1.23)\end{array}$ & $\begin{array}{c}0.91 \\
(0.78-1.05) \\
\end{array}$ & $\frac{1.21}{(1.05-1.39)}$ & $\begin{array}{c}1.34 \\
(0.91-1.88) \\
\end{array}$ & $\begin{array}{c}0.96 \\
(0.70-1.30) \\
\end{array}$ & $\begin{array}{c}1.05 \\
(0.72-1.46) \\
\end{array}$ & $\begin{array}{c}1.06 \\
(0.88-1.25) \\
\end{array}$ & $\begin{array}{c}1.05 \\
(0.84-1.31) \\
\end{array}$ & $\begin{array}{c}0.97 \\
(0.62-1.42)\end{array}$ & $\begin{array}{c}1.14 \\
(0.67-1.84) \\
\end{array}$ & $\begin{array}{c}1.86 \\
(0.96-3.47) \\
\end{array}$ & $\frac{1.70}{(1.14-2.45)}$ \\
\hline $\begin{array}{c}1.10 \\
(0.54-2.01) \\
\end{array}$ & \begin{tabular}{c|}
0.94 \\
$(0.27-2.43)$ \\
\end{tabular} & ARB & \begin{tabular}{|c|}
1.00 \\
$(0.89-1.12)$ \\
\end{tabular} & $\begin{array}{c}0.84 \\
(0.71-0.97) \\
\end{array}$ & $\begin{array}{c}1.12 \\
(0.95-1.29) \\
\end{array}$ & $\begin{array}{c}1.23 \\
(0.86-1.71) \\
\end{array}$ & \begin{tabular}{|c|}
0.89 \\
$(0.64-1.19)$ \\
\end{tabular} & \begin{tabular}{|c|}
0.96 \\
$(0.66-1.34)$ \\
\end{tabular} & $\begin{array}{c}0.98 \\
(0.80-1.18) \\
\end{array}$ & \begin{tabular}{|c|}
0.97 \\
$(0.79-1.18)$ \\
\end{tabular} & $\begin{array}{c}0.89 \\
(0.58-1.30) \\
\end{array}$ & \begin{tabular}{|c|}
1.05 \\
$(0.61-1.68)$ \\
\end{tabular} & $\begin{array}{c}1.72 \\
(0.88-3.15) \\
\end{array}$ & $\frac{1.56}{(1.04-2.25)}$ \\
\hline$\frac{2.15}{(1.30-3.52)}$ & $\begin{array}{c}1.80 \\
(0.66-4.19) \\
\end{array}$ & $\begin{array}{c}2.18 \\
(0.90-4.65) \\
\end{array}$ & ACEi & $\begin{array}{c}0.84 \\
(0.71-0.97) \\
\end{array}$ & $\begin{array}{c}1.11 \\
(0.95-1.30)\end{array}$ & $\begin{array}{c}1.23 \\
(0.86-1.72) \\
\end{array}$ & $\begin{array}{c}0.88 \\
(0.64-1.19) \\
\end{array}$ & \begin{tabular}{c|}
0.96 \\
$(0.66-1.35)$ \\
\end{tabular} & $\begin{array}{c}0.98 \\
(0.80-1.17)\end{array}$ & $\begin{array}{c}0.97 \\
(0.78-1.19) \\
\end{array}$ & $\begin{array}{c}0.87 \\
(0.58-1.31) \\
\end{array}$ & $\begin{array}{c}1.05 \\
(0.61-1.69) \\
\end{array}$ & $\begin{array}{c}1.71 \\
(0.88-3.16) \\
\end{array}$ & $\frac{1.56}{(1.04-2.26)}$ \\
\hline $\begin{array}{c}1.86 \\
(0.56-4.59) \\
\end{array}$ & $\begin{array}{c}1.45 \\
(0.42-3.71)\end{array}$ & $\begin{array}{c}1.89 \\
(0.44-5.28) \\
\end{array}$ & $\begin{array}{c}0.91 \\
(0.24-2.33) \\
\end{array}$ & Diuretic & $\frac{1.34}{(1.11-1.58)}$ & $\frac{1.47}{(1.02-2.08)}$ & $\begin{array}{c}1.06 \\
(0.76-1.44) \\
\end{array}$ & \begin{tabular}{c|}
1.16 \\
$(0.79-1.63)$ \\
\end{tabular} & $\begin{array}{c}1.17 \\
(0.94-1.45) \\
\end{array}$ & $\begin{array}{c}1.16 \\
(0.91-1.48) \\
\end{array}$ & $\begin{array}{c}1.07 \\
(0.68-1.58) \\
\end{array}$ & $\begin{array}{c}1.25 \\
(0.73-2.03) \\
\end{array}$ & $\frac{2.05}{(1.05-3.79)}$ & $\frac{1.87}{(1.25-2.75)}$ \\
\hline $\begin{array}{c}1.26 \\
(0.44-2.89) \\
\end{array}$ & $\begin{array}{c}1.08 \\
(0.24-3.21) \\
\end{array}$ & $\begin{array}{c}1.28 \\
(0.35-3.38) \\
\end{array}$ & $\begin{array}{c}0.62 \\
(0.18-1.52)\end{array}$ & $\begin{array}{c}0.91 \\
(0.17-2.92) \\
\end{array}$ & BB & $\begin{array}{c}1.11 \\
(0.77-1.57) \\
\end{array}$ & $\begin{array}{c}0.80 \\
(0.57-1.09)\end{array}$ & $\begin{array}{c}0.87 \\
(0.59-1.23) \\
\end{array}$ & $\begin{array}{c}0.88 \\
(0.70-1.09) \\
\end{array}$ & $\begin{array}{c}0.87 \\
(0.69-1.11) \\
\end{array}$ & $\begin{array}{c}0.80 \\
(0.52-1.20) \\
\end{array}$ & $\begin{array}{c}0.94 \\
(0.55-1.53) \\
\end{array}$ & $\begin{array}{c}1.55 \\
(0.80-2.89) \\
\end{array}$ & $\begin{array}{c}1.41 \\
(0.94-2.05) \\
\end{array}$ \\
\hline $\begin{array}{c}3.10 \\
(0.64-9.27) \\
\end{array}$ & $\begin{array}{c}2.68 \\
(0.39-9.42) \\
\end{array}$ & $\begin{array}{c}3.15 \\
(0.54-10.52) \\
\end{array}$ & $\begin{array}{c}1.53 \\
(0.28-4.78) \\
\end{array}$ & $\begin{array}{c}2.28 \\
(0.29-8.45) \\
\end{array}$ & $\begin{array}{c}3.13 \\
(0.43-11.23) \\
\end{array}$ & $\begin{array}{c}\text { ACEi+ } \\
\text { diuretic }\end{array}$ & $\begin{array}{c}0.74 \\
(0.47-1.11) \\
\end{array}$ & \begin{tabular}{c|}
0.81 \\
$(0.49-1.25)$ \\
\end{tabular} & $\begin{array}{c}0.82 \\
(0.55-1.17) \\
\end{array}$ & $\begin{array}{c}0.81 \\
(0.54-1.18) \\
\end{array}$ & $\begin{array}{c}0.75 \\
(0.43-1.20) \\
\end{array}$ & $\begin{array}{c}0.85 \\
(0.58-1.21) \\
\end{array}$ & $\begin{array}{c}1.43 \\
(0.68-2.78) \\
\end{array}$ & $\begin{array}{c}1.31 \\
(0.76-2.11) \\
\end{array}$ \\
\hline $\begin{array}{c}1.82 \\
(0.14-7.68) \\
\end{array}$ & $\begin{array}{c}1.41 \\
(0.11-6.01) \\
\end{array}$ & $\begin{array}{c}1.88 \\
(0.12-8.23) \\
\end{array}$ & $\begin{array}{c}0.89 \\
(0.64-3.76) \\
\end{array}$ & $\begin{array}{c}0.95 \\
(0.12-3.46) \\
\end{array}$ & $\begin{array}{c}1.87 \\
(0.10-8.63) \\
\end{array}$ & $\begin{array}{c}0.99 \\
(0.04-4.58) \\
\end{array}$ & $\begin{array}{c}\mathrm{CCB}+ \\
\text { diuretic }\end{array}$ & $\begin{array}{c}1.11 \\
(0.70-1.67) \\
\end{array}$ & $\begin{array}{c}1.13 \\
(0.79-1.56) \\
\end{array}$ & $\begin{array}{c}1.12 \\
(0.77-1.59) \\
\end{array}$ & $\begin{array}{c}1.02 \\
(0.64-1.56) \\
\end{array}$ & $\begin{array}{c}1.21 \\
(0.65-2.04) \\
\end{array}$ & $\frac{2.00}{(1.03-3.61)}$ & $\frac{1.80}{(1.09-2.80)}$ \\
\hline $\begin{array}{c}1.20 \\
(0.26-3.51) \\
\end{array}$ & $\begin{array}{c}1.06 \\
(0.16-3.63) \\
\end{array}$ & $\begin{array}{c}1.23 \\
(0.21-3.93) \\
\end{array}$ & $\begin{array}{c}0.60 \\
(0.11-1.81)\end{array}$ & $\begin{array}{c}0.88 \\
(0.11-3.15) \\
\end{array}$ & $\begin{array}{c}1.23 \\
(0.18-4.24) \\
\end{array}$ & $\begin{array}{c}0.63 \\
(0.06-2.53) \\
\end{array}$ & $\begin{array}{c}2.03 \\
(0.86-9.90) \\
\end{array}$ & \begin{tabular}{c|c} 
ARB + \\
diuretic
\end{tabular} & $\begin{array}{c}1.05 \\
(0.70-1.51) \\
\end{array}$ & $\begin{array}{c}1.04 \\
(0.69-1.52) \\
\end{array}$ & $\begin{array}{c}0.93 \\
(0.64-1.34) \\
\end{array}$ & $\begin{array}{c}1.12 \\
(0.58-1.95) \\
\end{array}$ & $\begin{array}{c}1.82 \\
(0.89-3.42) \\
\end{array}$ & $\begin{array}{c}1.67 \\
(0.98-2.66)\end{array}$ \\
\hline- & - & - & - & - & - & - & - & - & $\begin{array}{c}\text { Diuretic } \\
\text { /BB }\end{array}$ & $\begin{array}{c}1.00 \\
(0.76-1.31)\end{array}$ & $\begin{array}{c}0.92 \\
(0.58-1.39)\end{array}$ & $\begin{array}{c}1.08 \\
(0.61-1.79)\end{array}$ & $\begin{array}{c}1.77 \\
(0.88-3.34)\end{array}$ & $\frac{1.61}{(1.05-2.39)}$ \\
\hline - & - & - & - & - & - & - & - & - & - & $\begin{array}{l}\text { ARB+ } \\
\text { ACEi }\end{array}$ & $\begin{array}{c}0.93 \\
(0.58-1.40) \\
\end{array}$ & $\begin{array}{c}1.09 \\
(0.61-1.80) \\
\end{array}$ & $\begin{array}{c}1.79 \\
(0.89-3.35) \\
\end{array}$ & $\frac{1.63}{(1.04-2.45)}$ \\
\hline- & - & - & - & - & - & - & - & - & - & - & $\begin{array}{c}\mathrm{ARB}+ \\
\mathrm{CCB}\end{array}$ & $\begin{array}{c}1.23 \\
(0.62-2.21) \\
\end{array}$ & $\frac{1.96}{(1.04-3.58)}$ & $\frac{1.83}{(1.03-3.01)}$ \\
\hline $\begin{array}{c}3.62 \\
(0.35-14.55) \\
\end{array}$ & $\begin{array}{c}3.20 \\
(0.22-13.90)\end{array}$ & $\begin{array}{c}3.72 \\
(0.30-15.73)\end{array}$ & $\begin{array}{c}1.79 \\
(0.15-7.27) \\
\end{array}$ & $\begin{array}{c}2.87 \\
(0.16-11.98)\end{array}$ & $\begin{array}{c}3.87 \\
(0.25-16.20)\end{array}$ & $\begin{array}{c}1.14 \\
(0.24-3.38) \\
\end{array}$ & $\begin{array}{c}9.05 \\
(0.14-31.86)\end{array}$ & $\begin{array}{c}5.35 \\
(0.24-22.43)\end{array}$ & - & - & - & \begin{tabular}{c|}
$\mathrm{ACEi+}$ \\
$\mathrm{CCB}$
\end{tabular} & $\begin{array}{c}1.75 \\
(0.74-3.65) \\
\end{array}$ & $\frac{1.59}{(1.81-2.83)}$ \\
\hline - & - & - & - & - & - & - & - & - & - & - & - & - & $\begin{array}{l}\mathrm{BB}+ \\
\mathrm{CCB}\end{array}$ & $\begin{array}{c}1.01 \\
(0.45-1.91) \\
\end{array}$ \\
\hline $\begin{array}{c}1.89 \\
(0.40-5.58)\end{array}$ & $\begin{array}{c}1.64 \\
(0.24-5.68)\end{array}$ & $\begin{array}{c}1.94 \\
(0.33-6.30)\end{array}$ & $\begin{array}{c}0.93 \\
(0.17-2.92)\end{array}$ & $\begin{array}{c}1.38 \\
(0.17-5.06)\end{array}$ & $\begin{array}{c}1.96 \\
(0.26-6.74)\end{array}$ & $\begin{array}{c}0.98 \\
(0.09-3.98)\end{array}$ & $\begin{array}{c}3.18 \\
(0.18-15.67)\end{array}$ & $\begin{array}{c}2.49 \\
(0.25-9.90)\end{array}$ & - & - & - & $\begin{array}{c}1.52 \\
(0.07-6.62)\end{array}$ & - & $\begin{array}{l}\text { Renin } \\
\text { inhibitor }\end{array}$ \\
\hline
\end{tabular}

Figure 5. Comparative efficacy and tolerability of all blood pressure lowering treatments in stroke prevention, as per the network meta-analyses. Effect sizes represent summary odds ratios and 95\% credible intervals. In the upper triangle (efficacy in stroke prevention), values greater than 1 favor the treatment in the corresponding row, whereas values less than 1 favor the treatment in the corresponding column. In the lower triangle (tolerability), values greater than 1 favor the treatment in the corresponding column, whereas values less than 1 favor the treatment in the corresponding row. Significant results are in bold and underlined. $C C B$, calcium channel blocker; $A R B$, angiotensin II receptor blocker; $A C E i$, angiotensin-converting enzyme inhibitor; $B B$, beta-blocker.

monotherapies, ACEi was inferior to CCB $(\mathrm{OR}, 4.201 ; 95 \% \mathrm{Cl}$, 2.206 to 7.998 ) and the combination of $A C E i+C C B$ was superior to the combination of ACEi+THZs (OR, 0.892; 95\% Cl, 0.823 to 0.966).

\section{Network meta-analysis-efficacy}

The results of the network meta-analysis are shown in Figure 5. Compared to the placebos, all BP-lowering treatments, including $\operatorname{CCB}(\mathrm{OR}, 0.74 ; 95 \% \mathrm{Cl}, 0.67$ to 0.82$)$, ARB (OR, $0.81 ; 95 \%$ $\mathrm{Cl}, 0.73$ to 0.89$)$, ACEi $(\mathrm{OR}, 0.81 ; 95 \% \mathrm{Cl}, 0.73$ to 0.90$)$, diuretic $(\mathrm{OR}, 0.68 ; 95 \% \mathrm{Cl}, 0.59$ to 0.77$), \mathrm{CCB}+\mathrm{THZ}(\mathrm{OR}, 0.71 ; 95 \% \mathrm{Cl}$, 0.53 to 0.94$)$, diuretic/BB (OR, $0.79 ; 95 \% \mathrm{Cl}, 0.65$ to 0.94$)$, and $A R B+A C E i(O R, 0.78 ; 95 \% \mathrm{Cl}, 0.63$ to 0.96$)$, showed a benefit in stroke prevention. However, there was no correlation between the $\mathrm{CCB}+\mathrm{BB}(\mathrm{OR}, 1.38 ; 95 \% \mathrm{Cl}, 0.72$ to 2.53$)$ or the renin inhibitor (OR, 1.26; $95 \% \mathrm{Cl}, 0.85$ to 1.79$)$ strategy and stroke prevention. Diuretic use was superior to $\mathrm{BB}(\mathrm{OR}, 1.34 ; 95 \% \mathrm{Cl}, 1.11$ to 1.58), ACEi+THZ (OR, 1.47; 95\% Cl, 1.02 to 2.08), BB+CCB (OR, 2.05; $95 \% \mathrm{Cl}, 1.05$ to 3.79), and renin inhibitor strategy (OR, $1.87 ; 95 \% \mathrm{Cl}, 1.25$ to 2.75 ) in stroke prevention. The renin inhibitor was probably inferior to all the other treatments. Results from the pairwise meta-analysis and network meta-analysis for stroke prevention are summarized in Supplementary Table 3.

The SUCRA values pertaining to the 15 different antihypertensive strategies were $88.4,76.7,74.8,72.9,62.5,61.4,59.2$,

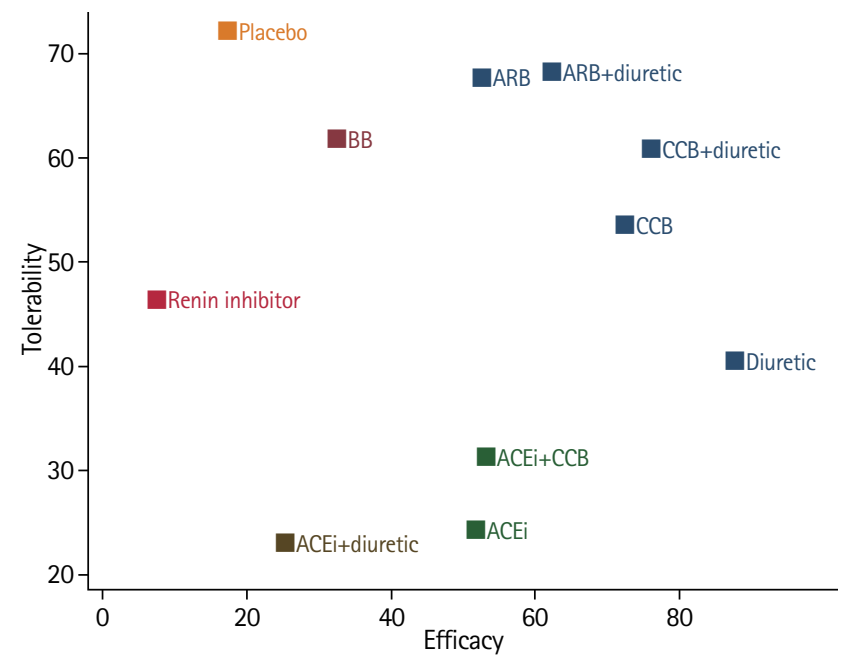

Figure 6. Cluster ranking for efficacy and tolerability of blood pressure lowering treatments in network meta-analyses. Each color represents a group of treatments that belong to the same cluster. Treatments located on the upper right corner are more effective and acceptable, compared to the other treatments. ARB, angiotensin II receptor blocker; $B B$, beta-blocker; $C C B$, calcium channel blocker; $A C E i$, angiotensin-converting enzyme inhibitor.

53.6, 53.1, 52.3, 32.9, 25.7, 17.9, 10.6, and 8.0 for diuretic, $\mathrm{CCB}+\mathrm{THZ}, \mathrm{ARB}+\mathrm{CCB}, \mathrm{CCB}, \mathrm{ARB}+\mathrm{THZ}, \mathrm{ARB}+\mathrm{ACEi}$, diuretic/BB, $A C E i+C C B, A R B, A C E i, B B, A C E i+T H Z$, placebo, BB+CCB, and renin inhibitor, respectively (Supplementary Figure 28). The mean 
rank associated with all the treatments is shown in Supplementary Figure 29. The cluster rank plot indicated that diuretics, $\mathrm{CCB}+\mathrm{THZ}, \mathrm{CCB}, \mathrm{ARB}+\mathrm{THZ}$, and $\mathrm{ARB}$ were associated not only with a reduction in stroke risk, but also a lower rate of withdrawal, owing to drug-related side effects (Figure 6). Sensitivity analyses stratified by age (age $\leq 60$ or $>60$ years), comorbidities (history of hypertension, stroke, diabetes, or heart failure), and baseline SBP (baseline SBP $\leq 150$ or $>150 \mathrm{~mm} \mathrm{Hg}$ ) showed robust results pertaining to the efficacy (Supplementary Table 4). Diuretics ranked first in most of the analyses. It is worth mentioning that the combination of $A R B+C C B$ ranked first in the participants with baseline SBP above $150 \mathrm{~mm} \mathrm{Hg}$.

\section{Network meta-analysis-tolerability}

Network meta-analysis also confirmed that ACEi (OR, 2.15; $95 \% \mathrm{Cl}, 1.30$ to 3.52 ) was likely to be associated with a significantly higher risk of withdrawal, owing to drug-related side effects compared to placebo. The comparative tolerability of different strategies is shown in Figure 5.

The SUCRA values for the 11 antihypertensive agents were 23.0, 24.3, 31.3, 40.4, 46.3, 53.6, 60.6, 61.9, 67.8, 68.4, and 72.5, for $\mathrm{ACEi}+\mathrm{THZ}, \mathrm{ACEi}, \mathrm{ACEi}+\mathrm{CCB}$, diuretic, renin inhibitor, $C C B, C C B+T H Z, B B, A R B, A R B+T H Z$, and placebo, respectively (Supplementary Figure 30 ). The mean ranks pertaining to all the treatments is shown in Supplementary Figure 31. Visual inspection of funnel plots for efficacy did not show any distinct asymmetry (Supplementary Figure 32). However, several trials fell outside the significance boundaries in the tolerability analysis (Supplementary Figure 33), which could be attributed to the limited number of trials.

The assessment of transitivity is shown in Supplementary Figure 34. No inconsistency between direct and indirect estimates in node splitting was apparent, except for the two comparisons (placebo-ARB, CCB-ARB) on efficacy (Supplementary Table 5) and two nodes (placebo-ACEi, CCB-ACEi) on tolerability (Supplementary Table 6). Finally, the design-by-treatment inconsistency model was applied, and inconsistency for efficacy or tolerability was not detected in the current analyses (Supplementary Table 7).

\section{Discussion}

Using the data pertaining to 504,613 participants in 93 large RCTs, the current study has supplemented the information regarding the selection of the most appropriate antihypertensive agents for different populations with regard to the efficacy and tolerability, and confirmed that the reduction in BP was significantly associated with lower mortality rates and stroke inci- dence. The therapeutic benefits existed regardless of the stratification by comorbidities, age, and baseline SBP. All the achieved SBP levels were associated with a 15\% to $45 \%$ stroke risk reduction. An interesting, but unexpected finding in the current study was that diuretics were more effective in stroke prevention, compared to the other BP-lowering treatments. $\mathrm{CCB}+\mathrm{THZs}, \mathrm{CCB}, \mathrm{ARB}+\mathrm{THZs}$, and ARB were also appropriate options in terms of efficacy and tolerability.

The observations in the present study are concurrent with the previously published meta-analyses with reference to the target SBP. ${ }^{3,21}$ Moreover, the present study supplemented the information that BP-lowering was significantly associated with the reduced stroke incidence in all subtypes including ischemic, hemorrhagic, and fatal or disabling stroke. The current study showed that lowering BP to a target of below $130 \mathrm{~mm} \mathrm{Hg}$ could reduce the risk associated with stroke. However, this should be interpreted with caution. Among the ischemic stroke patients without intracranial artery stenosis (lacunar infarction), intensive lowering of BP to a target of below $130 \mathrm{~mm} \mathrm{Hg}$ is more beneficial in the reduction of intracerebral hemorrhage, rather than risk of ischemic stroke. ${ }^{22}$ Moreover, intensive BP-lowering in patients with intracranial atherosclerotic stenosis may increase the ischemic lesion volume in the subacute stage. ${ }^{23}$ Hence, intensive BP control to a target of below $130 \mathrm{~mm} \mathrm{Hg}$ should mainly be recommended for the primary prevention of both ischemic and hemorrhagic strokes. The results of the present study, confirmed that a changed in target SBP from 140 to $130 \mathrm{~mm} \mathrm{Hg}$ was necessary. ${ }^{2,3}$ The target SBP for antihypertensive treatment is controversial, especially for the populations in different age groups. The guidelines of the Eighth Joint National Committee (JNC8) (2014) recommend a goal of BP below $140 / 90 \mathrm{~mm} \mathrm{Hg}$ in patients younger than 60 years and a more relaxed goal of below 150/90 $\mathrm{mm} \mathrm{Hg}$ in those older than 60 years. ${ }^{24}$ Another meta-analysis explored the benefits and harms of intensive BP management in adults aged 60 years or above and found that the treatment with a target BP below $150 \mathrm{~mm}$ $\mathrm{Hg}$ improves the health outcomes including stroke in older adults and lower targets $(\leq 140 / 85 \mathrm{~mm} \mathrm{Hg}$ ) are associated with a marginally significant decrease in stroke incidence. ${ }^{25}$

In the present study, the network meta-analysis suggested that diuretics, CCB, ARB, ACEi, and all diuretic-based combination therapies were effective in stroke prevention. This was consistent with the 2017 high BP guideline, which observed that no class of antihypertensive medications were better than THZs in reducing the risk of stroke and various cardiovascular outcomes. ${ }^{5}$ However, the present study differs from the 2017 high BP guideline in some aspects. For instance, the 2017 high BP guideline excluded placebo-controlled trials, whereas the 
current study included the trials that compared BP-lowering agents to placebo controls. Moreover, the 2017 high BP guideline examined only the first-line antihypertensive medications including diuretics, ACEis, ARBs, CCBs, and BBs, whereas the current study examined all the available antihypertensive medications.

Diuretics have been preferred as the first-line antihypertensive agents since the release of the results of the Antihypertensive and Lipid-Lowering Treatment to Prevent Heart Attack Trial (ALLHAT), which suggested that diuretics were as effective as CCBs in reducing specified endpoints. ${ }^{26}$ However, a previous meta-analysis explored the efficacy of CCBs and other antihypertensive agents and reported that there was no significant difference between CCBs and other comparators with regard to the efficacy. ${ }^{6}$ the present analysis included the trials published in or after 2000 and suggested that CCB+THZs is the most effective therapy for the reduction of stroke incidence, followed by $A R B+C C B$, diuretics, and $A R B$ +diuretics. In view of these findings, $C C B, A R B$, and diuretics could be employed as the firstline drugs for stroke prevention. However, in view of the adverse effects of diuretics, especially at high dosages, caution should be exercised when prescribing to populations with an increased risk of developing diabetes and gout. In the aforementioned patients, monotherapy using CCBs and ARBs or combinations with diuretic therapies might be appropriate alternatives.

Thus far, no network meta-analysis has been performed to examine the efficacy and tolerability of various antihypertensive agents for stroke prevention in the entire population. A previous network meta-analysis studied the various antihypertensive agents for stroke prevention in patients with type 2 diabetes and concluded that none of the antihypertensive agents were superior to one another, including the placebos. ${ }^{27}$ The current study demonstrated that ACEi-based single or combination therapies were most likely to be associated with the withdrawal, owing to drug-related side effects, whereas ARB-based single or combination therapies were well tolerated. This advantage might be helpful in the decision-making process when balancing the efficacy and feasibility.

The current study has certain limitations. First, a relatively small number of trials exploring the effects of antihypertensive agents for secondary stroke prevention were included, which precluded the execution of a formal network meta-analysis to determine the relative efficacy of different antihypertensive therapies for secondary stroke prevention. Second, the transitivity assumption during the network analysis was unavoidable. Many RCTs included in the present analysis involved combination therapies and the inclusion of combination therapies in network meta-analysis of first-line treatments would introduce intransitivity. ${ }^{28}$ Third, the concurrent discretionary use of statins, dual anti-platelets therapy, stringent glycemic control by new diabetes drugs, lifestyle coaching, and the 'add-on' antihypertensive drugs allowed in the recent/newer trials might diminish the marginal benefit of the new classes of antihypertensive drugs. Fourth, the present study failed to acquire the relevant data from studies involving diabetic subgroups, stroke subtypes, reason for withdrawal, the elapsed time between initiation of antihypertensive agents and the index stroke, as most of these studies were not included. Fifth, as the present review includes the studies that were published over a long period of time (1966-2018), the definition of stroke and the incorporation of the advances in neuroimaging can be considered to be different among the trials. Sixth, considering the ageing population, an average duration of follow-up of 3.3 years remains limited and trials with longer follow-up periods are warranted. Lastly, the trials included in the current study varied in several aspects, including the study population, race, baseline characteristics, study methodology, and concurrent use of multiple classes of antihypertensive drug. Consequently, the possibility that the differences between treatment strategies attributed to the aforementioned biases could not be excluded. The present study attempted to minimize the heterogeneity by performing sensitivity and subgroup analyses, in order to provide more robust conclusions.

In conclusion, the BP-lowering strategy is significantly associated with the risk reduction of all-cause mortality, cardiovascular-related death, all stroke types (fatal or nonfatal), disabling stroke, ischemic stroke, and hemorrhagic stroke. Monotherapy with diuretics, CCB or ARB, and their combinations could be employed as the first-line treatments for stroke prevention in terms of the efficacy and tolerability. Relatively, ACEi has a higher risk of side effect-related withdrawal.

\section{Supplementary materials}

Supplementary materials related to this article can be found online at https://doi.org/10.5853/jos.2020.02698.

\section{Disclosure}

The authors have no financial conflicts of interest.

\section{Acknowledgments}

This study was supported by grants from the National Key R\&D Program of China (2018YFC1314700), Shanghai Municipal Science and Technology Major Project (No.2018SHZDZX01), and 
ZHANGJIANG LAB, Tianqiao and Chrissy Chen Institute, and the State Key Laboratory of Neurobiology and Frontiers Center for Brain Science of the Ministry of Education, Fudan University, and Qingdao Municipal Medical Research Guidance Program (2019-WJZD082).

\section{References}

1. Krishnamurthi RV, Ikeda T, Feigin VL. Global, regional and country-specific burden of ischaemic stroke, intracerebral haemorrhage and subarachnoid haemorrhage: a systematic analysis of the global burden of disease study 2017. Neuroepidemiology 2020;54:171-179.

2. Whelton PK, Carey RM, Aronow WS, Casey DE Jr, Collins KJ, Dennison Himmelfarb C, et al. 2017 ACC/AHA/AAPA/ABC/ ACPM/AGS/APhA/ASH/ASPC/NMA/PCNA guideline for the prevention, detection, evaluation, and management of high blood pressure in adults: a report of the American College of Cardiology/American Heart Association task force on clinical practice guidelines. Hypertension 2018;71:e13-e115.

3. Ettehad D, Emdin CA, Kiran A, Anderson SG, Callender T, Emberson J, et al. Blood pressure lowering for prevention of cardiovascular disease and death: a systematic review and meta-analysis. Lancet 2016;387:957-967.

4. Katsanos AH, Filippatou A, Manios E, Deftereos S, Parissis J, Frogoudaki $A$, et al. Blood pressure reduction and secondary stroke prevention: a systematic review and metaregression analysis of randomized clinical trials. Hypertension 2017; 69:171-179.

5. Reboussin DM, Allen NB, Griswold ME, Guallar E, Hong $Y_{\text {, }}$ Lackland DT, et al. Systematic review for the 2017 ACC/ AHA/AAPA/ABC/ACPM/AGS/APhA/ASH/ASPC/NMA/PCNA guideline for the prevention, detection, evaluation, and management of high blood pressure in adults: a report of the American College of Cardiology/American Heart Association Task Force on Clinical Practice Guidelines. J Am Coll Cardiol 2018:71:2176-2198.

6. Jeffers BW, Robbins J, Bhambri R. Efficacy of calcium channel blockers versus other classes of antihypertensive medication in the treatment of hypertensive patients with previous stroke and/or coronary artery disease: a systematic review and meta-analysis. Am J Ther 2017;24:e68-e80.

7. Salanti G. Indirect and mixed-treatment comparison, network, or multiple-treatments meta-analysis: many names, many benefits, many concerns for the next generation evidence synthesis tool. Res Synth Methods 2012;3:80-97.

8. Jansen JP, Fleurence $R$, Devine $B$, Itzler $R$, Barrett A, Hawkins $\mathrm{N}$, et al. Interpreting indirect treatment comparisons and network meta-analysis for health-care decision making: report of the ISPOR Task Force on Indirect Treatment Comparisons Good Research Practices: part 1. Value Health 2011;14:417-428.

9. Moher D, Liberati A, Tetzlaff J, Altman DG; PRISMA Group. Preferred reporting items for systematic reviews and meta-analyses: the PRISMA statement. PLoS Med 2009;6: e1000097.

10. Hutton B, Salanti G, Caldwell DM, Chaimani A, Schmid CH, Cameron $\mathrm{C}$, et al. The PRISMA extension statement for reporting of systematic reviews incorporating network meta-analyses of health care interventions: checklist and explanations. Ann Intern Med 2015;162:777-784.

11. Law MR, Morris JK, Wald NJ. Use of blood pressure lowering drugs in the prevention of cardiovascular disease: meta-analysis of 147 randomised trials in the context of expectations from prospective epidemiological studies. BMJ 2009;338:b1665

12. Higgins J, Green SE. Cochrane Handbook for Systematic Reviews of Interventions. Version 5.1.0. The Cochrane Collaboration. https://handbook-5-1.cochrane.org. 2011. Accessed December 1, 2020.

13. Egger M, Davey Smith G, Schneider M, Minder C. Bias in meta-analysis detected by a simple, graphical test. BMJ 1997;315:629-634.

14. Dias S, Welton NJ, Sutton AJ, Ades AE. NICE DSU technical support document 2: a generalised linear modelling framework for pairwise and network meta-analysis of randomized controlled trials. National Institute for Health and Care Excellence. www.nicedsu.org.uk. 2016. Accessed December 1, 2020.

15. Biondi-Zoccai G, Abbate A, Benedetto U, Palmerini T, D'Ascenzo F, Frati G. Network meta-analysis for evidence synthesis: what is it and why is it posed to dominate cardiovascular decision making? Int J Cardiol 2015;182:309-314.

16. Dias $\mathrm{S}$, Welton NJ, Caldwell DM, Ades AE. Checking consistency in mixed treatment comparison meta-analysis. Stat Med 2010;29:932-944.

17. Lu G, Ades AE. Assessing evidence inconsistency in mixed treatment comparisons. J Am Stat Assoc 2006;101:447-459.

18. Higgins JP, Jackson D, Barrett JK, Lu G, Ades AE, White IR. Consistency and inconsistency in network meta-analysis: concepts and models for multi-arm studies. Res Synth Methods 2012;3:98-110.

19. Salanti $G$, Ades AE, loannidis JP. Graphical methods and numerical summaries for presenting results from multiple-treatment meta-analysis: an overview and tutorial. $J$ Clin Epidemiol 2011;64:163-171. 
20. Chaimani A, Higgins JP, Mavridis D, Spyridonos P, Salanti G. Graphical tools for network meta-analysis in STATA. PLoS One 2013;8:e76654.

21. Mukete BN, Cassidy M, Ferdinand KC, Le Jemtel TH. Longterm anti-hypertensive therapy and stroke prevention: a meta-analysis. Am J Cardiovasc Drugs 2015;15:243-257.

22. SPS3 Study Group, Benavente OR, Coffey CS, Conwit R, Hart RG, McClure LA, et al. Blood-pressure targets in patients with recent lacunar stroke: the SPS3 randomised trial. Lancet 2013;382:507-515.

23. Park JM, Kim BJ, Kwon SU, Hwang YH, Heo SH, Rha JH, et al. Intensive blood pressure control may not be safe in subacute ischemic stroke by intracranial atherosclerosis: a result of randomized trial. J Hypertens 2018;36:1936-1941.

24. James PA, Oparil S, Carter BL, Cushman WC, Dennison-Himmelfarb C, Handler J, et al. 2014 Evidence-based guideline for the management of high blood pressure in adults: re- port from the panel members appointed to the Eighth Joint National Committee (JNC 8). JAMA 2014;311:507-520.

25. Weiss J, Freeman M, Low A, Fu R, Kerfoot $A$, Paynter R, et al. Benefits and harms of intensive blood pressure treatment in adults aged 60 years or older: a systematic review and meta-analysis. Ann Intern Med 2017;166:419-429.

26. SoRelle R. National Heart, Lung, and Blood Institute halts part of antihypertensive and lipid-lowering treatment to prevent heart attack trial (ALLHAT). Circulation 2000;101: E9025.

27. Xie XX, Liu P, Wan FY, Lin SG, Zhong WL, Yuan ZK, et al. Blood pressure lowering and stroke events in type 2 diabetes: a network meta-analysis of randomized controlled trials. Int J Cardiol 2016;208:141-146.

28. Rouse B, Chaimani A, Li T. Network meta-analysis: an introduction for clinicians. Intern Emerg Med 2017;12:103-111. 
Appendix 1. Electronic search strategies

HYPERTENSION/dt [dt=Drug Therapy]

BLOOD PRESSURE/de [de=Drug Effects]

ANTIHYPERTENSIVE AGENTS/tu [tu=Therapeutic Use]

*VASODILATOR AGENTS/(vasodilator* AND agent*).ti

ambrisentan.ti

bosentan.ti

*DIAZOXIDE/diazoxide.ti

*HYDRALAZINE/hydralazine.ti

*ILOPROST/iloprost.ti

${ }^{*}$ MINOXIDIL/minoxidil.ti

sildenafil.ti

${ }^{*}$ NITROPRUSSIDE/nitroprusside.ti

tadalafil.ti

*METHYLDOPA/methyldopa.ti

${ }^{*}$ CLONIDINE/clonidine.ti

moxonidine.ti

${ }^{*}$ GUANETHIDINE/guanethidine.ti

*ADRENERGIC ALPHA-ANTAGONISTS/*DOXAZOSIN/doxazosin.ti

*INDORAMIN/indoramin.ti

*PRAZOSIN/prazosin.ti

terazosin.ti

*PHENOXYBENZAMINE/phenoxybenzamine.ti

*PHENTOLAMINE/phentolamine.ti

*ADRENERGIC BETA-ANTAGONISTS/*ATENOLOL/atenolol.ti

*METOPROLOL/metoprolol.ti

${ }^{*}$ PINDOLOL/pindolol.ti

${ }^{*}$ TIMOLOL/timolol.ti

*OXPRENOLOL/oxprenolol.ti

nebivolol.ti

${ }^{*}$ NADOLOL/nadolol.ti

*LABETALOL/labetalol.ti

${ }^{*}$ CELIPROLOL/celiprolol.ti

carvedilol.ti

*BISOPROLOL/bisoprolol.ti

*ACEBUTOLOL/acebutolol.ti

*PROPRANOLOL/propranolol.ti

*SODIUM CHLORIDE SYMPORTERINHIBITORS/(diuretic* ANDthiazide*).ti

*HYDROCHLOROTHIAZIDE/hydrochlorothiazide.ti

*TRICHLORMETHIAZIDE/trichlormethiazide.ti

*SPIRONOLACTONE/spironolactone.ti

${ }^{*}$ CHLORTHALIDONE/chlorthalidone.ti

*INDAPAMIDE/indapamide.ti

*ANGIOTENSIN-CONVERTING ENZYMEINHIBITORS/(ace AND inhibitor*).ti

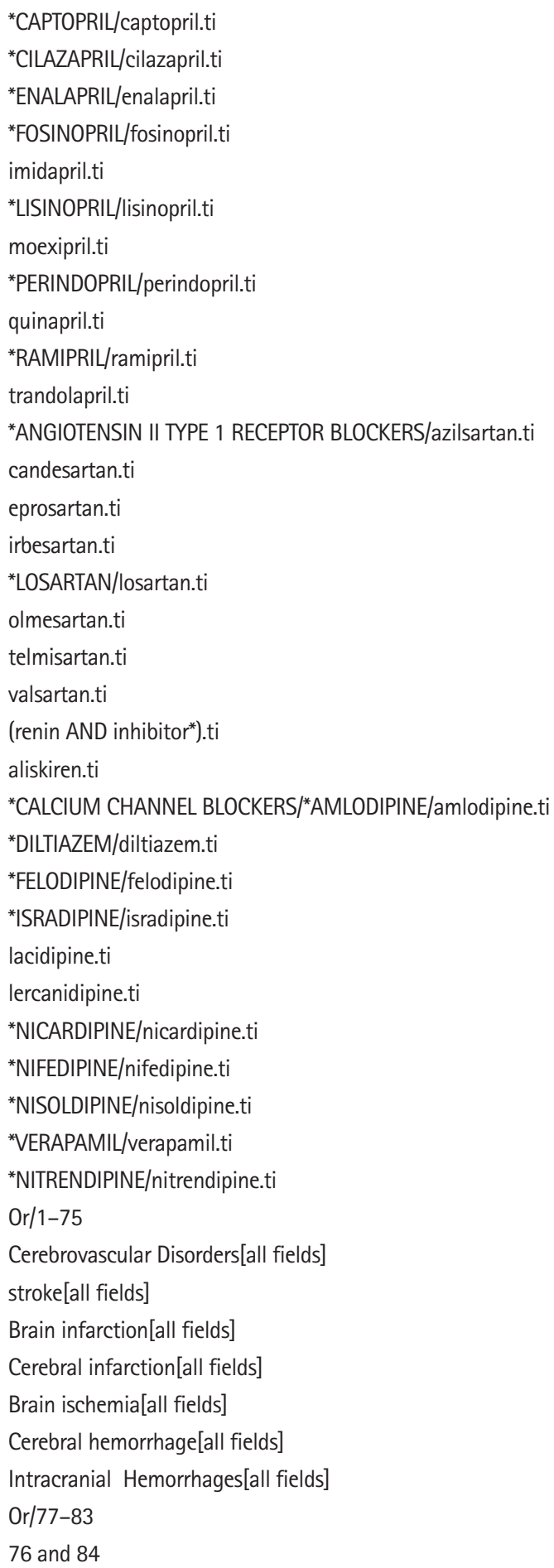


Appendix 2. The OpenBUGS code for random effects model

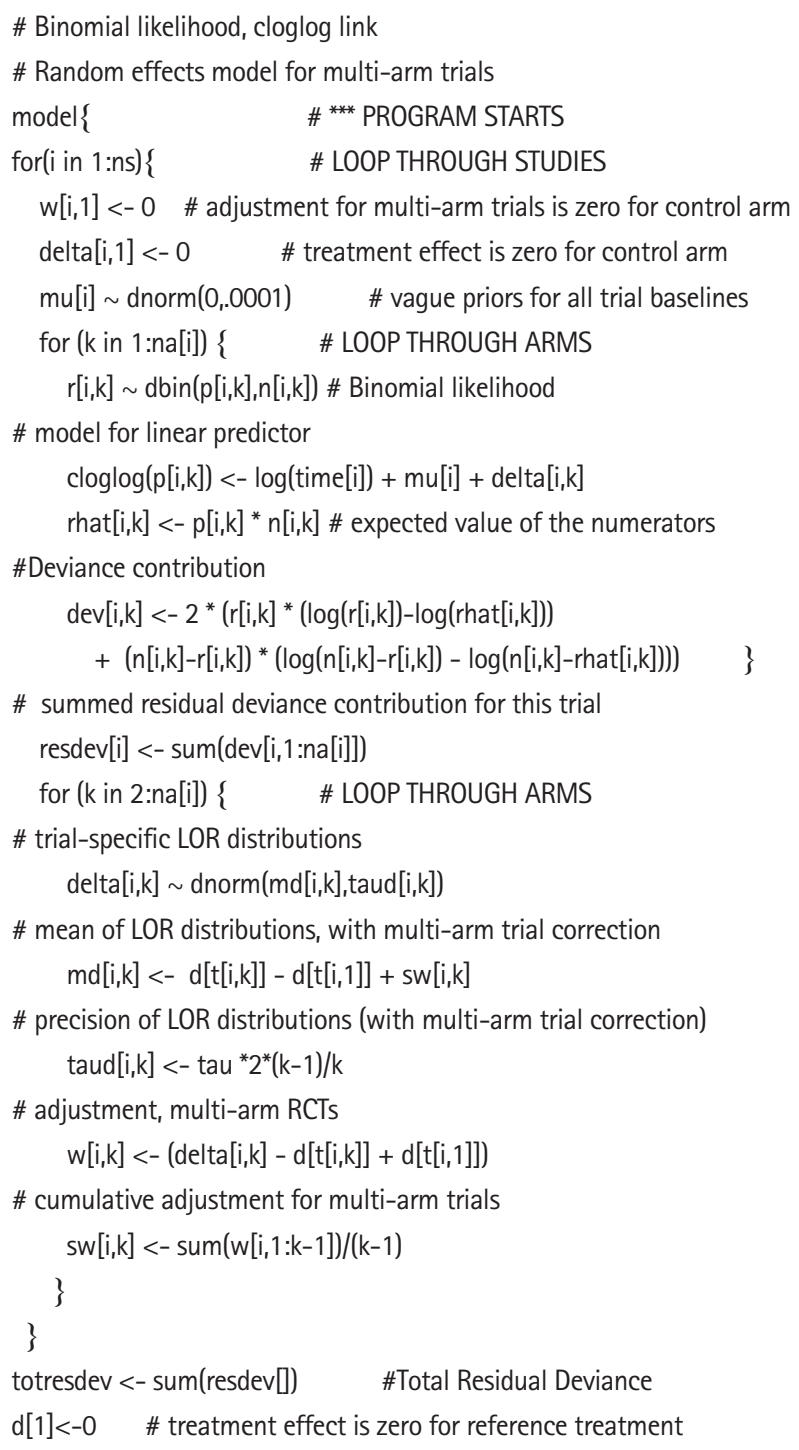

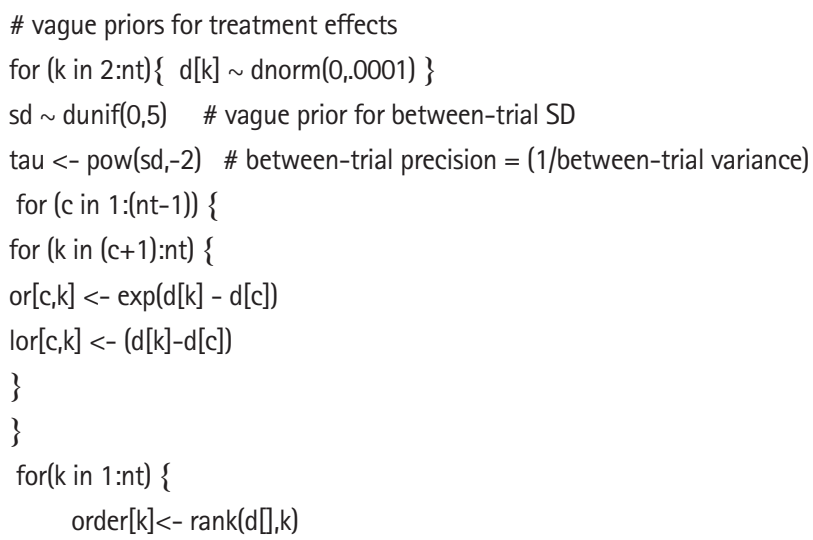

\# this is when the outcome is positive - omit 'nt+1-' when the outcome is negative most.effective $[k]<-$ equals(order $[k], 1)$

for(j in $1: n t)\{$ effectiveness $\left.\left[k_{j}\right]\right]_{<-}$equals(order $\left.[k]_{i j}\right)$ 


\section{Supplementary methods. Details about statistical analysis}

To clarify the effects of blood pressure lowering agents on the relative risk of stroke, ischemic stroke, hemorrhagic stroke, fatal or disabling stroke, cardiovascular death, and all cause death, we combined trials of blood pressure lowering agents versus placebo and higher versus lower blood pressure lowering targets and performed traditional meta-analysis. Two trials which compared angiotensin II receptor blocker (ARB)+angiotensin-converting enzyme inhibitor (ACEi) with ACEi were also included for the first objective. ${ }^{1,2}$ For another two trials with two active groups and a placebo group, ${ }^{3,4}$ we combined the events of the active groups for blood pressure lowering analysis. For one trial with three different blood pressure lowering targets, ${ }^{5}$ we combined the two lower targets for analysis. We calculated relative risks from the number of events and participants for each outcome in each trial and pooled results with Mantel-Haenszel and Hartung-Knapp adjustment for random effects models. Random model other than fixed model was chosen because the included trials differed to some extent, both clinically and methodologically, and random model is generally more conservative compared with fixed effects model if heterogeneity is present. We assessed the magnitude of statistical heterogeneity among studies using standard cochrane chi-square test, the $\mathrm{I}^{2}$ statistic $\left(I^{2}\right.$ values of at least $50 \%$ were considered to represent substantial heterogeneity, while values of at least $75 \%$ indicated considerable heterogeneity). ${ }^{6}$ We explored evidence for heterogeneity in estimates of treatment effect attributable to the baseline characteristics of trials by comparing summary results obtained from subsets of studies grouped by age, history of cardiovascular disease, history of stroke, history of diabetes, baseline, and achieved blood pressure level. Publication bias was evaluated both graphically using a funnel plot and with the Egger statistical test for funnel plot asymmetry, if at least 10 studies were available for each outcome. A leave-one-out sensitivity analysis was performed by repeating the meta-analysis, each time with one of the included studies omitted, to see whether any one study had disproportionately large impact on the pooled relative risk. Data used in this meta-analysis were intention to treat because most of the included trials did not report as treated results.

To clarify the efficacy and tolerability of different blood pressure lowering drugs for prevention of stroke, we combined the three groups of trials and did pair-wise and network metaanalysis. Ten trials of different blood pressure lowering targets which undefined any specific drugs were excluded from analysis. The outcome measure for efficacy and tolerability are stroke and drug-related side effects withdraw, respectively. First, we did pair-wise meta-analysis with a random effects model to analyze direct treatment comparisons. We calculated the summary effect sizes as odds ratios, with 95\% confidence intervals. We assessed heterogeneity among studies with the $I^{2}$ statistic. We did not do funnel plots to test publication bias because most of the comparisons had less than 10 trials. Second, we analyzed pooled data for all blood pressure lowering treatments with random effects models, within a Bayesian framework in OpenBUGS. ${ }^{8}$ See Appendix 2 for details about the OpenBUGS codes used. Models were computed with Markov chain Monte Carlo simulations, using three chains with overdispersed initial values, with Gibbs sampling based on 100,000 iterations after a burn-in phase of 50,000 iterations. Noninformative or vague priors for the overall mean effect $(\theta$ to $N(0$, 1002)) and the between-study standard deviation ( $\tau$ to uniform $(0,2))$ were given..$^{9-11}$ The mean of the posterior distribution was reported as the point estimate odds ratio, and the corresponding 95\% credible intervals were obtained with the 2.5th and 97.5th percentiles of the posterior distribution, after adjustment for multiple arm trials. We tested the adequacy of burn-in and convergence (reaching a stable equilibrium distribution) using visual inspection of parameter fluctuation depicted in trace plots and estimating the values of the Brooks-Gelman-Rubin statistic. $^{12}$ Model fit was evaluated with the total residual deviance, which indicated good fit, if it approximated the number of data points.

Inconsistency between direct and indirect evidence can suggest that the transitivity assumption might not hold. We assessed evidence for consistency in the networks in two ways. First, we used node-split approach to contrast direct evidence with indirect evidence from the entire network on each node. ${ }^{11,13,14}$ A Bayesian $P$-value was calculated to estimate difference between direct and indirect evidence by counting the proportion of times the direct treatment effect exceeded the indirect treatment effect. ${ }^{14}$ Second, we used the design-bytreatment interaction model that provides a single inference, using the chi-square test, about the plausibility of assuming consistency throughout the entire network. ${ }^{15}$

The surface under the cumulative ranking curve (SUCRA) and rankograms was used to provide a hierarchy of the regimens. ${ }^{16}$ We also used two-dimensional plots and clustering methods to obtain meaningful groups of the treatments. ${ }^{17}$ We assessed small study effects with comparison adjusted funnel plot symmetry. ${ }^{17}$

To investigate the generalisability of the findings, we assessed the effects of differing trial and participant characteristics on the outcomes in sensitivity analyses by restricting analyses to 
studies with the following design characteristics: hypertensive participants; excluding heart failure participants; published in 2000 or later; duration of follow-up longer than 3 years. We did subgroup analyses according to age (age $\leq 60$ and $>60$ years), history of stroke (no defines as participants with a history of stroke account for less than $5 \%$ of overall participants in a trial, yes defines as all of the participants has a history of stroke in a trial), history of diabetes mellitus (DM; no defines as participants with a history of DM account for less than
$5 \%$ of overall participants in a trial, yes defines as all of the participants has a history of DM in a trial), and baseline systolic blood pressure ( $\leq 150$ or $>150 \mathrm{~mm} \mathrm{Hg}$ ).

For traditional meta-analyses we used $\mathrm{R}$ version 3.4.1 ( $\mathrm{R}$ Foundation for Statistical Computing, Vienna, Austria). For network meta-analyses we used OpenBUGS 3.2.3 and STATA 14.0 (StataCorp., College Station, TX, USA). 


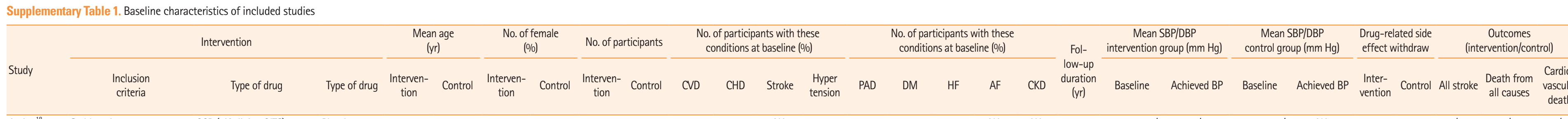

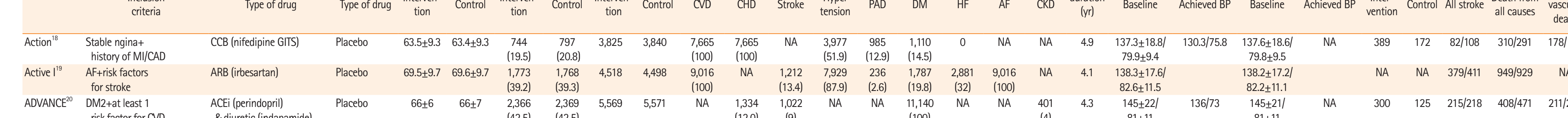

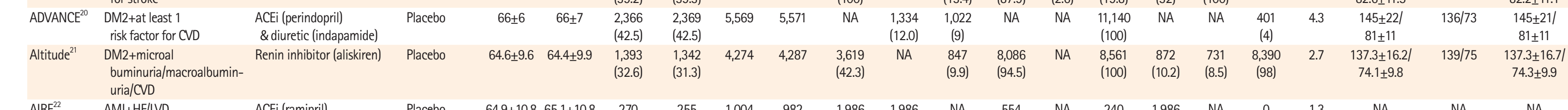

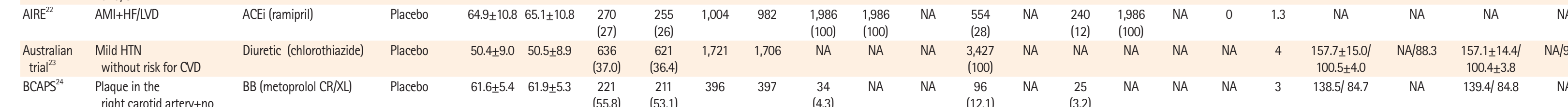

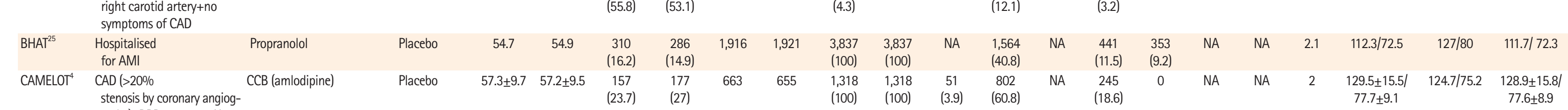

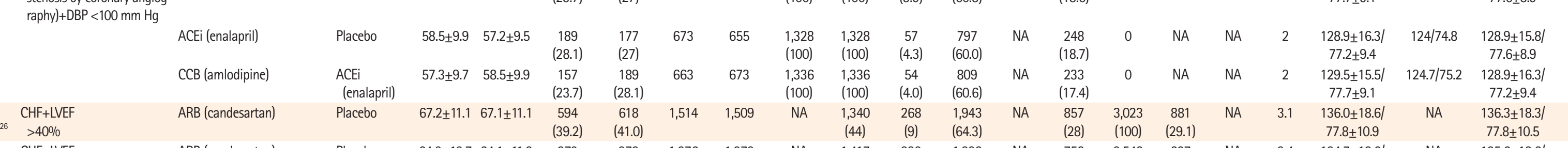

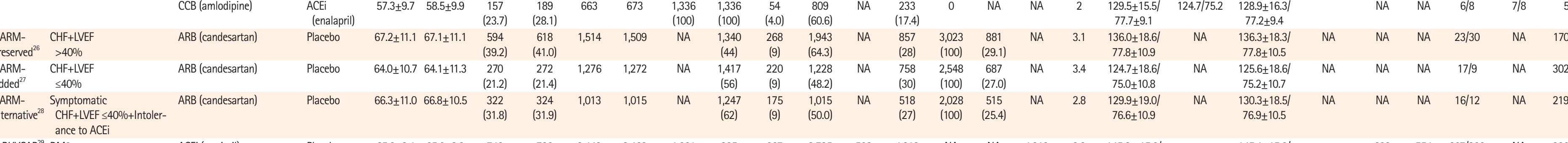

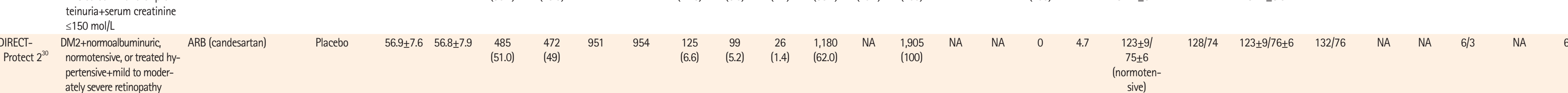

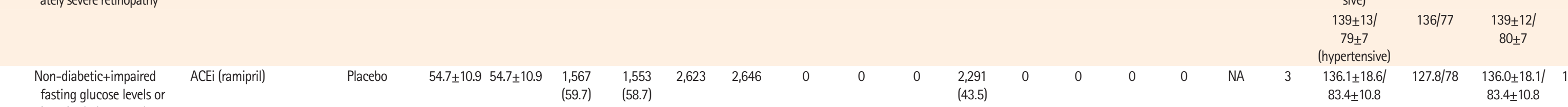

actine

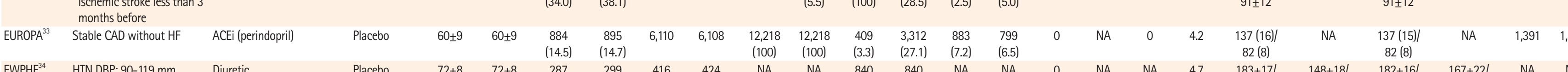

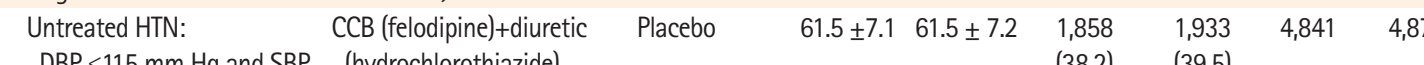

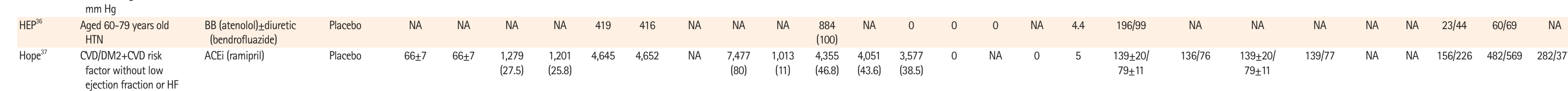

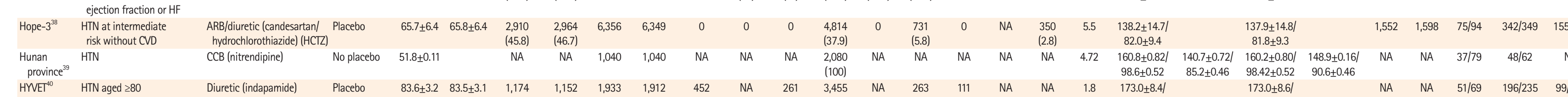

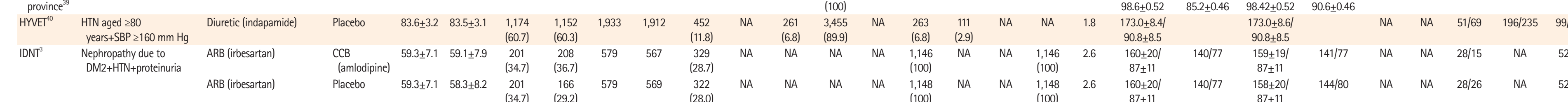

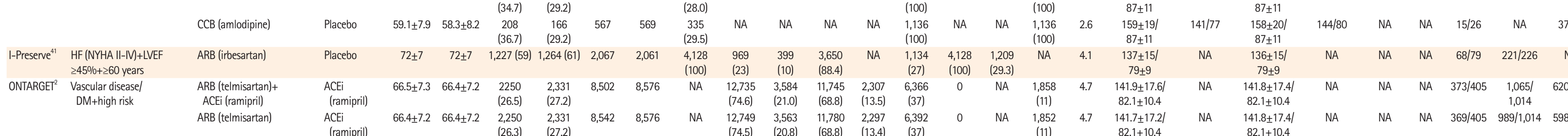

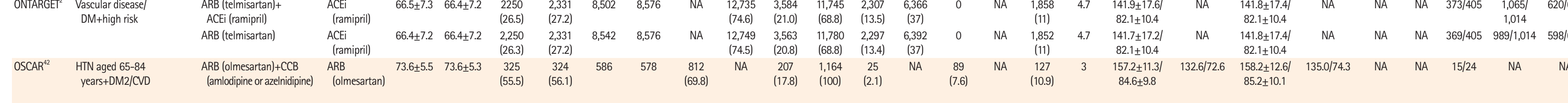

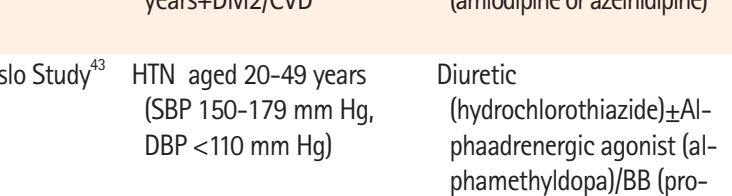

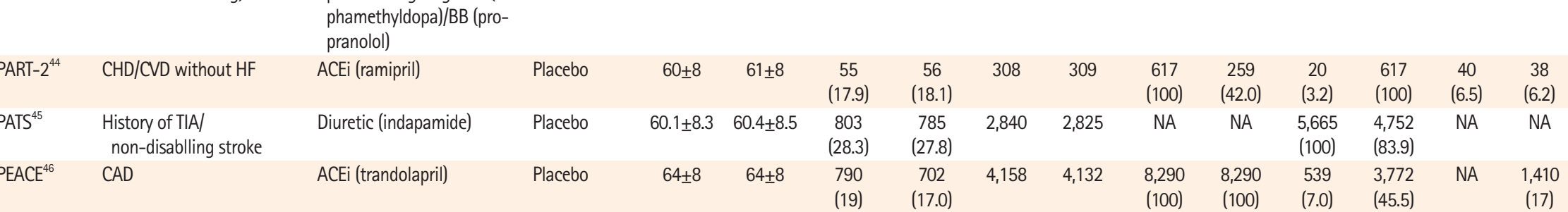

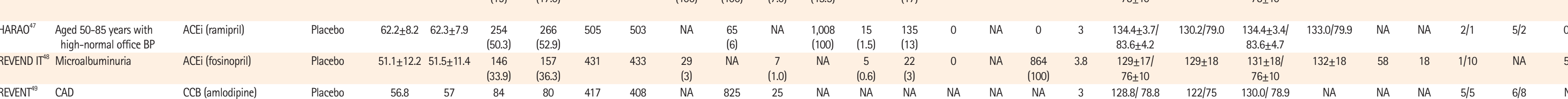

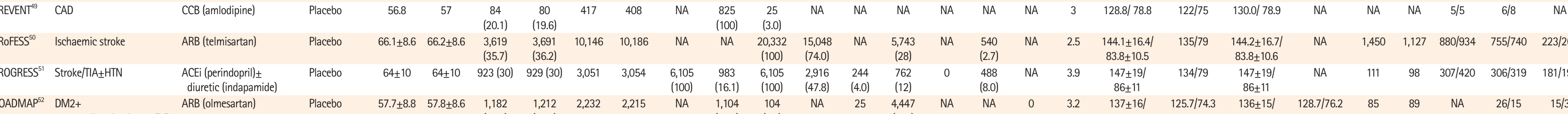

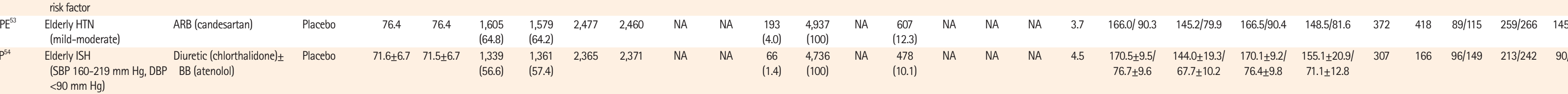

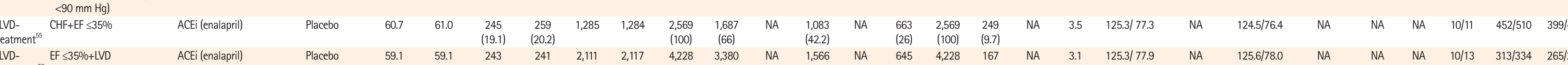

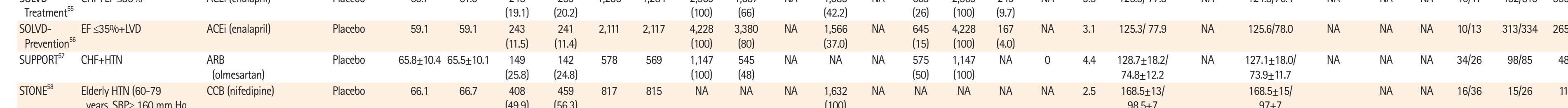

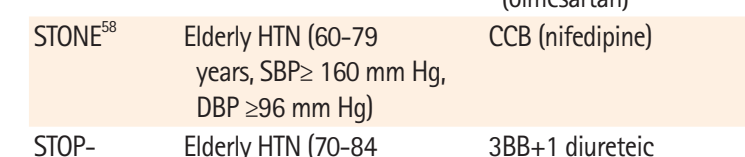

ats

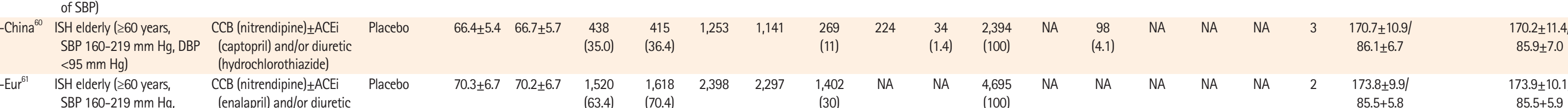

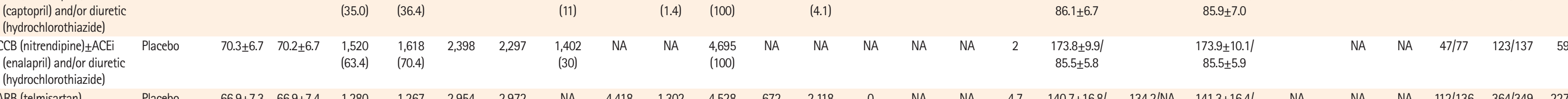

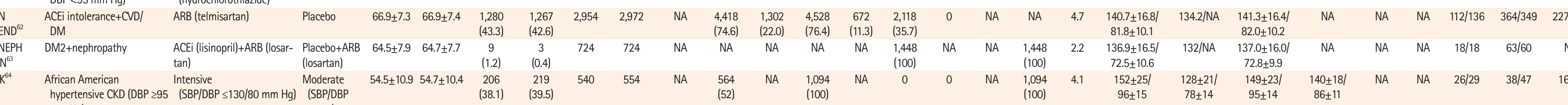

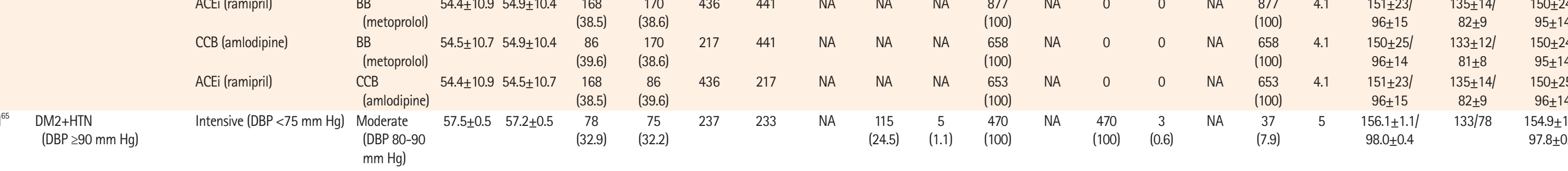

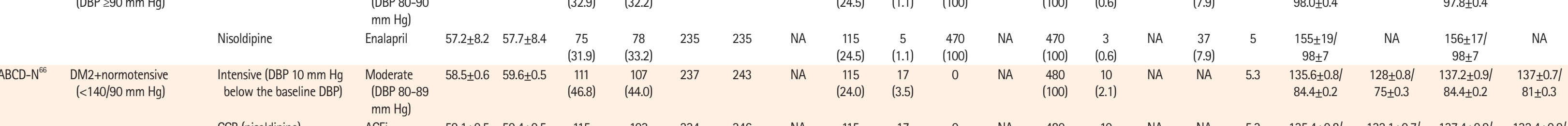

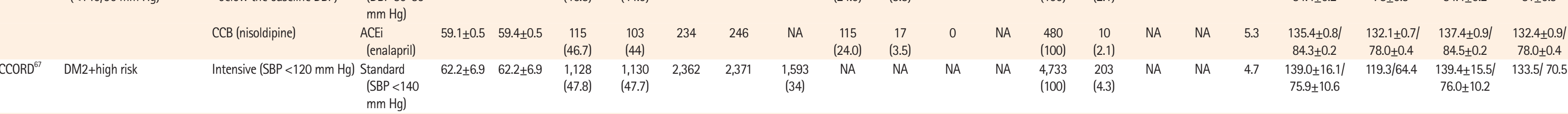

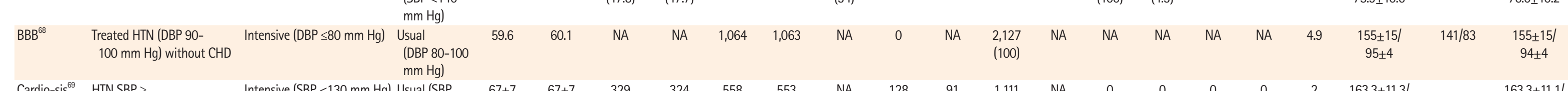

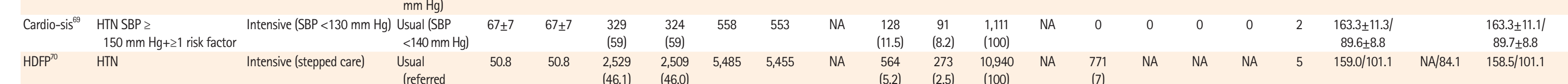

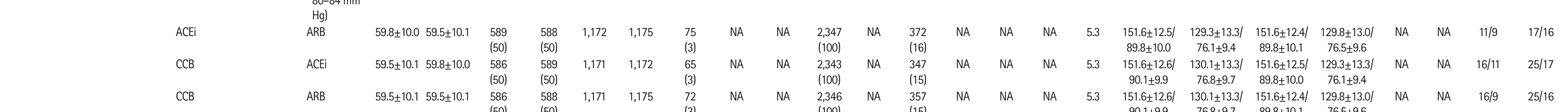

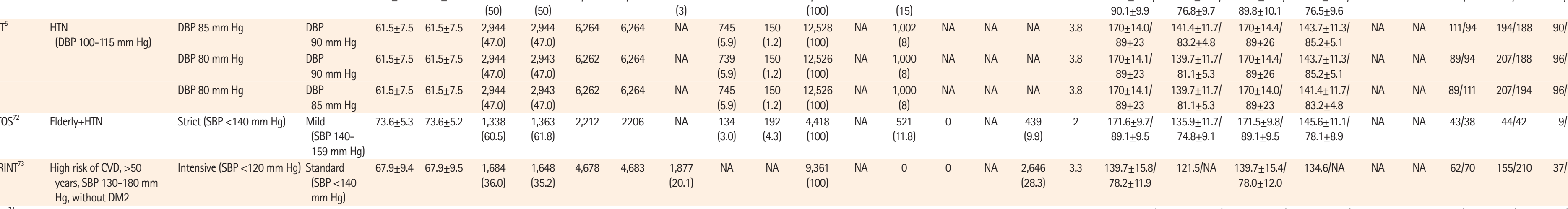

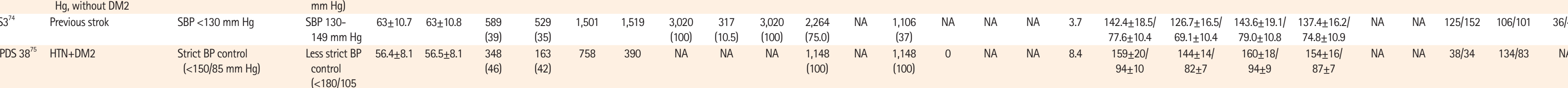

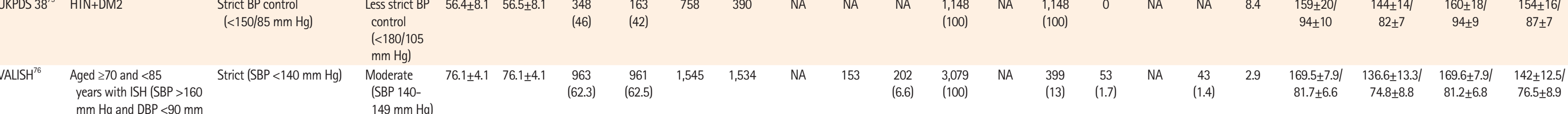

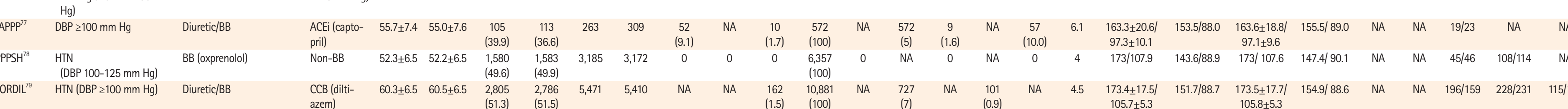

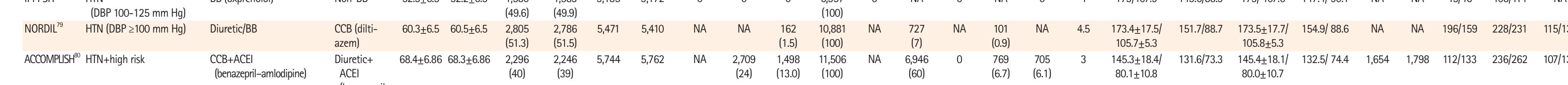

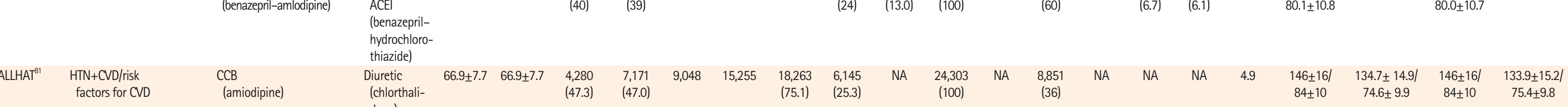

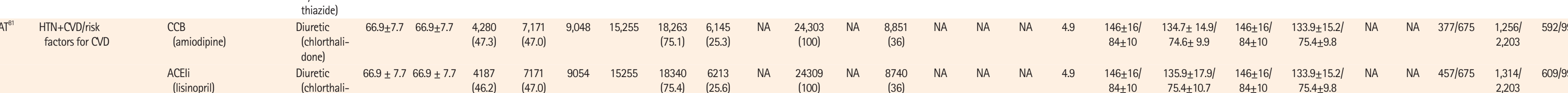

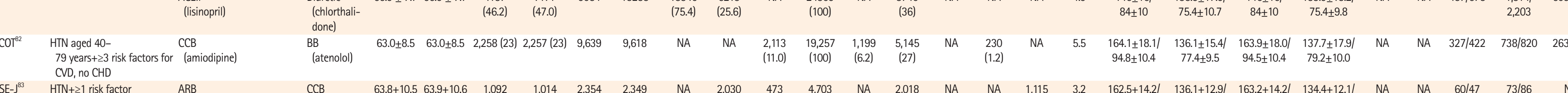

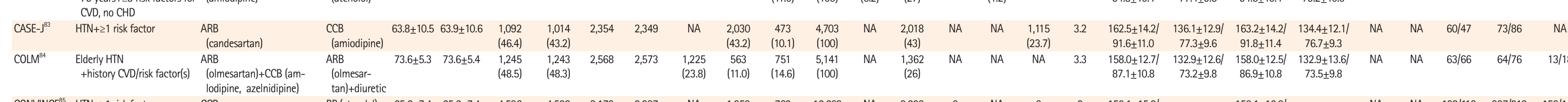

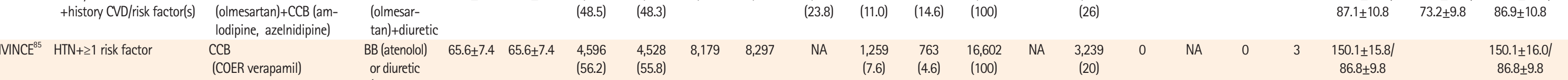

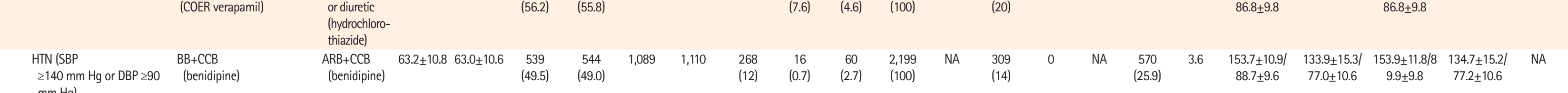

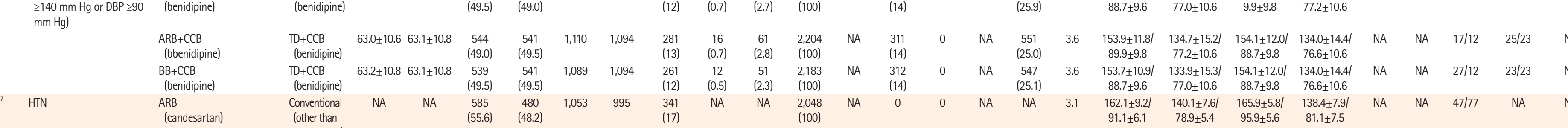

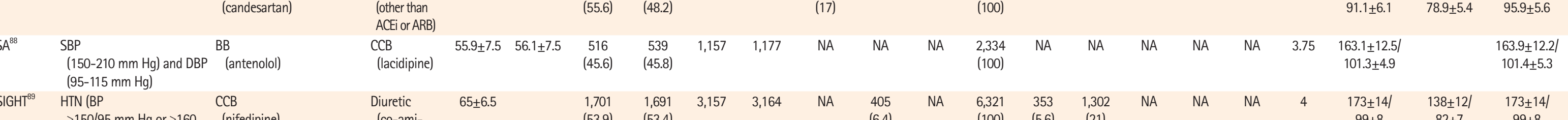

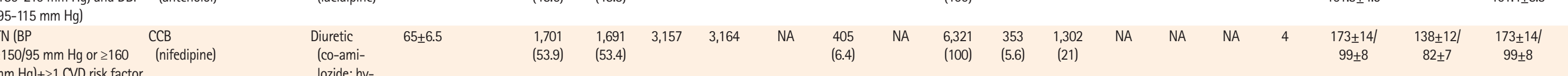

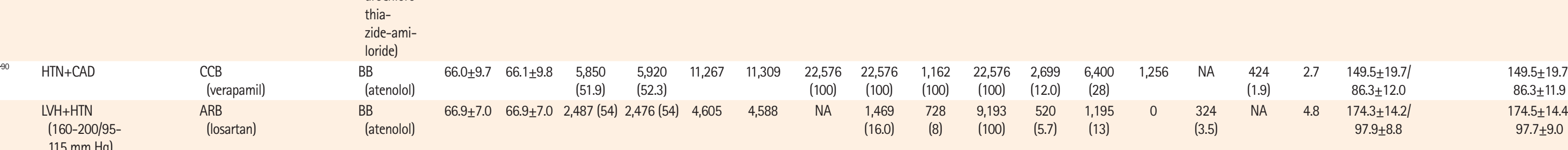

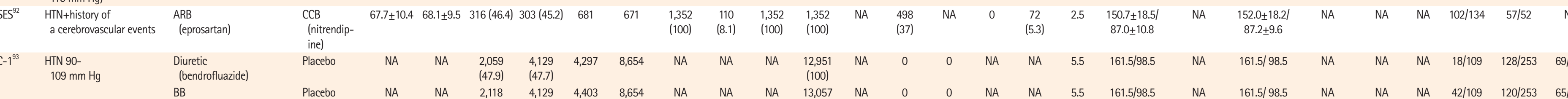

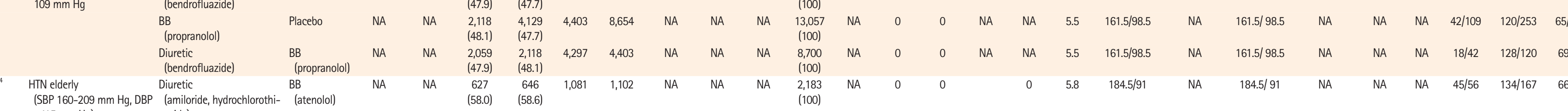

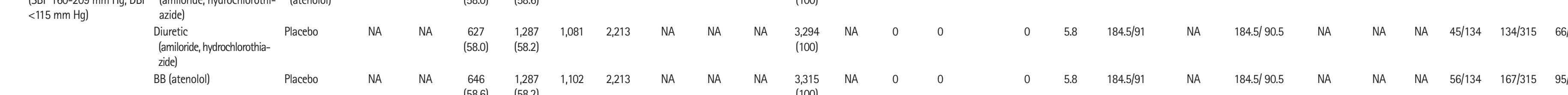

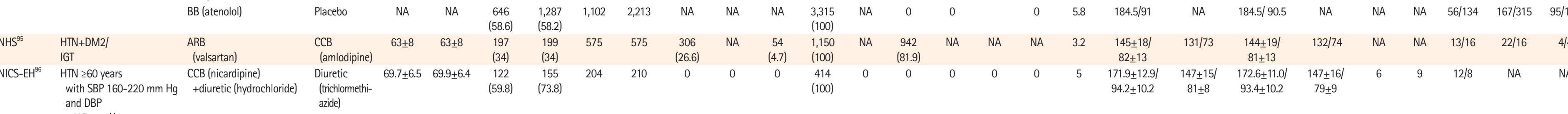

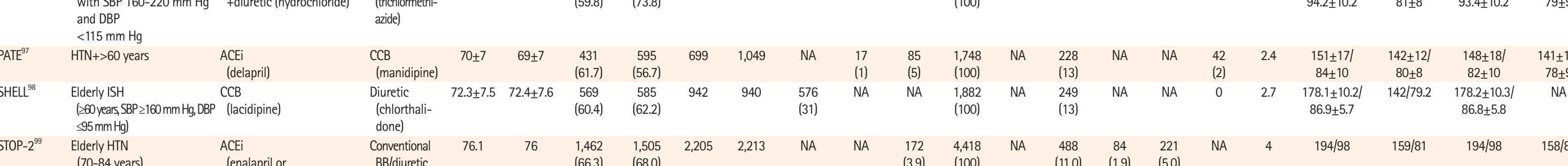

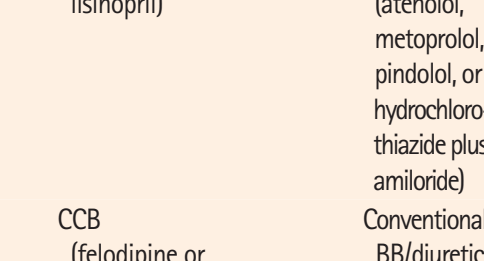

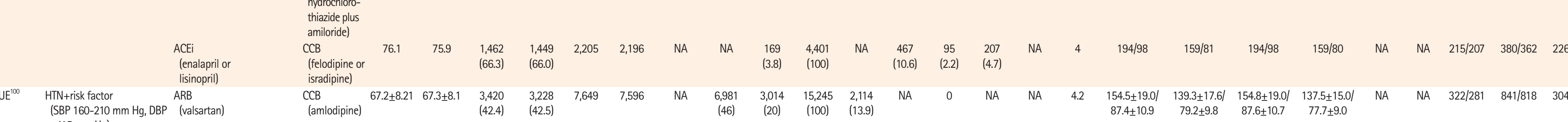

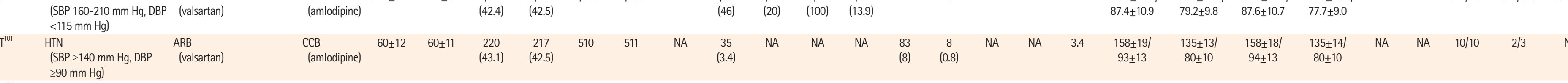

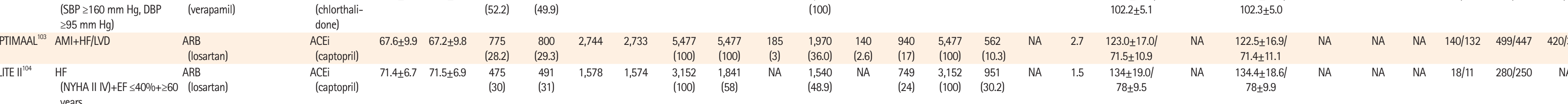

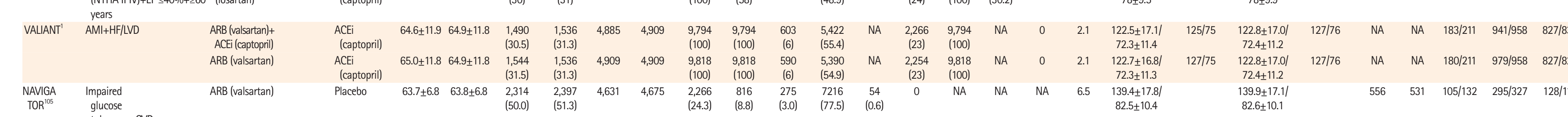

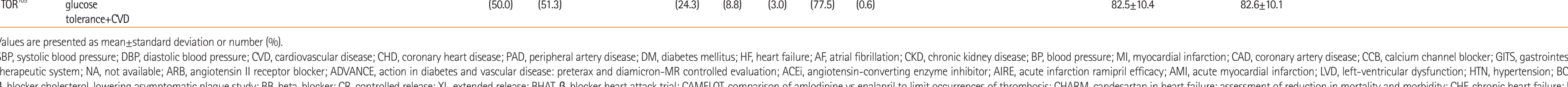


Supplementary Table 2. Pairwise meta-analysis results of efficacy and tolerability for direct comparisons of interventions

\begin{tabular}{|c|c|c|c|c|c|c|}
\hline Comparisons & & Pairwise meta-analysis odds ratio (95\% Cl) & $P$ & No. of trials & No. of participants & Heterogeneity $\left.\right|^{2}$ \\
\hline \multicolumn{7}{|l|}{ Efficacy } \\
\hline $\mathrm{CCB}$ & vs. Placebo & $0.642(0.539-0.765)$ & $<0.001$ & 7 & 19,665 & 0 \\
\hline ARB & & $0.919(0.864-0.978)$ & 0.008 & 13 & 69,891 & 0 \\
\hline ACEi & & $0.813(0.747-0.885)$ & $<0.001$ & 13 & 58,691 & 49.4 \\
\hline Diuretic & & $0.632(0.556-0.718)$ & $<0.001$ & 8 & 35,543 & 30.6 \\
\hline $\mathrm{BB}$ & & $0.791(0.673-0.929)$ & 0.004 & 7 & 29,667 & 20.8 \\
\hline ACEi+Diuretic & & $0.986(0.814-1.195)$ & 0.886 & 1 & 11,140 & NA \\
\hline $\mathrm{CCB}+$ Diuretic & & $0.698(0.574-0.850)$ & $<0.001$ & 1 & 9,711 & NA \\
\hline ARB+Diuretic & & $0.795(0.585-1.078)$ & 0.140 & 1 & 12,705 & NA \\
\hline Diuretic/BB & & $0.532(0.335-0.847)$ & 0.008 & 1 & 1,627 & NA \\
\hline Renin inhibitor & & 1.209 (0.954-1.531) & 0.116 & 1 & 8,561 & NA \\
\hline ARB & vs. CCB & 0.977 (0.869-1.099) & 0.698 & 8 & 29,011 & 72.3 \\
\hline ACEi & & $1.123(1.008-1.252)$ & 0.036 & 8 & 29,533 & 12 \\
\hline Diuretic & & 1.063 (0.947-1.194) & 0.300 & 4 & 33,920 & 0 \\
\hline BB & & $1.261(1.116-1.425)$ & $<0.001$ & 4 & 4,825 & 0 \\
\hline Diuretic/BB & & $0.922(0.762-1.114)$ & 0.399 & 3 & 31,766 & 55.8 \\
\hline ACEi & vs. ARB & $1.074(0.972-1.186)$ & 0.159 & 5 & 37,912 & 5.5 \\
\hline $\mathrm{BB}$ & & 1.361 (1.142-1.622) & 0.001 & 1 & 9,193 & NA \\
\hline $\mathrm{ARB}+\mathrm{ACEi}$ & & 1.017 (0.908-1.139) & 0.771 & 3 & 28,320 & 0 \\
\hline $\mathrm{ARB}+\mathrm{CCB}$ & & $0.606(0.315-1.168)$ & 0.135 & 1 & 1,164 & NA \\
\hline Diuretic & vs. ACEi & $0.871(0.771-0.984)$ & 0.026 & 1 & 24,309 & NA \\
\hline $\mathrm{BB}$ & & $0.988(0.546-1.789)$ & 0.968 & 1 & 877 & NA \\
\hline Diuretic/BB & & $1.097(0.911-1.321)$ & 0.329 & 2 & 4,990 & 0 \\
\hline $\mathrm{ARB}+\mathrm{ACEi}$ & & $0.909(0.813-1.017)$ & 0.097 & 2 & 26,872 & 0 \\
\hline $\mathrm{BB}$ & vs. Diuretic & 1.629 (0.890-2.982) & 0.113 & 2 & 10,883 & 68.3 \\
\hline CCB+Diuretic & & $1.578(0.631-3.945)$ & 0.329 & 1 & 414 & NA \\
\hline $\mathrm{ACEi}+\mathrm{CCB}$ & vs. ACEi+Diuretic & $0.842(0.653-1.085)$ & 0.184 & 1 & 11,506 & NA \\
\hline $\mathrm{ARB}+\mathrm{CCB}$ & vs. $\mathrm{CCB}+$ Diuretic & $1.402(0.667-2.950)$ & 0.373 & 1 & 2,204 & NA \\
\hline $\mathrm{BB}+\mathrm{CCB}$ & & $2.292(1.155-4.549)$ & 0.018 & 1 & 2,183 & NA \\
\hline $\mathrm{ARB}+\mathrm{CCB}$ & vs. ARB+Diuretic & 0.955 (0.673-1.355) & 0.798 & 1 & 5,141 & NA \\
\hline $\mathrm{BB}+\mathrm{CCB}$ & vs. $A R B+C C B$ & 1.635 (0.886-3.016) & 0.116 & 1 & 2,199 & NA \\
\hline \multicolumn{7}{|l|}{ Safety } \\
\hline $\mathrm{CCB}$ & vs. Placebo & $2.414(2.006-2.906)$ & $<0.001$ & 1 & 7,665 & NA \\
\hline ARB & & $1.141(1.081-1.204)$ & $<0.001$ & 4 & 39,022 & 89.9 \\
\hline ACEi & & $1.682(1.271-2.226)$ & $<0.001$ & 7 & 31,306 & 94.4 \\
\hline Diuretic & & $1.981(1.625-2.416)$ & $<0.001$ & 1 & 4,736 & NA \\
\hline ACEi+Diuretic & & $2.481(2.007-3.067)$ & $<0.001$ & 1 & 11,140 & NA \\
\hline ARB+Diuretic & & $0.960(0.886-1.041)$ & 0.327 & 1 & 12,705 & NA \\
\hline Renin inhibitor & & 1.475 (1.250-1.741) & $<0.001$ & 1 & 8,561 & NA \\
\hline ACEi & vs. CCB & 4.201 (2.206-7.998) & $<0.001$ & 1 & 1,748 & NA \\
\hline Diuretic & & 1.000 (0.516-1.938) & 1.000 & 1 & 1,414 & NA \\
\hline CCB+Diuretic & vs. Diuretic & 0.677 (0.236-1.937) & 0.467 & 1 & 414 & NA \\
\hline $\mathrm{ACEi}+\mathrm{CCB}$ & vs. ACEi+Diuretic & $0.892(0.823-0.966)$ & 0.005 & 1 & 11,506 & NA \\
\hline
\end{tabular}

An odds ratios $<1$ favor the former intervention and an odds ratios $>1$ favor the latter intervention.

$\mathrm{Cl}$, confidence interval; $\mathrm{CCB}$, calcium channel blocker; $\mathrm{ARB}$, angiotensin II receptor blocker; $\mathrm{ACEi}$, angiotensin-converting enzyme inhibitor; $\mathrm{BB}$, beta-blocker; $N A$, not applicable. 
Supplementary Table 3. Summary of results from pairwise meta-analysis and network meta-analysis for stroke prevention from randomized controlled trials

\begin{tabular}{|c|c|c|c|c|}
\hline \multirow{2}{*}{ Comparison } & & \multirow{2}{*}{ No. of trials } & \multicolumn{2}{|c|}{ OR $(95 \% \mathrm{Cl})$} \\
\hline & & & Pairwise meta-analysis & Network meta-analysis \\
\hline \multicolumn{5}{|l|}{ Efficacy } \\
\hline $\mathrm{CCB}$ & vs. Placebo & 7 & $0.642(0.539-0.765)$ & $0.74(0.67-0.82)$ \\
\hline ARB & & 13 & 0.919 (0.864-0.978) & $0.81(0.73-0.89)$ \\
\hline ACEi & & 13 & $0.813(0.747-0.885)$ & $0.81(0.73-0.90)$ \\
\hline Diuretic & & 8 & $0.632(0.556-0.718)$ & $0.68(0.59-0.77)$ \\
\hline $\mathrm{BB}$ & & 7 & $0.791(0.673-0.929)$ & $0.90(0.78-1.03)$ \\
\hline ACEi+THZ & & 1 & $0.986(0.814-1.195)$ & $0.99(0.71-1.37)$ \\
\hline $\mathrm{CCB}+\mathrm{THZ}$ & & 1 & $0.698(0.574-0.850)$ & $0.71(0.53-0.94)$ \\
\hline $\mathrm{ARB}+\mathrm{THZ}$ & & 1 & 0.795 (0.585-1.078) & $0.78(0.54-1.07)$ \\
\hline Diuretic/BB & & 1 & $0.532(0.335-0.847)$ & $0.79(0.65-0.94)$ \\
\hline Renin inhibitor & & 1 & 1.209 (0.954-1.531) & $1.26(0.85-1.79)$ \\
\hline ARB & vs. CCB & 8 & $0.977(0.869-1.099)$ & $1.09(0.97-1.22)$ \\
\hline ACEi & & 8 & $1.123(1.008-1.252)$ & $1.09(0.97-1.23)$ \\
\hline Diuretic & & 4 & 1.063 (0.947-1.194) & $0.91(0.78-1.05)$ \\
\hline $\mathrm{BB}$ & & 4 & $1.261(1.116-1.425)$ & $1.21(1.05-1.39)$ \\
\hline Diuretic/BB & & 3 & $0.922(0.762-1.114)$ & $1.06(0.88-1.25)$ \\
\hline ACEi & vs. ARB & 5 & $1.074(0.972-1.186)$ & $1.00(0.89-1.12)$ \\
\hline $\mathrm{BB}$ & & 1 & 1.361 (1.142-1.622) & $1.12(0.95-1.29)$ \\
\hline$A R B+A C E i$ & & 3 & $1.017(0.908-1.139)$ & $0.97(0.79-1.18)$ \\
\hline $\mathrm{ARB}+\mathrm{CCB}$ & & 1 & $0.606(0.315-1.168)$ & $0.89(0.58-1.30)$ \\
\hline Diuretic & vs. ACEi & 1 & $0.871(0.771-0.984)$ & $0.84(0.71-0.97)$ \\
\hline $\mathrm{BB}$ & & 1 & $0.988(0.546-1.789)$ & $1.11(0.95-1.30)$ \\
\hline Diuretic/BB & & 2 & $1.097(0.911-1.321)$ & $0.98(0.80-1.17)$ \\
\hline $\mathrm{ARB}+\mathrm{ACEi}$ & & 2 & $0.909(0.813-1.017)$ & $0.97(0.78-1.19)$ \\
\hline $\mathrm{BB}$ & vs. diuretic & 2 & 1.629 (0.890-2.982) & $1.34(1.11-1.58)$ \\
\hline $\mathrm{CCB}+\mathrm{THZ}$ & & 1 & $1.578(0.631-3.945)$ & $1.06(0.76-1.44)$ \\
\hline $\mathrm{ACE}+\mathrm{CCB}$ & vs. ACEi+THZ & 1 & $0.842(0.653-1.085)$ & $0.85(0.58-1.21)$ \\
\hline $\mathrm{ARB}+\mathrm{CCB}$ & vs. $\mathrm{CCB}+\mathrm{THZ}$ & 1 & $1.402(0.667-2.950)$ & $1.02(0.64-1.56)$ \\
\hline $\mathrm{BB}+\mathrm{CCB}$ & & 1 & $2.292(1.155-4.549)$ & $2.00(1.03-3.61)$ \\
\hline $\mathrm{ARB}+\mathrm{CCB}$ & vs. $A R B+T H Z$ & 1 & $0.955(0.673-1.355)$ & $0.93(0.64-1.34)$ \\
\hline $\mathrm{BB}+\mathrm{CCB}$ & vs. $A R B+C C B$ & 1 & $1.635(0.886-3.016)$ & $1.96(1.04-3.58)$ \\
\hline \multicolumn{5}{|l|}{ Tolerability } \\
\hline $\mathrm{CCB}$ & vs. Placebo & 1 & $2.414(2.006-2.906)$ & $1.43(0.53-3.09)$ \\
\hline ARB & & 4 & $1.141(1.081-1.204)$ & $1.10(0.54-2.01)$ \\
\hline ACEi & & 7 & $1.682(1.271-2.226)$ & $2.15(1.30-3.52)$ \\
\hline Diuretic & & 1 & $1.981(1.625-2.416)$ & $1.86(0.56-4.59)$ \\
\hline ACEi+THZ & & 1 & $2.481(2.007-3.067)$ & $3.10(0.64-9.27)$ \\
\hline $\mathrm{ARB}+\mathrm{THZ}$ & & 1 & $0.960(0.886-1.041)$ & $1.20(0.26-3.51)$ \\
\hline Renin inhibitor & & 1 & $1.475(1.250-1.741)$ & $1.89(0.40-5.58)$ \\
\hline ACEi & vs. CCB & 1 & 4.201 (2.206-7.998) & $1.45(0.42-3.71)$ \\
\hline Diuretic & & 1 & 1.000 (0.516-1.938) & $1.45(0.42-3.71)$ \\
\hline $\mathrm{CCB}+\mathrm{THZ}$ & vs. diuretic & 1 & $0.677(0.236-1.937)$ & $0.95(0.12-3.46)$ \\
\hline $\mathrm{ACEi}+\mathrm{CCB}$ & vs. ACEi+THZ & 1 & $0.892(0.823-0.966)$ & $1.14(0.24-3.38)$ \\
\hline
\end{tabular}

$\mathrm{OR}$, odds ratio; $\mathrm{Cl}$, confidence interval; $\mathrm{CCB}$, calcium channel blocker; $\mathrm{ARB}$, angiotensin II receptor blocker; $\mathrm{ACE}$, angiotensin-converting enzyme inhibitor; $\mathrm{BB}$, beta-blocker; $\mathrm{THZ}$, thiazide-like diuretic. 


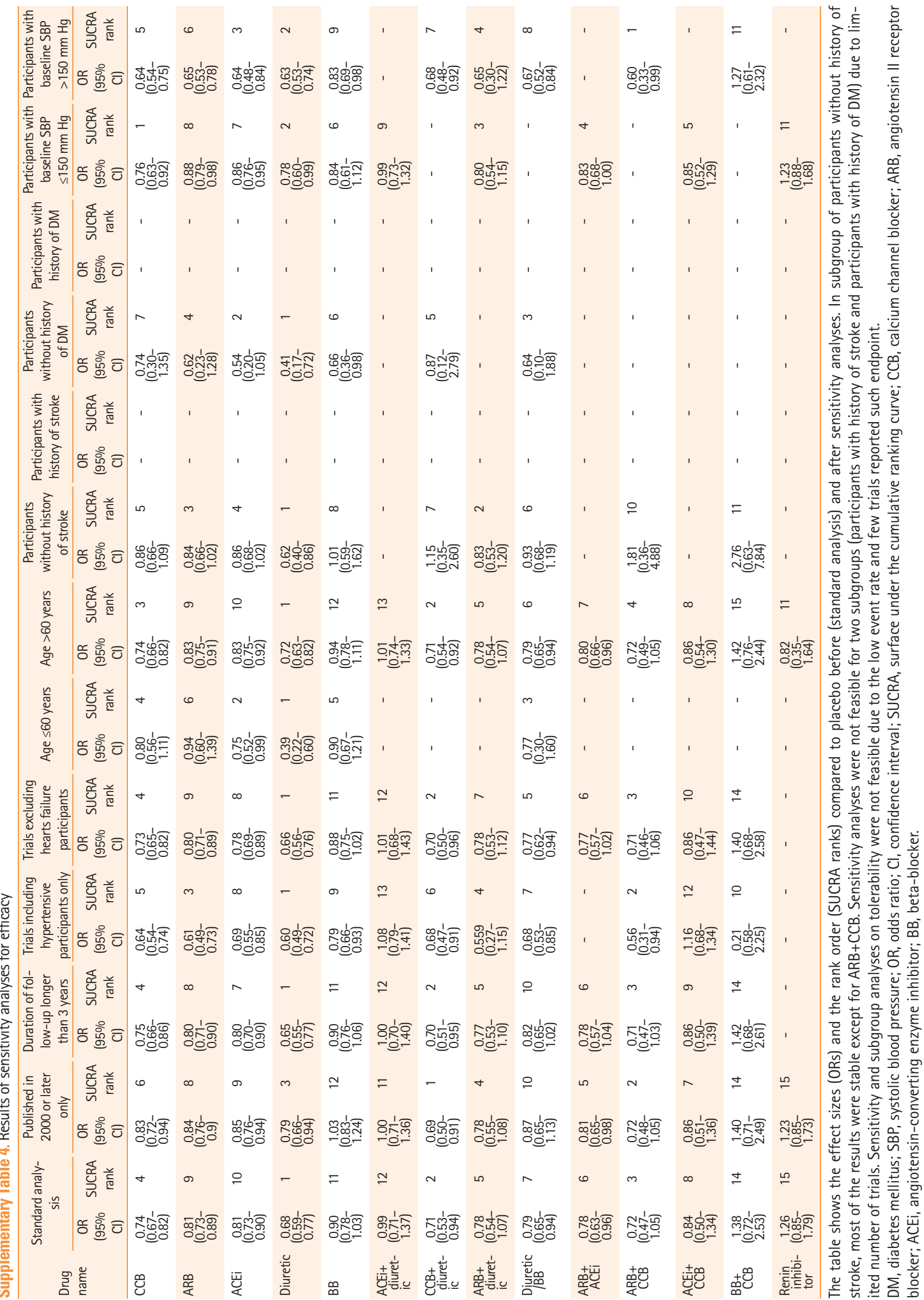


Supplementary Table 5. Inconsistency test by node-splitting for efficacy

\begin{tabular}{|c|c|c|c|c|c|c|c|c|}
\hline \multirow{2}{*}{ Side } & \multicolumn{2}{|c|}{ Direct } & \multicolumn{2}{|c|}{ Indirect } & \multicolumn{2}{|c|}{ Difference } & \multirow{2}{*}{$P>|z|$} & \multirow{2}{*}{ tau } \\
\hline & Coefficient & SE & Coefficient & SE & Coefficient & SE & & \\
\hline$A B$ & -0.451284 & 0.1068399 & -0.2510002 & 0.0631098 & -0.2002838 & 0.1243141 & 0.107 & 0.1242378 \\
\hline$A C$ & -0.0993669 & 0.0520806 & -0.3976046 & 0.0644907 & 0.2982377 & 0.0829809 & 0.000 & 0.0888897 \\
\hline$A D$ & -0.1920362 & 0.0714549 & -0.232732 & 0.076429 & 0.0406958 & 0.1053677 & 0.699 & 0.1283594 \\
\hline$A E$ & -0.4643451 & 0.0847979 & -0.2713766 & 0.1006676 & -0.1929685 & 0.1293544 & 0.136 & 0.1182247 \\
\hline$A F$ & -0.2418242 & 0.0961056 & 0.0165464 & 0.0910915 & -0.2583706 & 0.1313758 & 0.050 & 0.1158177 \\
\hline$A G^{*}$ & -0.0140438 & 0.1571743 & 0.0781284 & 217.4085 & -0.0921723 & 217.4086 & 1.000 & 0.1228489 \\
\hline $\mathrm{AH}$ & -0.3589984 & 0.1597569 & -0.3847499 & 0.334987 & 0.0257515 & 0.3711314 & 0.945 & 0.1243285 \\
\hline Al & -0.2299547 & 0.1994513 & -0.3698523 & 0.3509167 & 0.1398976 & 0.4036376 & 0.729 & 0.1244593 \\
\hline AJ & -0.6301822 & 0.2651127 & -0.1922366 & 0.0978299 & -0.4379456 & 0.2825871 & 0.121 & 0.119769 \\
\hline A 0 & - & - & - & - & - & - & - & - \\
\hline B C & -0.0701689 & 0.0855201 & 0.1973536 & 0.0743317 & -0.2675225 & 0.1141232 & 0.019 & 0.120526 \\
\hline B D & 0.0495561 & 0.0963298 & 0.1198465 & 0.0790357 & -0.0702904 & 0.1255804 & 0.576 & 0.1287696 \\
\hline BE & 0.0605161 & 0.1030118 & -0.2094289 & 0.0979282 & 0.269945 & 0.1424187 & 0.058 & 0.1165115 \\
\hline B F & 0.2197186 & 0.105716 & 0.1710801 & 0.0985393 & 0.0486385 & 0.1449476 & 0.737 & 0.127049 \\
\hline B J & 0.0822924 & 0.0974244 & -0.0422592 & 0.1880368 & 0.1245516 & 0.2117605 & 0.556 & 0.1264311 \\
\hline$C D$ & 0.0514294 & 0.0883482 & -0.0205073 & 0.0719231 & 0.0719367 & 0.1138033 & 0.527 & 0.124331 \\
\hline$C F$ & 0.3083339 & 0.1486445 & 0.0536351 & 0.0817897 & 0.2546988 & 0.1696607 & 0.133 & 0.1186854 \\
\hline$C K^{*}$ & 0.0172791 & 0.1024207 & -0.3017673 & 0.2237688 & 0.3190464 & 0.246183 & 0.195 & 0.1211038 \\
\hline$C L$ & -0.5002282 & 0.3563764 & 0.0453293 & 0.2466586 & -0.5455575 & 0.4334104 & 0.208 & 0.1229408 \\
\hline$D E$ & -0.1350791 & 0.1418873 & -0.1944038 & 0.0911882 & 0.0593247 & 0.1688091 & 0.725 & 0.1276075 \\
\hline$D F$ & -0.012024 & 0.3272441 & 0.1095738 & 0.0798881 & -0.1215978 & 0.3368545 & 0.718 & 0.1237679 \\
\hline D J & 0.081128 & 0.1434105 & -0.1187521 & 0.1217839 & 0.1998801 & 0.1881917 & 0.288 & 0.1223478 \\
\hline DK & -0.1067001 & 0.105547 & 0.1686203 & 0.1995086 & -0.2753204 & 0.2250074 & 0.221 & 0.1207032 \\
\hline EF & 0.3827491 & 0.1882641 & 0.2493307 & 0.1005048 & 0.1334183 & 0.2139697 & 0.533 & 0.1259243 \\
\hline $\mathrm{EH}$ & 0.4562378 & 0.483335 & -0.0271547 & 0.1642594 & 0.4833925 & 0.510484 & 0.344 & 0.1229657 \\
\hline $\mathrm{G} \mathrm{M}^{*}$ & -0.1723831 & 0.1785902 & 0.0668541 & 438.5716 & -0.2392372 & 438.5717 & 1.000 & 0.122849 \\
\hline$H L^{*}$ & 0.3381917 & 0.399266 & -0.139543 & 0.2746922 & 0.4777347 & 0.484633 & 0.324 & 0.1241665 \\
\hline $\mathrm{H} \mathrm{N}^{*}$ & 0.8295874 & 0.3710168 & -0.125879 & 0.8421779 & 0.9554665 & 0.9692651 & 0.324 & 0.1241662 \\
\hline IL & -0.0457219 & 0.2175149 & -0.1856204 & 0.3400159 & 0.1398984 & 0.4036379 & 0.729 & 0.1244593 \\
\hline $\mathrm{LN}^{*}$ & 0.4913958 & 0.3363546 & 1.446865 & 0.8847719 & -0.9554689 & 0.9692654 & 0.324 & 0.1241666 \\
\hline
\end{tabular}

$\mathrm{SE}$, standard error; $\mathrm{A}$, placebo; $\mathrm{B}$, calcium channel blocker (CCB); $\mathrm{C}$, angiotensin II receptor blocker (ARB); $\mathrm{D}$, angiotensin-converting enzyme inhibitor (ACEi); $\mathrm{E}_{\text {, }}$

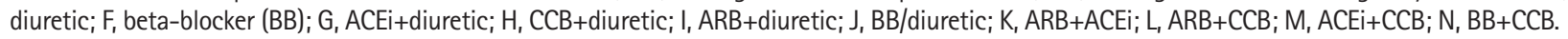

*Warning: all the evidence about these contrasts comes from the trials which directly compare them. 
Supplementary Table 6. Inconsistency test by node-splitting for tolerability

\begin{tabular}{|c|c|c|c|c|c|c|c|c|}
\hline \multirow{2}{*}{ Side } & \multicolumn{2}{|c|}{ Direct } & \multicolumn{2}{|c|}{ Indirect } & \multicolumn{2}{|c|}{ Difference } & \multirow{2}{*}{$P>|z|$} & \multirow{2}{*}{ tau } \\
\hline & Coefficient & SE & Coefficient & SE & Coefficient & SE & & \\
\hline$A B$ & 0.8814234 & 0.4786115 & -0.2520848 & 0.47102 & 1.133508 & 0.6715123 & 0.091 & 0.4691702 \\
\hline$A C$ & - & - & - & - & - & - & - & - \\
\hline$A D$ & 0.5349264 & 0.1638938 & 2.2638 & 0.5903911 & -1.728874 & 0.613268 & 0.005 & 0.3675151 \\
\hline$A E$ & 0.6838528 & 0.5614273 & 0.190057 & 0.7790083 & 0.4937958 & 0.9602367 & 0.607 & 0.5522498 \\
\hline$A F$ & - & - & - & - & - & - & - & - \\
\hline$A G^{*}$ & 0.9085095 & 0.5370918 & 0.0566346 & 69.0073 & 0.8518749 & 69.00939 & 0.990 & 0.5260806 \\
\hline Al & - & - & - & - & - & - & - & - \\
\hline$A K$ & - & - & - & - & - & - & - & - \\
\hline B D & 1.435238 & 0.4929838 & -0.2936447 & 0.3647816 & 1.728883 & 0.6132688 & 0.005 & 0.367515 \\
\hline BE & 7.31E-10 & 0.6472978 & 0.4937874 & 0.7092778 & -0.4937874 & 0.9602445 & 0.607 & 0.5522505 \\
\hline $\mathrm{EH}^{*}$ & -0.3904272 & 0.7513723 & -1.078526 & 338.4009 & 0.6880987 & 338.4016 & 0.998 & 0.5260769 \\
\hline G J* & -0.1147697 & 0.5276537 & -1.818516 & 138.0747 & 1.703746 & 138.0757 & 0.990 & 0.5260807 \\
\hline
\end{tabular}

$\mathrm{SE}$, standard error; $\mathrm{A}$, placebo; $\mathrm{B}$, calcium channel blocker (CCB); C, angiotensin II receptor blocker (ARB); D, angiotensin-converting enzyme inhibitor (ACEi); $\mathrm{E}_{\text {, }}$

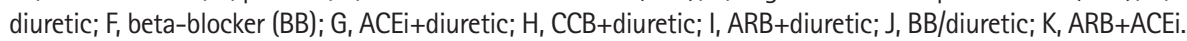

*Warning: all the evidence about these contrasts comes from the trials which directly compare them.

Supplementary Table 7. Inconsistency test by design-by-treatment for efficacy and tolerability

\begin{tabular}{lcc}
\hline Network outcome & Chi-square & Pfor test of global inconsistency \\
\hline Efficacy & 31.35 & 0.26 \\
Safety & 7.14 & 0.03
\end{tabular}

Assessment of global inconsistency in networks for efficacy and tolerability in preventing stroke using the 'design-by-treatment' interaction model. 
Random sequence generation (selection bias)

Allocation concealment (selection bias)

Blinding of participants and personnel (performance bias)

Blinding of outcome assessment (detection bias)

Incomplete outcome data (attrition bias)

Selective reporting (reporting bias)

Other bias

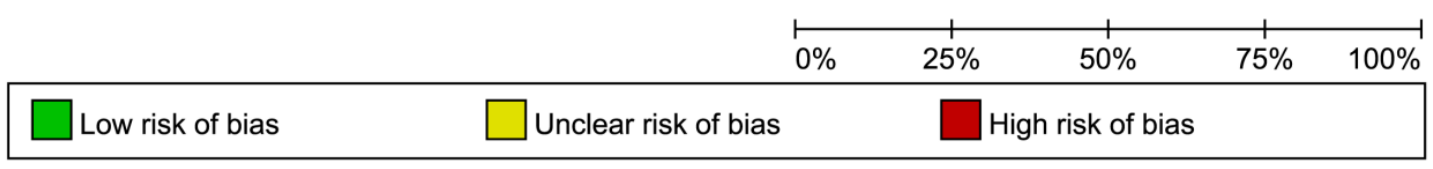
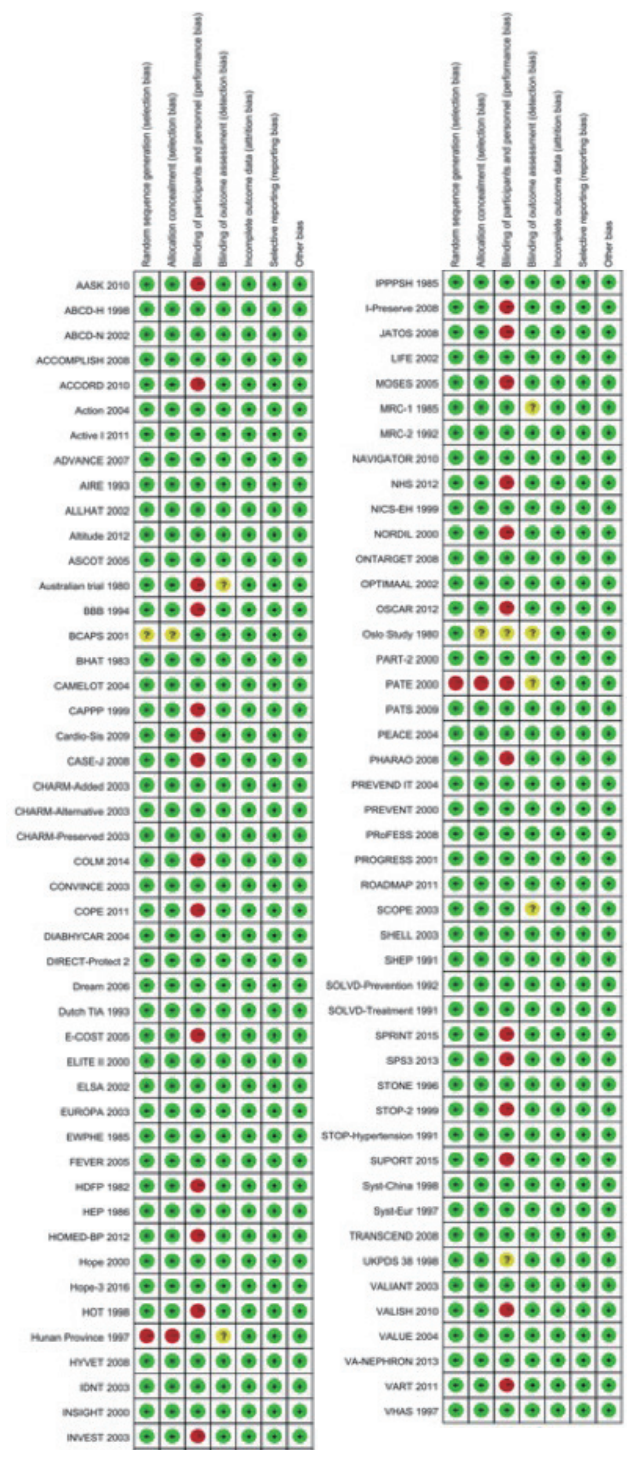

B

Supplementary Figure 1. Risk of bias of the included studies. (A) Risk of bias graph. (B) Risk of bias summary. "+" indicates low risk of bias; "?" indicates unclear risk of bias; "-" indicates high risk of bias. 


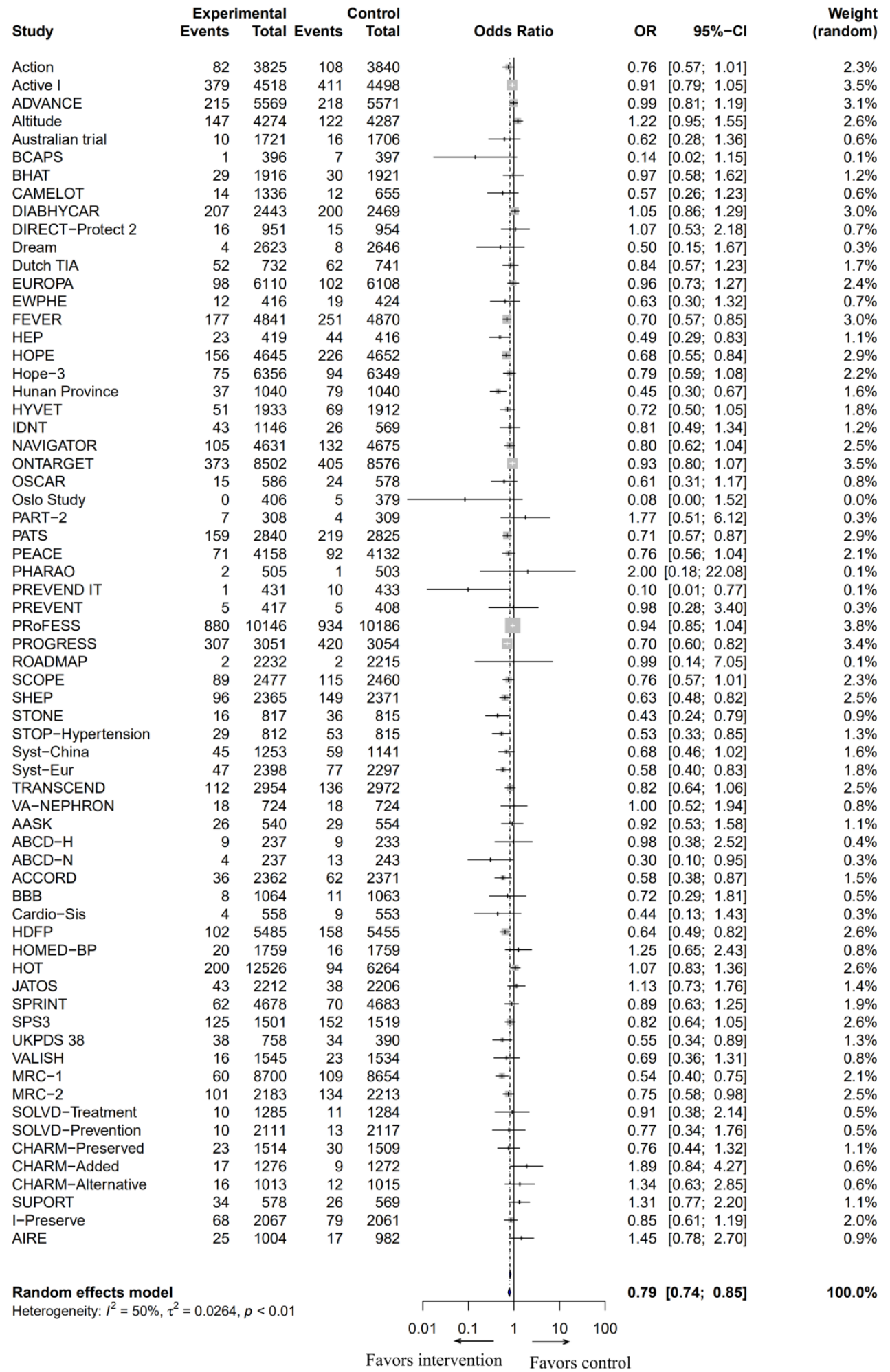

Supplementary Figure 2. Reduction in systolic blood pressure on the odds ratio (OR) of stroke. $\mathrm{Cl}$, confidence interval. 


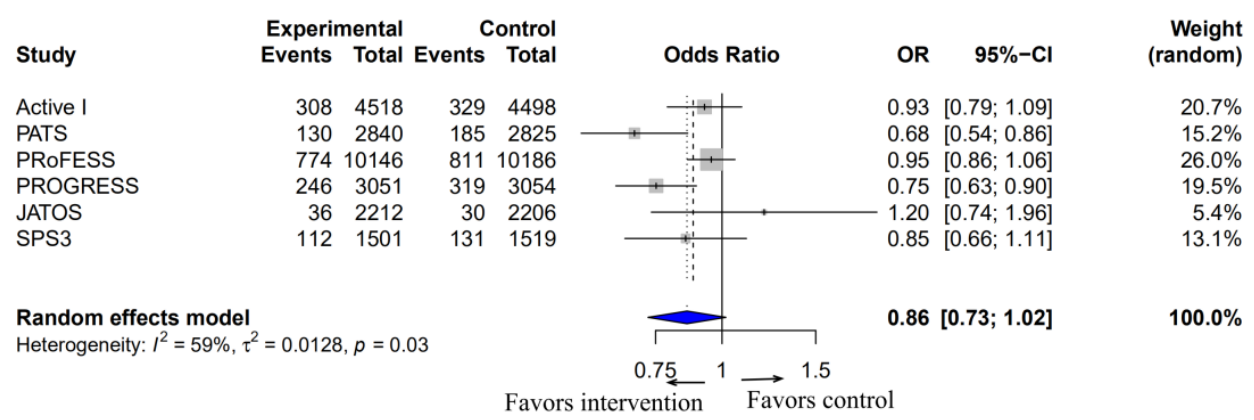

Supplementary Figure 3. Reduction in systolic blood pressure on the odds ratio (OR) of ischemic stroke. $\mathrm{Cl}$, confidence interval.

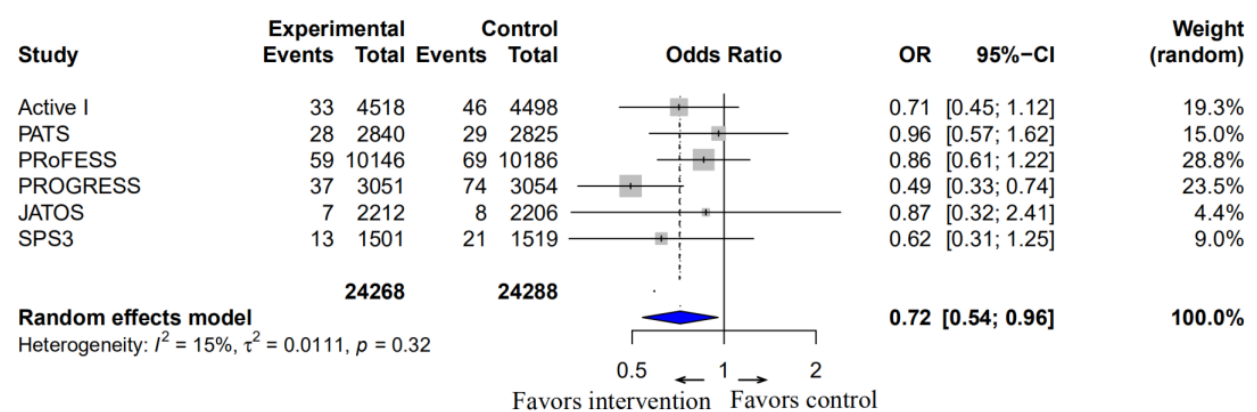

Supplementary Figure 4. Reduction in systolic blood pressure on the odds ratio (OR) of hemorrhagic stroke. Cl, confidence interval.

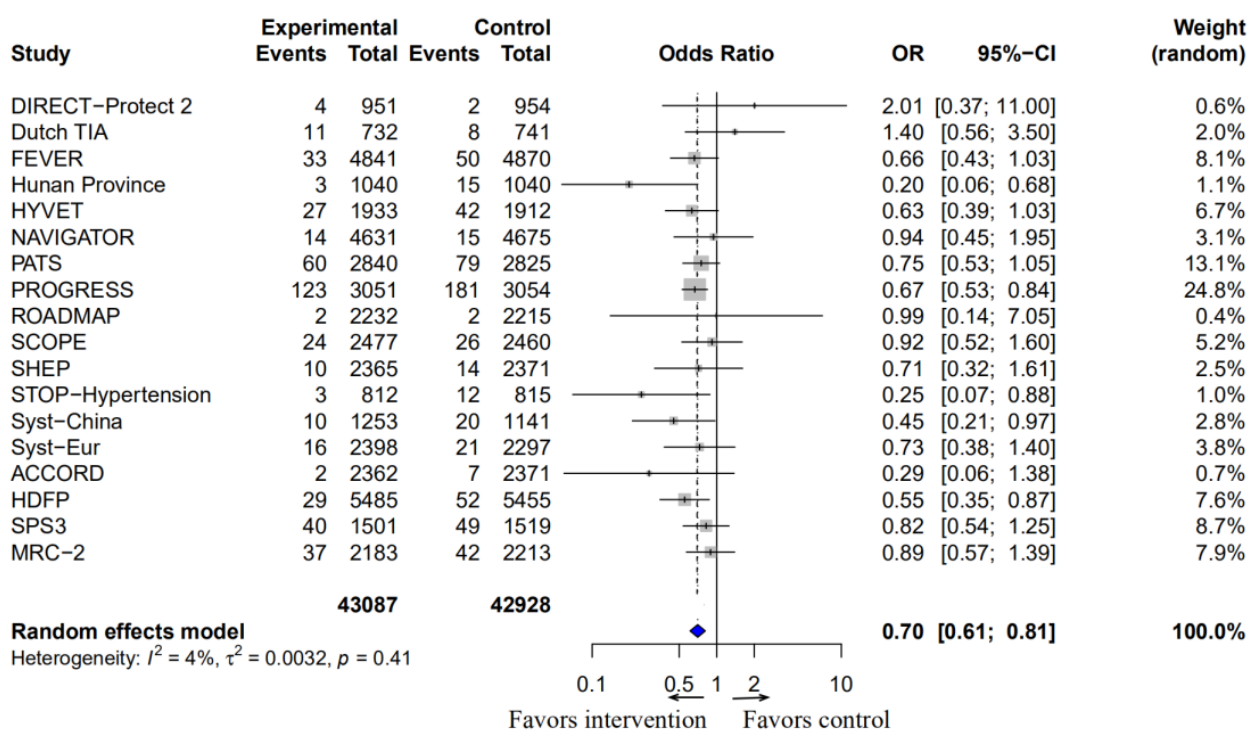

Supplementary Figure 5. Reduction in systolic blood pressure on the odds ratio (OR) of fatal or disabling stroke. Cl, confidence interval. 


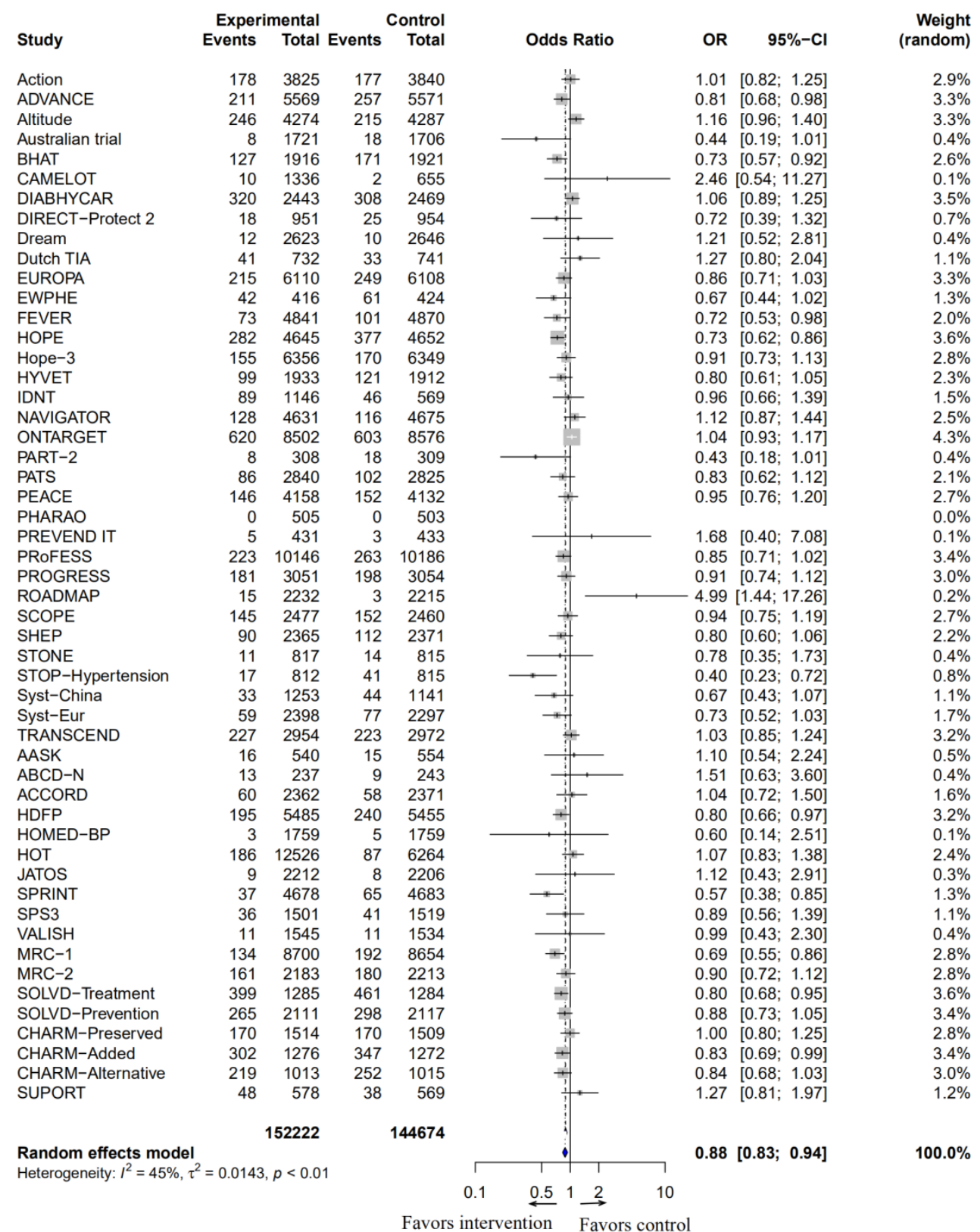

Supplementary Figure 6. Reduction in systolic blood pressure on the odds ratio (OR) of cardiovascular death. $\mathrm{Cl}$, confidence interval. 


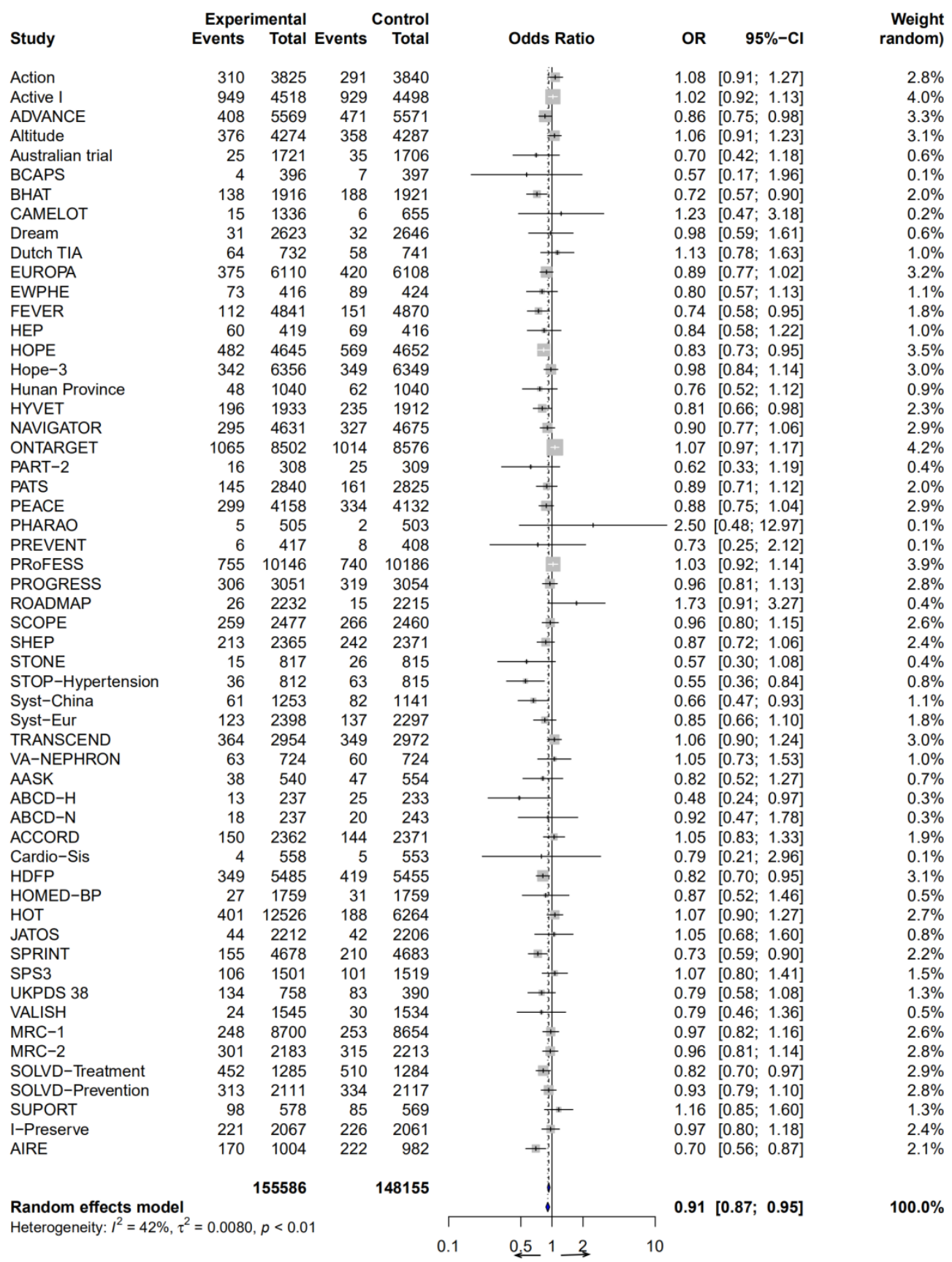

Favors intervention Favors control

Supplementary Figure 7. Reduction in systolic blood pressure on the odds ratio (OR) of all cause death. $\mathrm{Cl}$, confidence interval. 


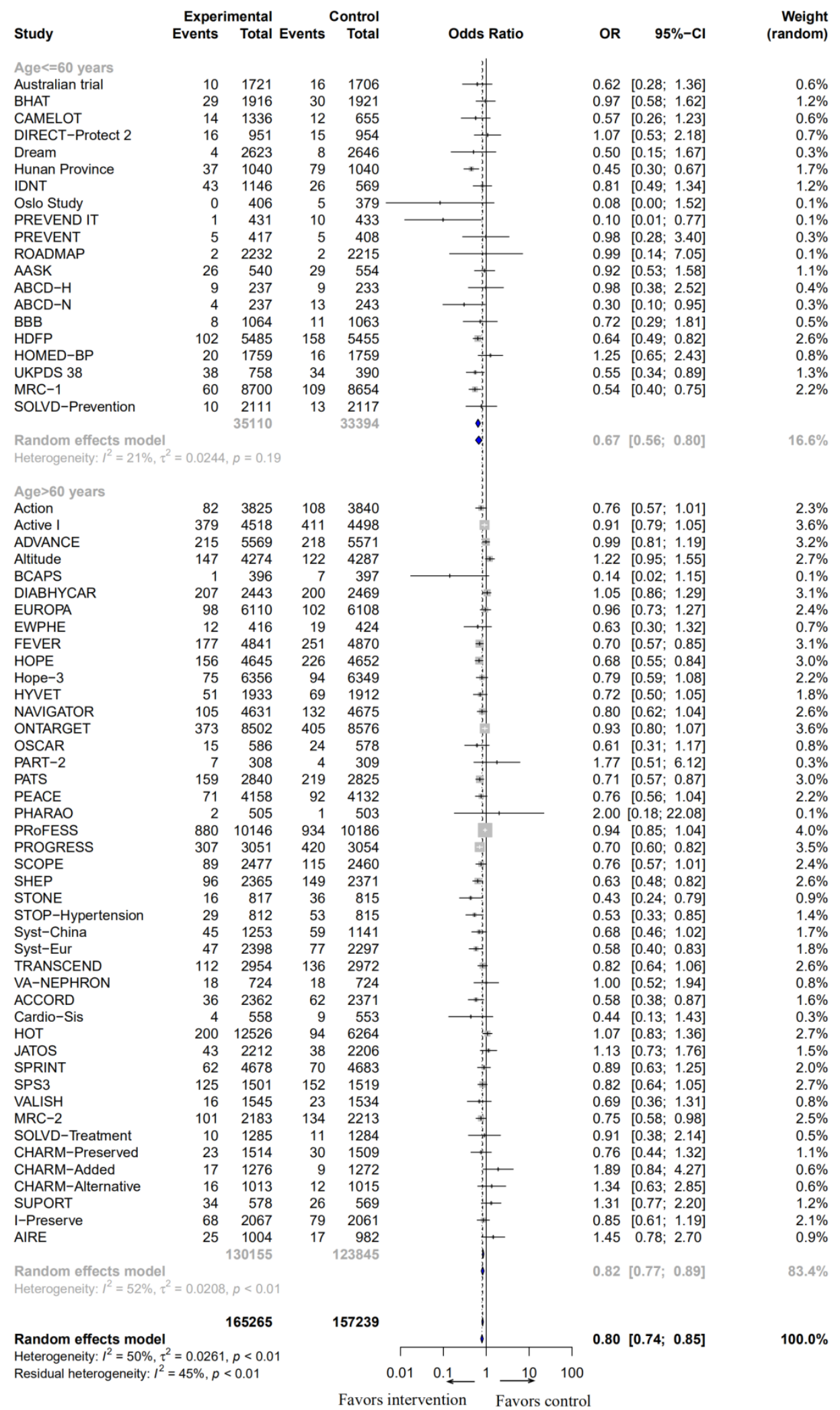

Supplementary Figure 8. Reduction in systolic blood pressure on the odds ratio (OR) of stroke stratified by age. Cl, confidence interval. 


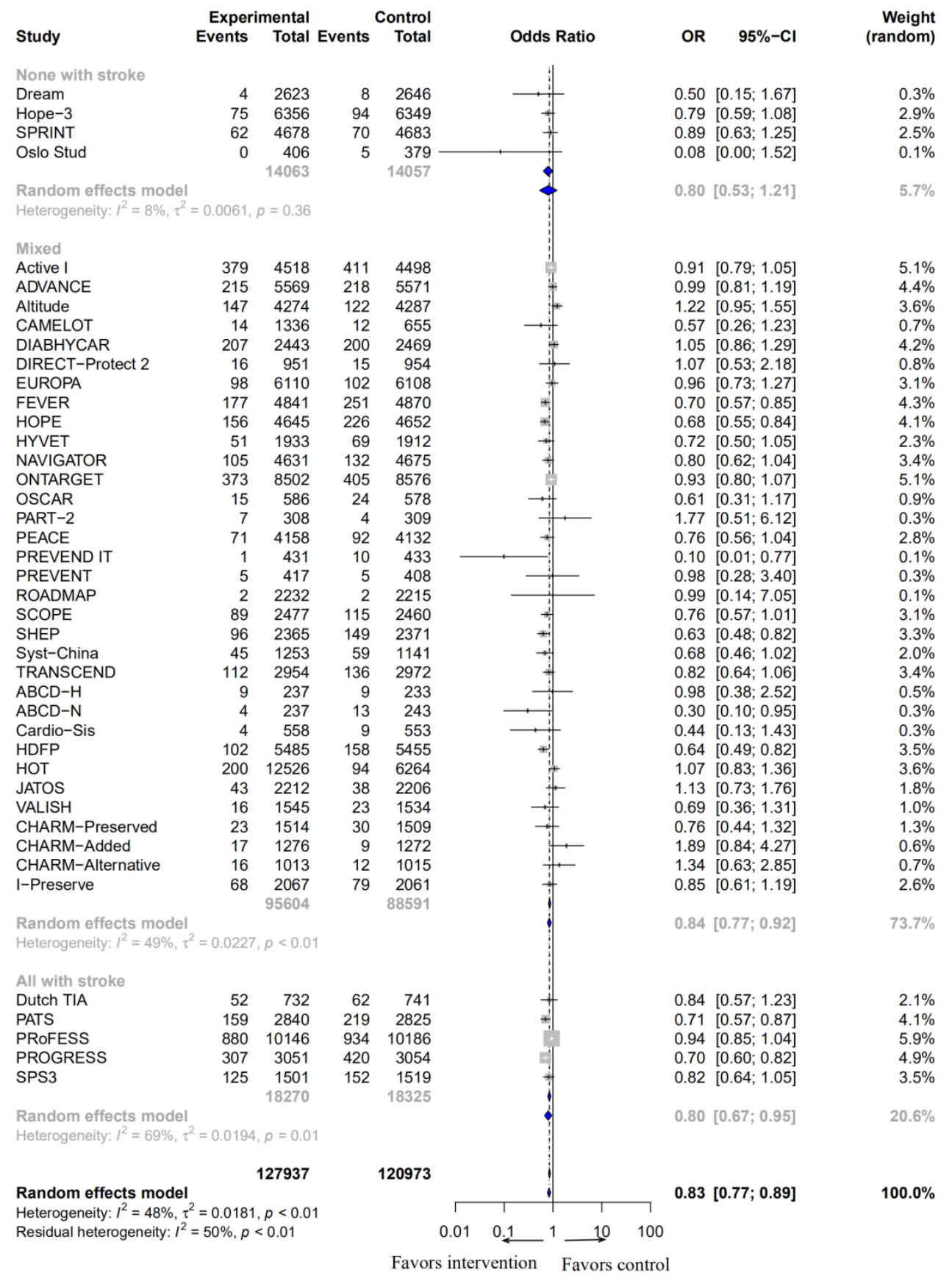

Supplementary Figure 9. Reduction in systolic blood pressure on the odds ratio (OR) of stroke stratified by history of stroke. $\mathrm{Cl}$, confidence interval. 


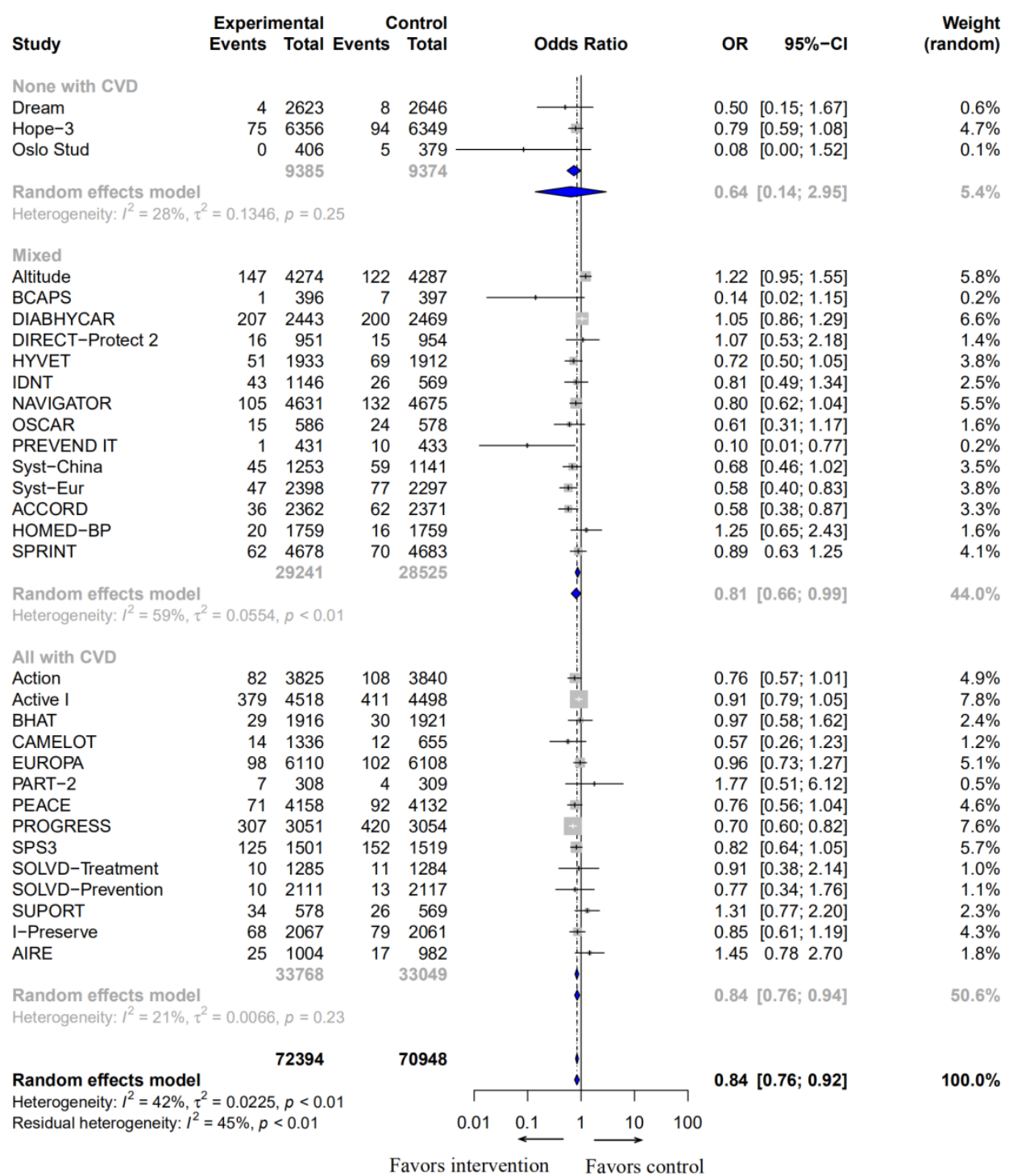

Supplementary Figure 10. Reduction in systolic blood pressure on the odds ratio (OR) of stroke stratified by history of cardiovascular disease (CVD). Cl, confidence interval. 


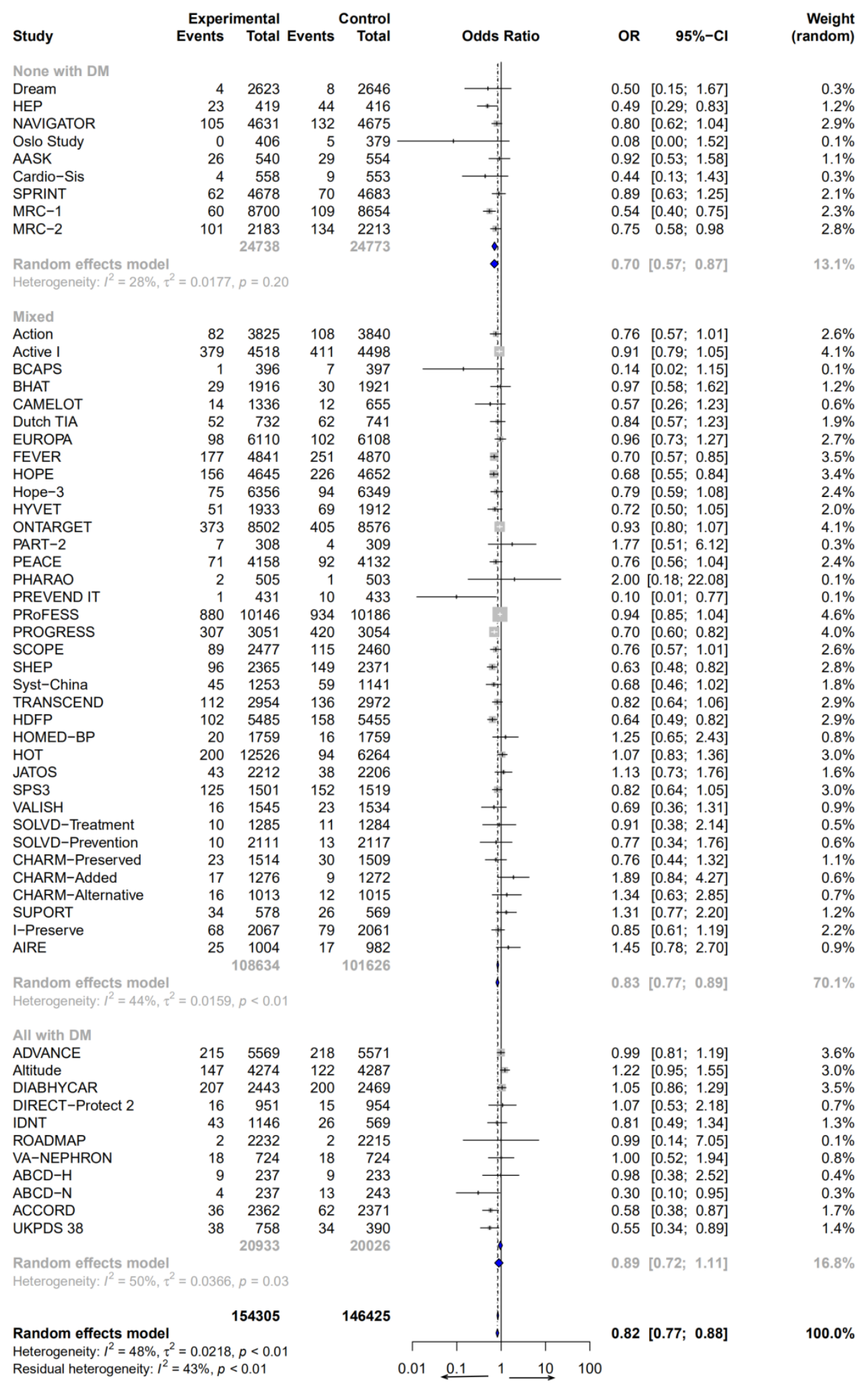

Favors intervention Favors control

Supplementary Figure 11. Reduction in systolic blood pressure on the odds ratio (OR) of stroke stratified by history of diabetes mellitus (DM). Cl, confidence interval. 


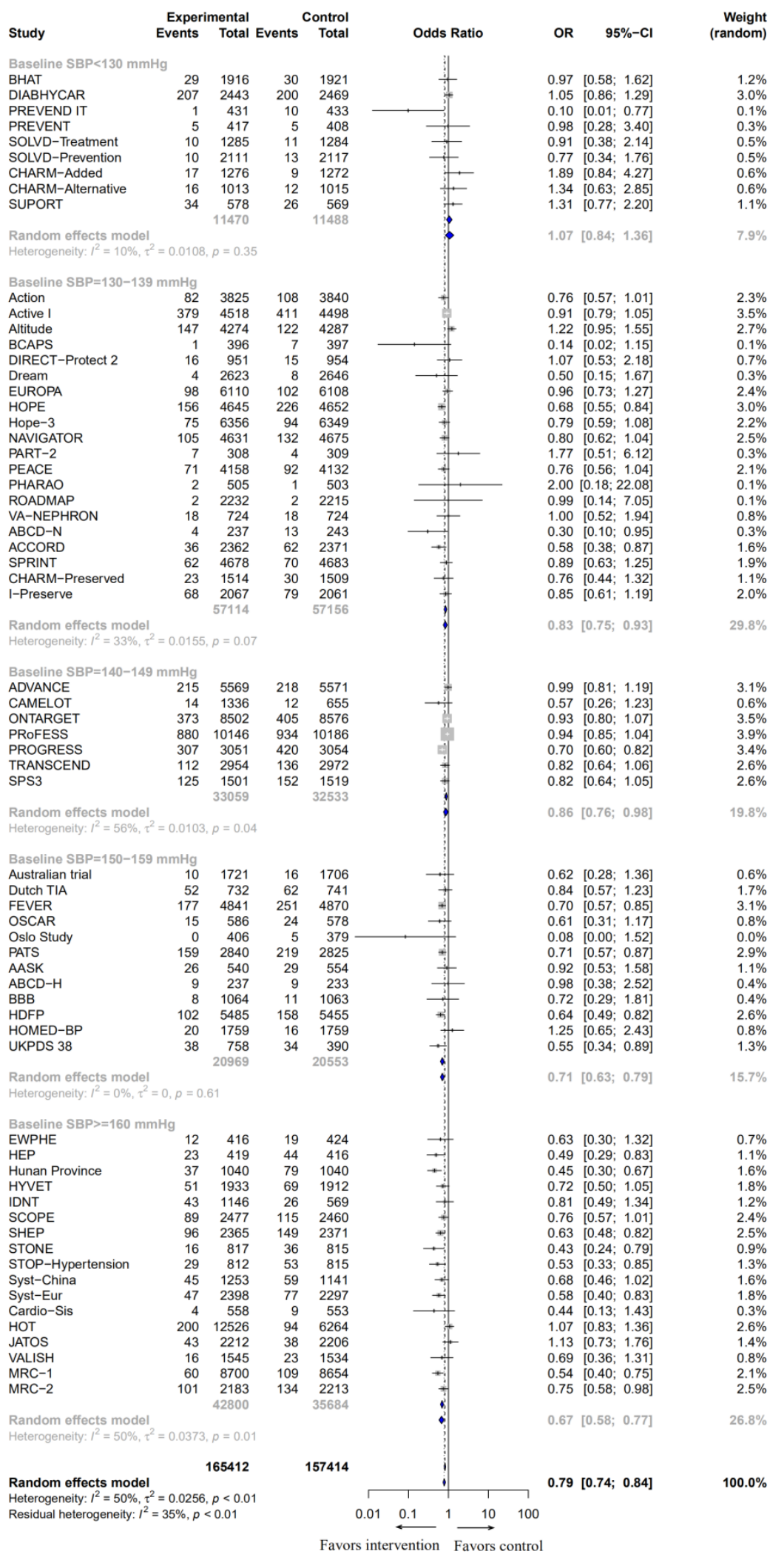

Supplementary Figure 12. Reduction in systolic blood pressure (SBP) on the odds ratio (OR) of stroke stratified by baseline SBP levels. $\mathrm{Cl}$, confidence interval. 


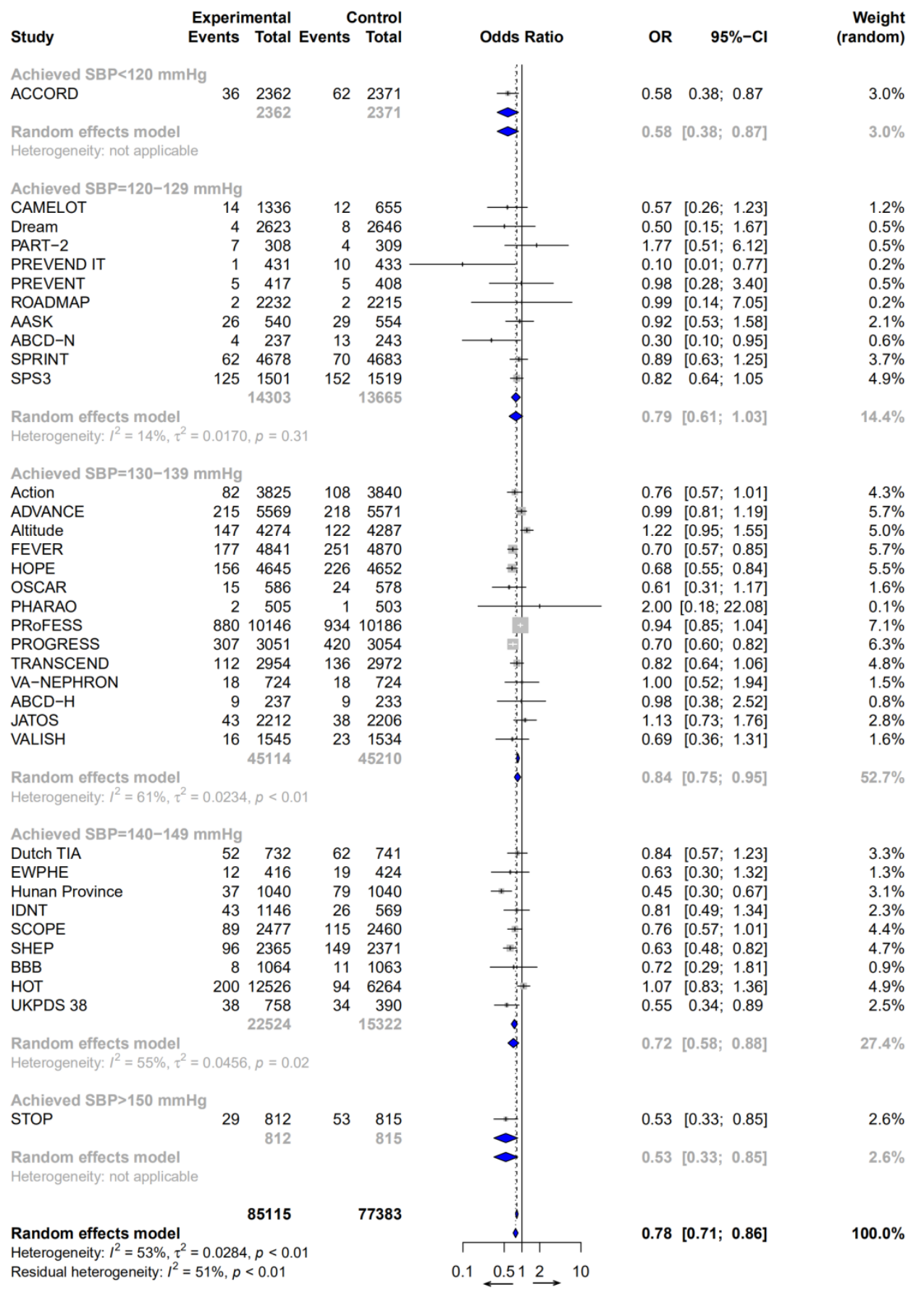

Favors intervention Favors control

Supplementary Figure 13. Reduction in systolic blood pressure (SBP) on the odds ratio (OR) of stroke stratified by achieved SBP levels. Cl, confidence interval. 


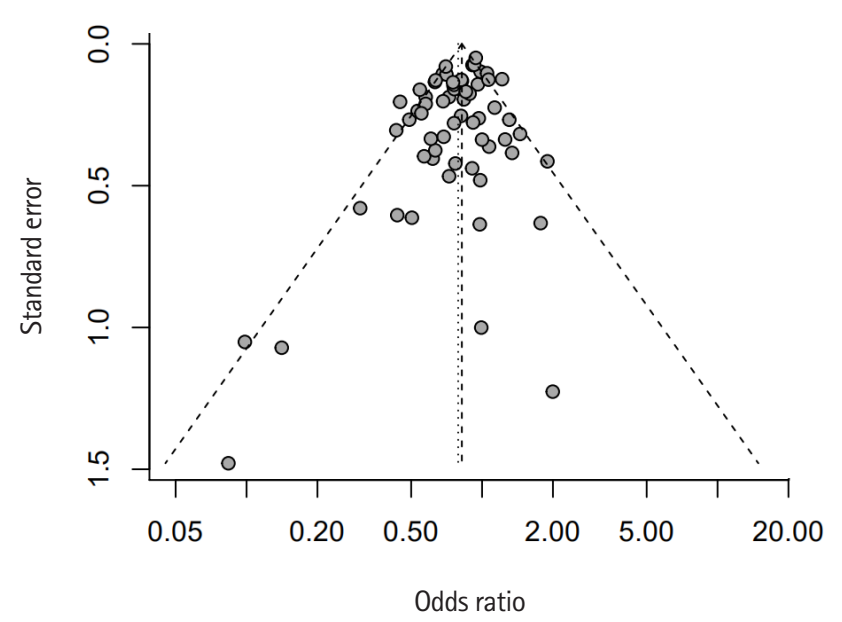

Supplementary Figure 14. Funnel plot for stroke.

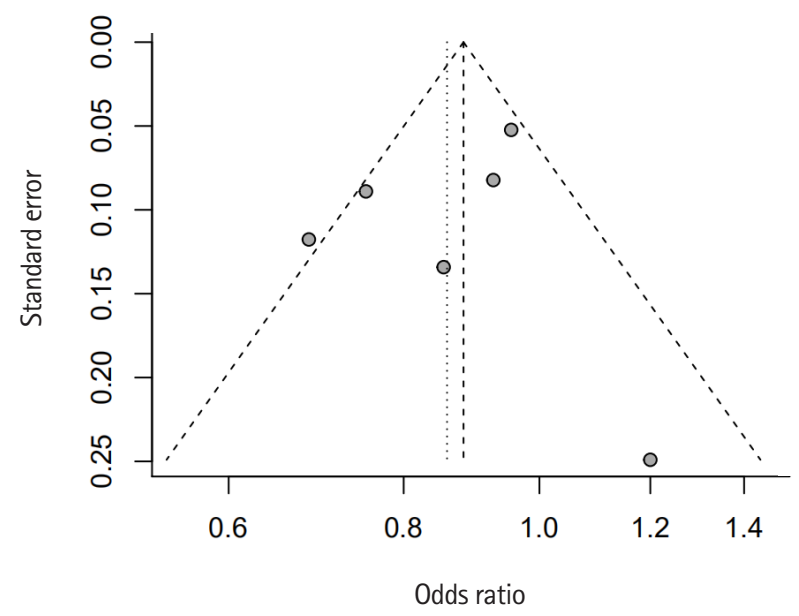

Supplementary Figure 15. Funnel plot for ischemic stroke.

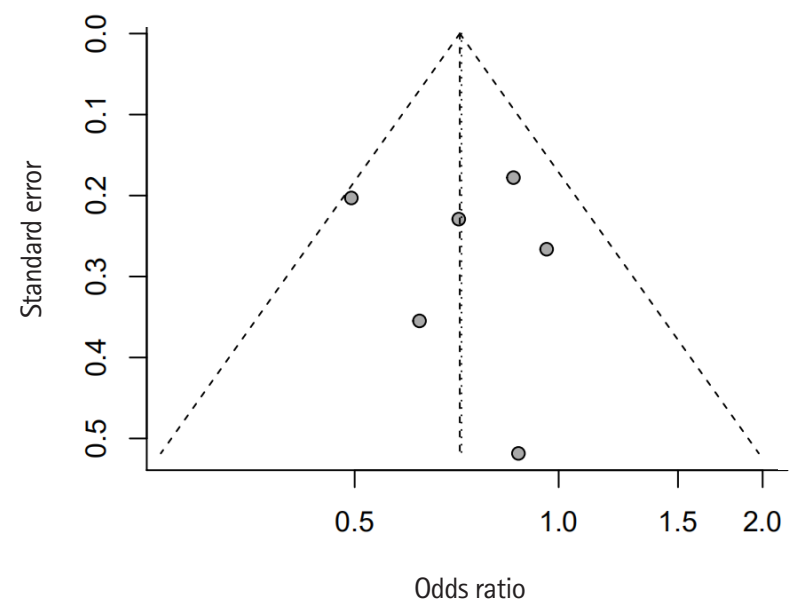

Supplementary Figure 16. Funnel plot for hemorrhagic stroke. 


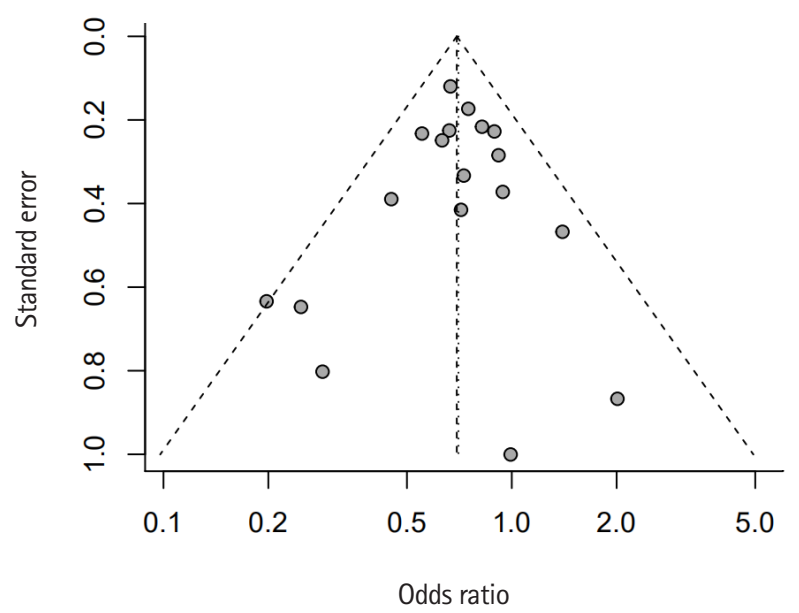

Supplementary Figure 17. Funnel plot for fatal or disabling stroke.

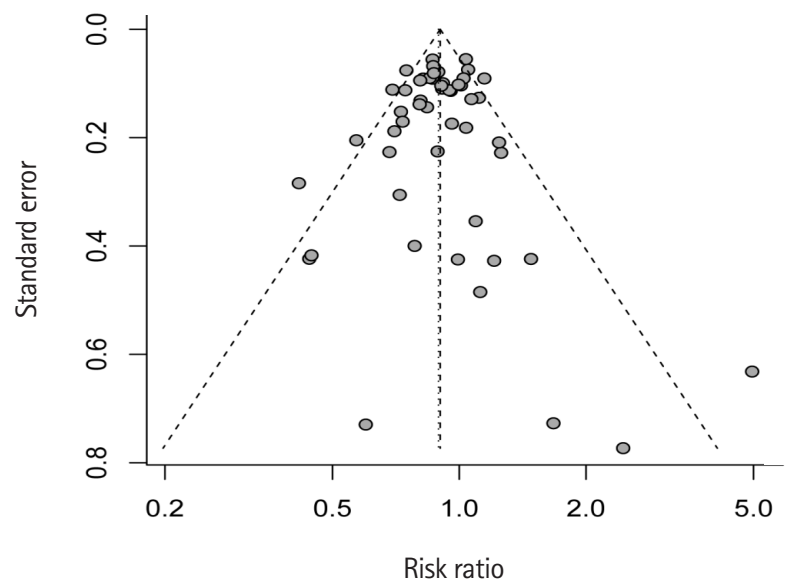

Supplementary Figure 18. Funnel plot for cardiovascular death.

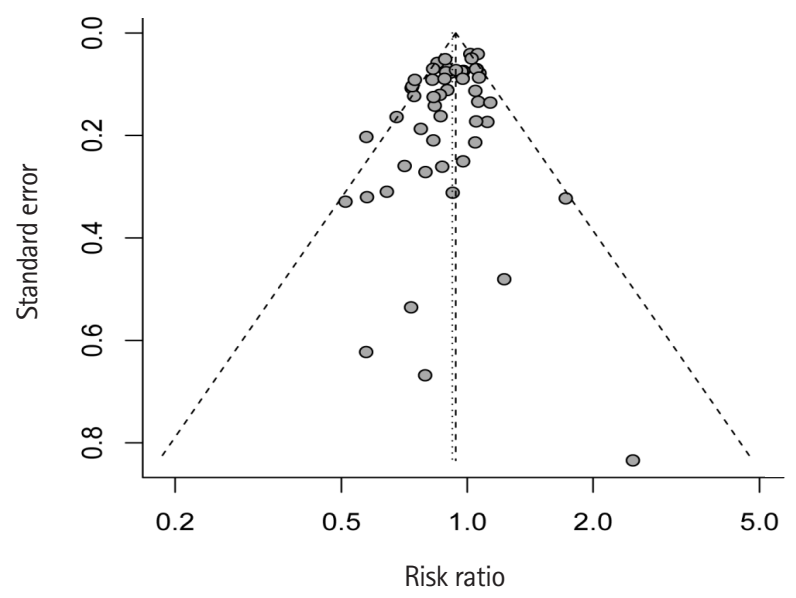

Supplementary Figure 19. Funnel plot for all cause death. 


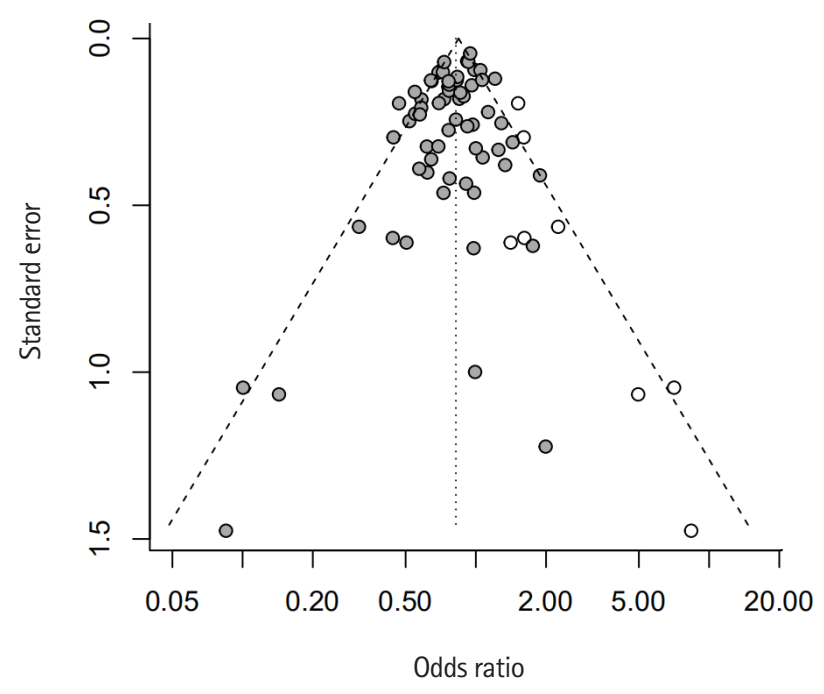

Supplementary Figure 20. Trimmed funnel plot for stroke.

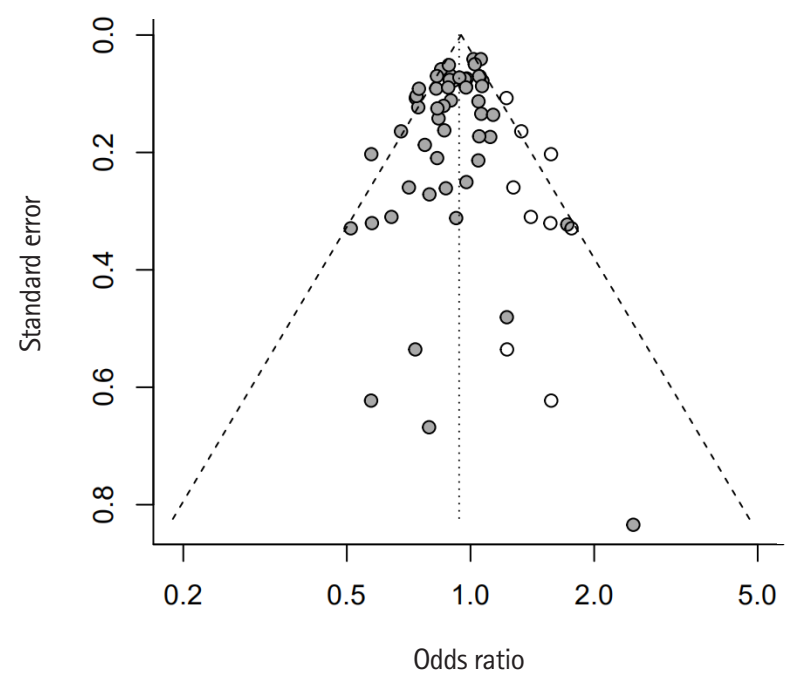

Supplementary Figure 21. Trimmed funnel plot for all cause death. 
Study

Omitting Action Omitting Active I Omitting ADVANCE

Omitting Altitude

Omitting Australian trial

Omitting BCAPS

Omitting BHAT

Omitting CAMELOT

Omitting DIABHYCAR

Omitting DIRECT-Protect 2

Omitting Dream

Omitting Dutch TIA

Omitting EUROPA

Omitting EWPHE

Omitting FEVER

Omitting HEP

Omitting HOPE

Omitting Hope-3

Omitting Hunan Province

Omitting HYVET

Omitting IDNT

Omitting NAVIGATOR

Omitting ONTARGET

Omitting OSCAR

Omitting Oslo Study

Omitting PART-2

Omitting PATS

Omitting PEACE

Omitting PHARAO

Omitting PREVEND IT

Omitting PREVENT

Omitting PRoFESS

Omitting PROGRESS

Omitting ROADMAP

Omitting SCOPE

Omitting SHEP

Omitting STONE

Omitting STOP-Hypertension

Omitting Syst-China

Omitting Syst-Eur

Omitting TRANSCEND

Omitting VA-NEPHRON

Omitting AASK

Omitting ABCD-H

Omitting $A B C D-N$

Omitting ACCORD

Omitting BBB

Omitting Cardio-Sis

Omitting HDFP

Omitting HOMED-BP

Omitting HOT

Omitting JATOS

Omitting SPRINT

Omitting SPS 3

Omitting UKPDS 38

Omitting VALISH

Omitting MRC-1

Omitting MRC-2

Omitting SOLVD-Treatment

Omitting SOLVD-Prevention

Omitting CHARM-Preserved

Omitting CHARM-Added

Omitting CHARM-Alternative

Omitting SUPORT

Omitting I-Preserve

Omitting AIRE

Random effects model

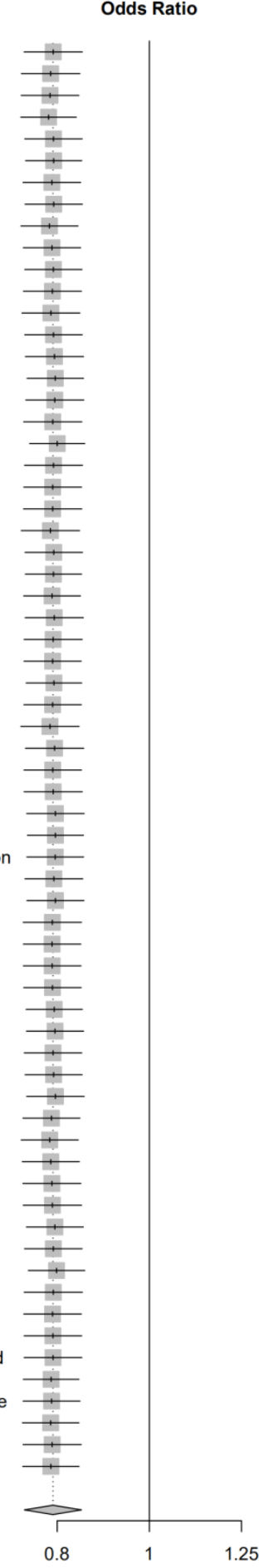

OR $\quad 95 \%-\mathrm{Cl}$

$0.79[0.74 ; 0.85]$

$0.79[0.73 ; 0.85]$

$0.79[0.73 ; 0.84]$

$0.78[0.73 ; 0.84]$

$0.79[0.74 ; 0.85$

$0.79[0.74 ; 0.85]$

$0.79[0.74 ; 0.85]$

$0.79[0.74 ; 0.85]$

$0.79[0.73 ; 0.84]$

$0.79[0.74 ; 0.85]$

$0.79[0.74 ; 0.85]$

$0.79[0.74 ; 0.85]$

$0.79[0.73 ; 0.85$

$0.79[0.74 ; 0.85$

$0.79[0.74 ; 0.85]$

$0.80[0.74 ; 0.85]$

$0.80[0.74 ; 0.85]$

$0.79[0.74 ; 0.85]$

$0.80[0.75 ; 0.86]$

$0.79[0.74 ; 0.85]$

$0.79[0.74 ; 0.85]$

$0.79[0.74 ; 0.85]$

$0.79[0.73 ; 0.84]$

$0.79[0.74 ; 0.85]$

$0.79[0.74 ; 0.85]$

$0.79[0.74 ; 0.85]$

$0.79[0.74 ; 0.85]$

$0.79[0.74 ; 0.85$

$0.79[0.74 ; 0.85]$

$0.79[0.74 ; 0.85]$

$0.79[0.74 ; 0.85]$

$0.79[0.73 ; 0.84]$

$0.79[0.74 ; 0.85]$

$0.79[0.74 ; 0.85]$

$0.79[0.74 ; 0.85]$

$0.80[0.74 ; 0.85]$

$0.80[0.74 ; 0.85]$

$0.80[0.74 ; 0.85]$

$0.79[0.74 ; 0.85]$

$0.80[0.74 ; 0.85]$

$0.79[0.74 ; 0.85]$

$0.79[0.74 ; 0.85]$

$0.79[0.74 ; 0.85]$

$0.79[0.74 ; 0.85]$

$0.79[0.74 ; 0.85]$

$0.80[0.74 ; 0.85]$

$0.79[0.74 ; 0.85]$

$0.79[0.74 ; 0.85]$

$0.80[0.74 ; 0.85]$

$0.79[0.74 ; 0.85]$

$0.79[0.73 ; 0.84$

$0.79[0.74 ; 0.84]$

$0.79[0.74 ; 0.85]$

$0.79[0.74 ; 0.85]$

$0.80[0.74 ; 0.85]$

$0.79[0.74 ; 0.85]$

$0.80[0.75 ; 0.86]$

$0.79[0.74 ; 0.85]$

$0.79[0.74 ; 0.85]$

$0.79[0.74 ; 0.85]$

$0.79[0.74 ; 0.85]$

$0.79[0.74 ; 0.84]$

$0.79[0.74 ; 0.85$

$0.79[0.74 ; 0.84]$

$0.79[0.74 ; 0.85$

$0.79[0.74 ; 0.84]$

$0.79[0.74 ; 0.85]$

Supplementary Figure 22. Sensitivity analysis for stroke. $\mathrm{OR}$, odds ratio; $\mathrm{Cl}$, confidence interval. 


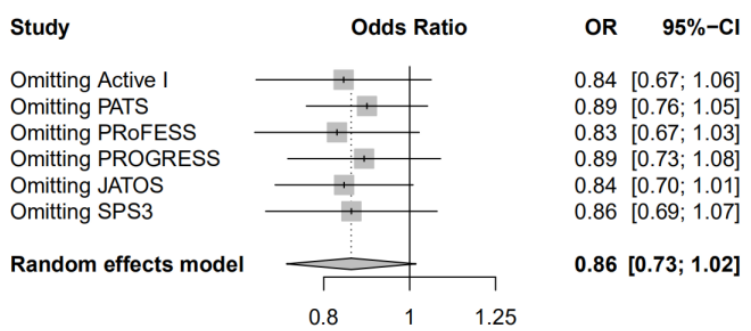

Supplementary Figure 23. Sensitivity analysis for ischemic stroke. OR, odds ratio; $\mathrm{Cl}$, confidence interval.

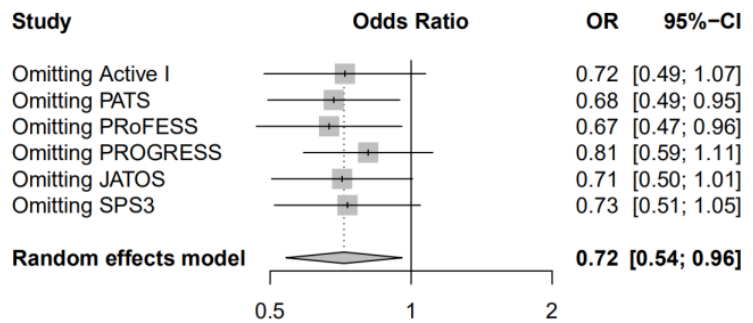

Supplementary Figure 24. Sensitivity analysis for hemorrhagic stroke. OR, odds ratio; $\mathrm{Cl}$, confidence interval.

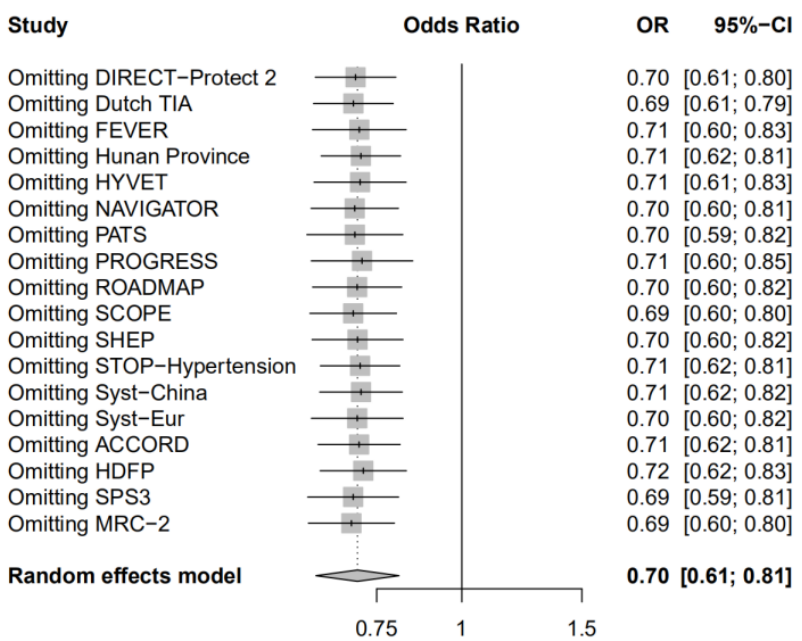

Supplementary Figure 25. Sensitivity analysis for fatal or disabling stroke. OR, odds ratio; $\mathrm{Cl}$, confidence interval. 
Study

Omitting Action

Omitting ADVANCE

Omitting Altitude

Omitting Australian trial

Omitting BHAT

Omitting CAMELOT

Omitting DIABHYCAR

Omitting DIRECT-Protect 2

Omitting Dream

Omitting Dutch TIA

Omitting EUROPA

Omitting EWPHE

Omitting FEVER

Omitting HOPE

Omitting Hope-3

Omitting HYVET

Omitting IDNT

Omitting NAVIGATOR

Omitting ONTARGET

Omitting PART-2

Omitting PATS

Omitting PEACE

Omitting PHARAO

Omitting PREVEND IT

Omitting PRoFESS

Omitting PROGRESS

Omitting ROADMAP

Omitting SCOPE

Omitting SHEP

Omitting STONE

Omitting STOP-Hypertension

Omitting Syst-China

Omitting Syst-Eur

Omitting TRANSCEND

Omitting AASK

Omitting ABCD-N

Omitting ACCORD

Omitting HDFP

Omitting HOMED-BP

Omitting HOT

Omitting JATOS

Omitting SPRINT

Omitting SPS3

Omitting VALISH

Omitting MRC-1

Omitting MRC-2

Omitting SOLVD-Treatment

Omitting SOLVD-Prevention

Omitting CHARM-Preserved

Omitting CHARM-Added

Omitting CHARM-Alternative

Omitting SUPORT

Random effects model

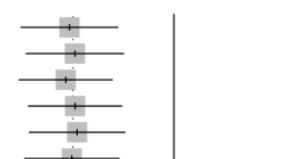

0.88 [0.83; 0.93]

$0.89[0.83 ; 0.94]$

$0.88[0.83 ; 0.93]$

$0.89[0.84 ; 0.94]$

$0.89[0.84 ; 0.94]$

0.88 [0.83; 0.93]

0.88 [0.83; 0.93]

$0.88[0.83 ; 0.94]$

$0.88[0.83 ; 0.94]$

$0.88[0.83 ; 0.93]$

0.88 [0.83; 0.94$]$

$0.89[0.84 ; 0.94]$

$0.89[0.84 ; 0.94]$

$0.89[0.84 ; 0.94]$

0.88 [0.83; 0.94]

0.88 [0.83; 0.94]

$0.88[0.83 ; 0.94]$

$0.88[0.83 ; 0.93]$

$0.88[0.83 ; 0.93]$

$0.89[0.84 ; 0.94]$

$0.88[0.83 ; 0.94]$

$0.88[0.83 ; 0.94]$

$0.88[0.83 ; 0.94]$

$0.88[0.83 ; 0.94]$

$0.88[0.83 ; 0.94]$

$0.88[0.83 ; 0.94]$

$0.88[0.83 ; 0.93]$

$0.88[0.83 ; 0.94]$

0.88 [0.83; 0.94$]$

0.88 [0.83; 0.94]

$0.89[0.84 ; 0.94]$

$0.89[0.83 ; 0.94]$

$0.89[0.83 ; 0.94]$

$0.88[0.83 ; 0.93]$

$0.88[0.83 ; 0.94]$

$0.88[0.83 ; 0.93]$

$0.88[0.83 ; 0.93]$

$0.89[0.83 ; 0.94]$

$0.88[0.83 ; 0.94]$

$0.88[0.83 ; 0.93]$

$0.88[0.83 ; 0.94]$

$0.89[0.84 ; 0.94]$

$0.88[0.83 ; 0.94]$

$0.88[0.83 ; 0.94]$

$0.89[0.84 ; 0.94]$

0.88 [0.83; 0.94$]$

$0.89[0.83 ; 0.94]$

$0.88[0.83 ; 0.94]$

$0.88[0.83 ; 0.93]$

$0.88[0.83 ; 0.94]$

$0.88[0.83 ; 0.94]$

$0.88[0.83 ; 0.93$ ]

$0.88[0.83 ; 0.94]$

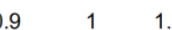

Supplementary Figure 26. Sensitivity analysis for cardiovascular death. $\mathrm{OR}$, odds ratio; $\mathrm{Cl}$, confidence interval. 
Study

Omitting Action Omitting Active

Omitting ADVANCE

Omitting Altitude

Omitting Australian trial

Omitting BCAPS

Omitting BHAT

Omitting CAMELOT

Omitting Dream

Omitting Dutch TIA

Omitting EUROPA

Omitting EWPHE

Omitting FEVER

Omitting HEP

Omitting HOPE

Omitting Hope-3

Omitting Hunan Province

Omitting HYVET

Omitting NAVIGATOR

Omitting ONTARGET

Omitting PART-2

Omitting PATS

Omitting PEACE

Omitting PHARAO

Omitting PREVENT

Omitting PRoFESS

Omitting PROGRESS

Omitting ROADMAP

Omitting SCOPE

Omitting SHEP

Omitting STONE

Omitting STOP-Hypertension

Omitting Syst-China

Omitting Syst-Eur

Omitting TRANSCEND

Omitting VA-NEPHRON

Omitting AASK

Omitting ABCD-H

Omitting ABCD-N

Omitting ACCORD

Omitting Cardio-Sis

Omitting HDFP

Omitting HOMED-BP

Omitting HOT

Omitting JATOS

Omitting SPRINT

Omitting SPS3

Omitting UKPDS 38

Omitting VALISH

Omitting MRC-1

Omitting MRC-2

Omitting SOLVD-Treatment

Omitting SOLVD-Prevention

Omitting SUPORT

Omitting I-Preserve

Omitting AIRE

Random effects mode
Odds Ratio

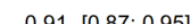

$0.91[0.87 ; 0.95]$

$0.91[0.87 ; 0.95$

$0.91[0.87 ; 0.95]$

$0.91[0.88 ; 0.95]$

$0.91[0.87 ; 0.95]$

$0.92[0.88 ; 0.96]$

$0.91[0.87 ; 0.95]$

$0.91[0.87 ; 0.95]$

$0.91[0.87 ; 0.95]$

$0.91[0.87 ; 0.95]$

$0.91[0.87 ; 0.95$

$0.92[0.88 ; 0.95]$

$0.91[0.87 ; 0.95]$

$0.91[0.88 ; 0.95]$

$0.91[0.87 ; 0.95]$

$0.91[0.88 ; 0.95]$

$0.91[0.88 ; 0.95$

$0.91[0.87 ; 0.95]$

$0.91[0.87 ; 0.94]$

$0.91[0.88 ; 0.95]$

$0.91[0.87 ; 0.95]$

$0.91[0.87 ; 0.95]$

$0.91[0.87 ; 0.95]$

$0.91[0.87 ; 0.95]$

$0.91[0.87 ; 0.95]$

$0.91[0.87 ; 0.95]$

$0.91[0.87 ; 0.95]$

$0.91[0.87 ; 0.95]$

$0.91[0.87 ; 0.95]$

$0.91[0.88 ; 0.95]$

$0.92[0.88 ; 0.95]$

$0.92[0.88 ; 0.95]$

$0.91[0.87 ; 0.95]$

$0.91[0.87 ; 0.95]$

$0.91[0.87 ; 0.95]$

$0.91[0.87 ; 0.95]$

$0.91[0.88 ; 0.95]$

$0.91[0.87 ; 0.95]$

$0.91[0.87 ; 0.95]$

$0.91[0.87 ; 0.95]$

$0.91[0.88 ; 0.95]$

$0.91[0.87 ; 0.95]$

$0.91[0.87 ; 0.95$

$0.91[0.87 ; 0.95]$

$0.92[0.88 ; 0.96]$

$0.91[0.87 ; 0.95]$

$0.91[0.88 ; 0.95]$

$0.91[0.87 ; 0.95]$

$0.91[0.87 ; 0.95]$

$0.91[0.87 ; 0.95]$

0.91 [0.88;0.95]

$0.91[0.87 ; 0.95$

$0.91[0.87 ; 0.95$

$0.91[0.87 ; 0.95]$

$0.92[0.88 ; 0.96]$

$0.91[0.87 ; 0.95]$

1.1

Supplementary Figure 27. Sensitivity analysis for all cause death. OR, odds ratio; $\mathrm{Cl}$, confidence interval. 

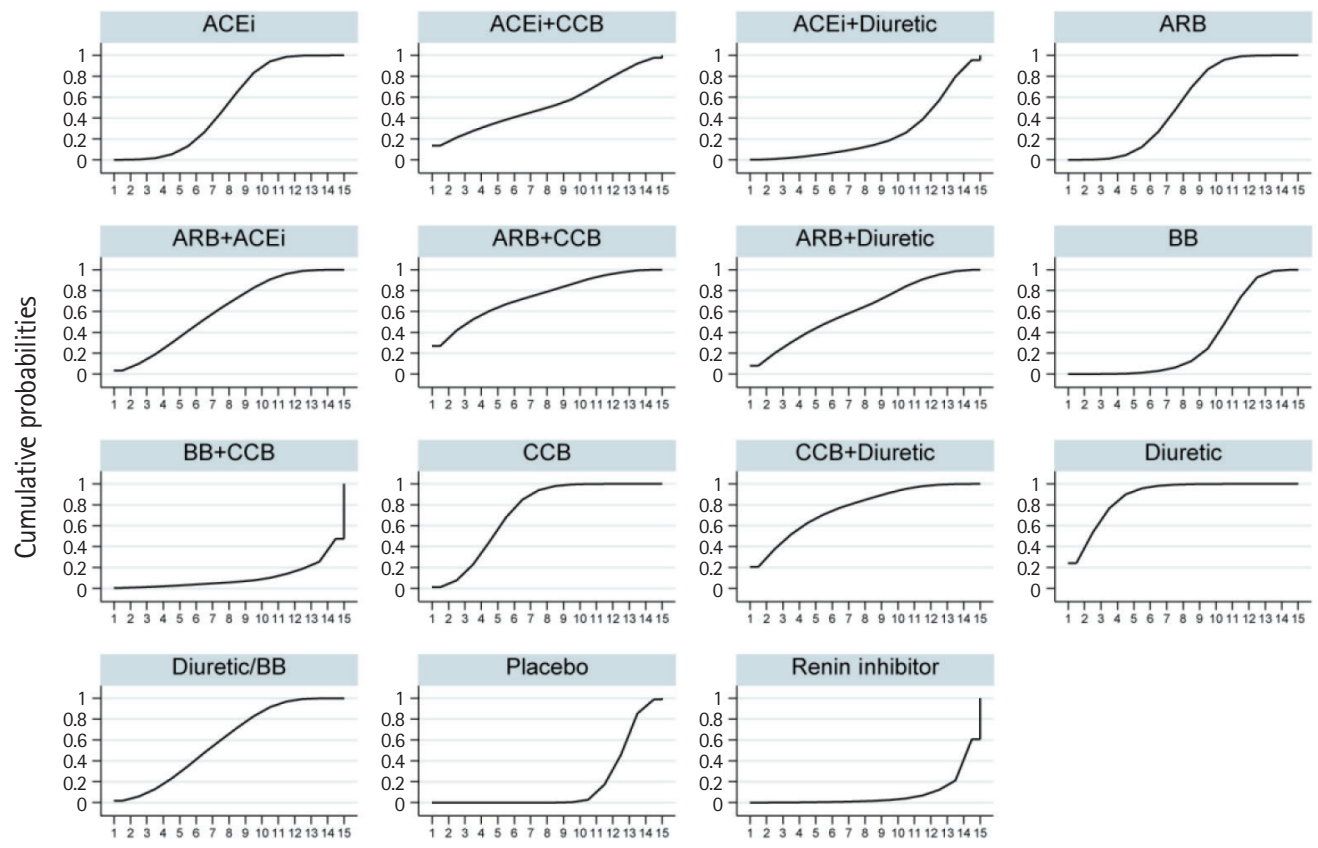

Rank

Supplementary Figure 28. The surface under the cumulative ranking curve (SUCRA) values of multiple treatments for efficacy. SUCRA, ranging from 1 to 0 , indicating that the treatment has a high likelihood of being best and has a high likelihood of being worst, respectively. ACEi, angiotensin-converting enzyme inhibitor; CCB, calcium channel blocker; ARB, angiotensin II receptor blocker; BB, beta-blocker.
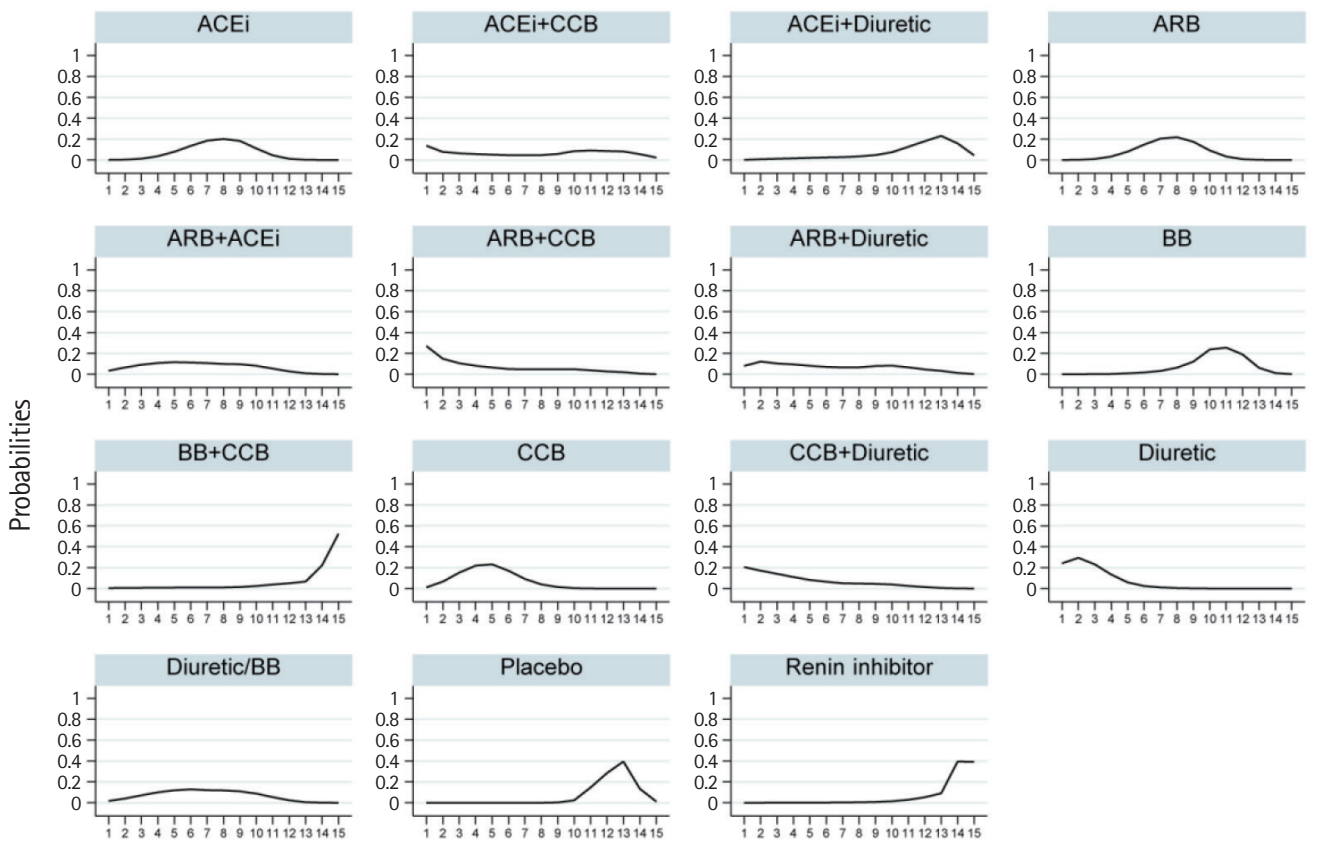

Rank

Supplementary Figure 29. Ranking of multiple treatments for efficacy. Ranking positions for all interventions (1 [best] to 15 [worst]). ACEi, angiotensin-converting enzyme inhibitor; $\mathrm{CCB}$, calcium channel blocker; $\mathrm{ARB}$, angiotensin II receptor blocker; $\mathrm{BB}$, beta-blocker. 

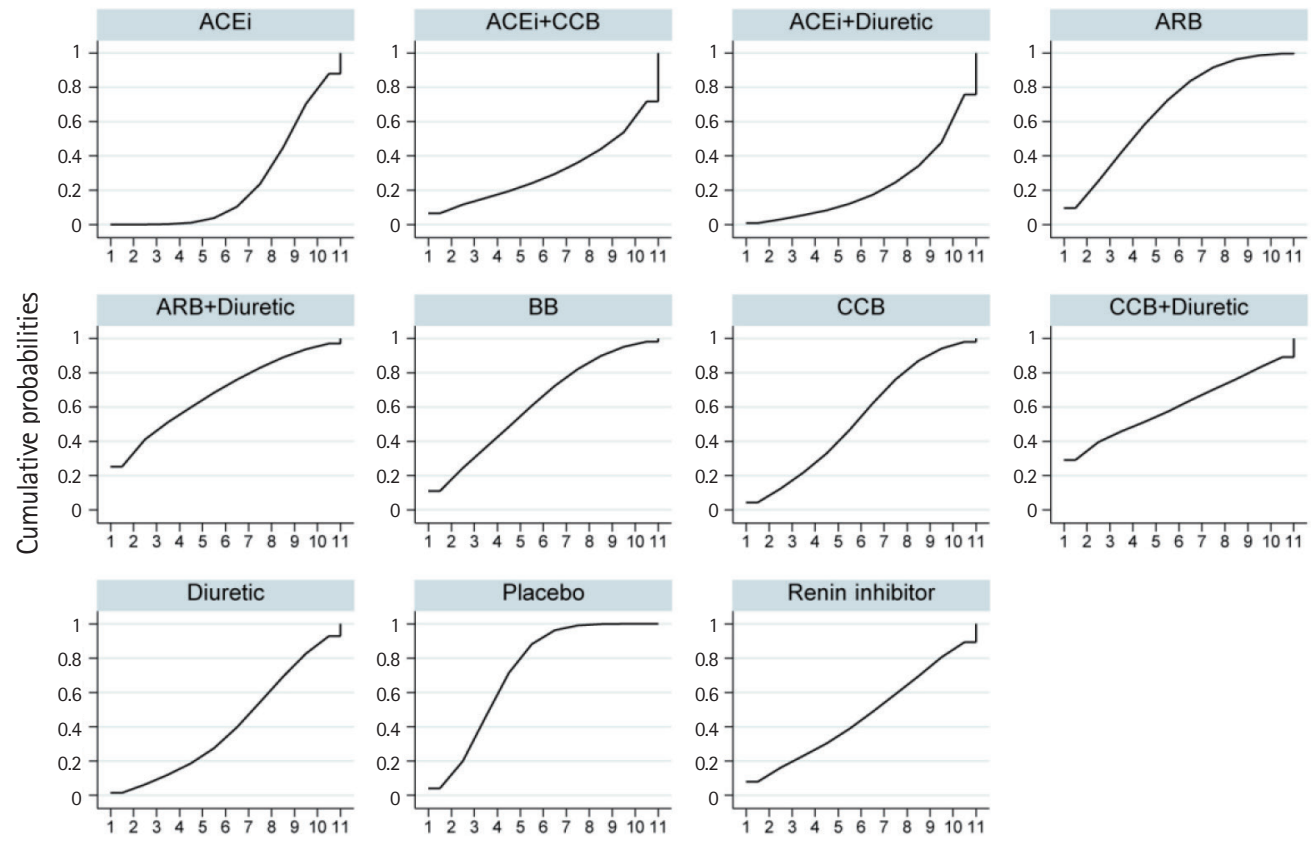

Rank

Supplementary Figure 30. The surface under the cumulative ranking curve (SUCRA) values of multiple treatments for tolerability. SUCRA, ranging from 1 to 0 , indicating that the treatment has a high likelihood of being best and has a high likelihood of being worst, respectively. ACEi, angiotensin-converting enzyme inhibitor; $C C B$, calcium channel blocker; ARB, angiotensin II receptor blocker; BB, beta-blocker.
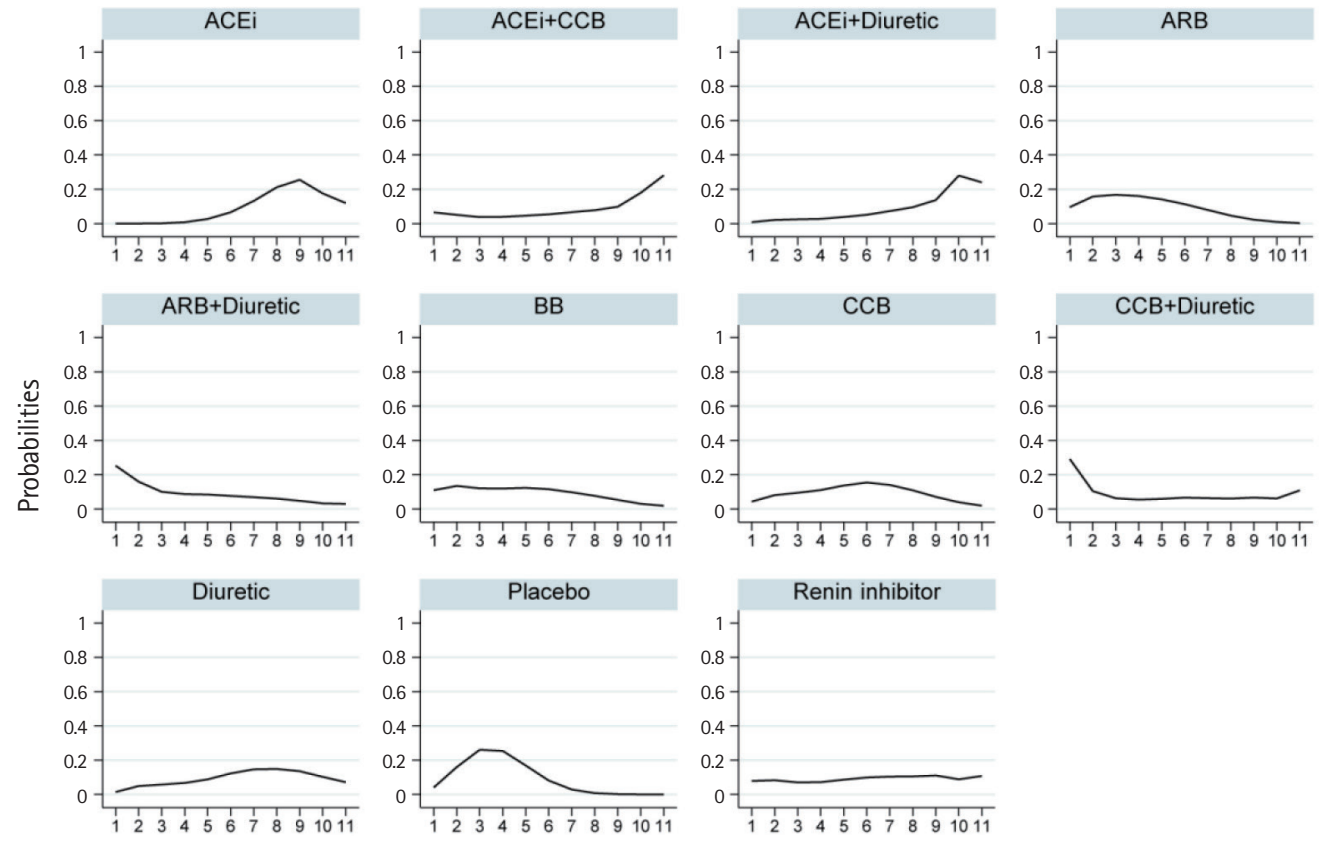

Rank

Supplementary Figure 31. Ranking of multiple treatments for tolerability. Ranking positions for all interventions (1 [best] to 15 [worst]). ACEi, angiotensin-converting enzyme inhibitor; $C C B$, calcium channel blocker; ARB, angiotensin II receptor blocker; BB, beta-blocker. 


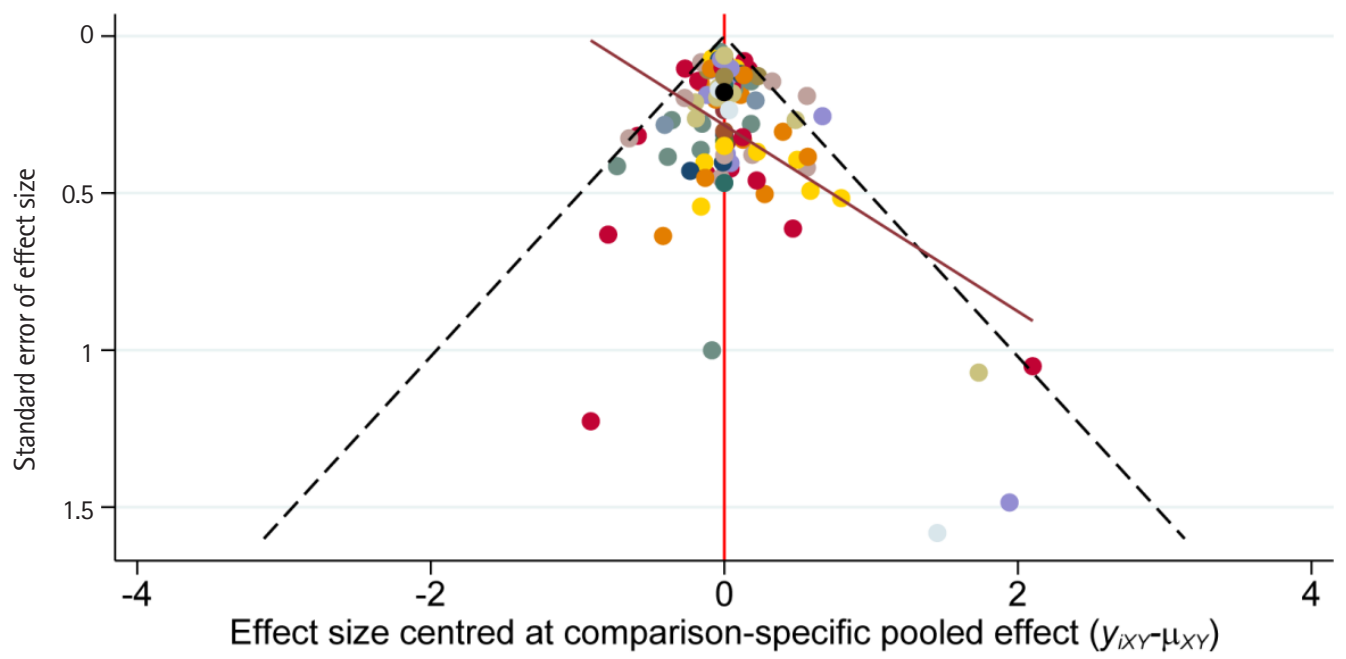

\begin{tabular}{|c|c|c|c|c|c|c|c|}
\hline - L vs N & - A vs J & - $\mathrm{A}$ vs $\mathrm{O}$ & - $A$ vs $B$ & $\bullet$ & $A$ vs $C$ & & $A$ vs $D$ \\
\hline - $A$ vs $E$ & - A vs F & - $A$ vs $G$ & - $\mathrm{A}$ vs $\mathrm{H}$ & $\bullet$ & A vs I & & $B$ vs $J$ \\
\hline - B vs C & - B vs D & $B$ vs $E$ & - B vs F & ---- & C vs $\mathrm{K}$ & & rval \\
\hline C V & C vs F & & D v & & D v & & vs $F$ \\
\hline$E$ vs $F$ & E vs $\mathrm{H}$ & G vs $M$ & H vs L & & $\mathrm{H}$ vs $\mathrm{N}$ & & I vs L \\
\hline
\end{tabular}

Supplementary Figure 32. Comparison-adjusted funnel plot for efficacy. A, placebo; B, calcium channel blocker (CCB); $C$, angiotensin II receptor blocker $(A R B) ; D$, angiotensin-converting enzyme inhibitor (ACEi); $E$, diuretic; $F$, beta-blocker (BB); $G, A C E i+d i u r e t i c ; H, C C B+d i u r e t i c ; ~ I, A R B+d i u r e t i c ; ~ J, B B / d i u r e t i c ; ~ K$, $A R B+A C E i ; L, A R B+C C B ; M, A C E i+C C B ; N, B B+C C B ; 0$, renin inhibitor. This is drawn only for comparisons with two or more studies.

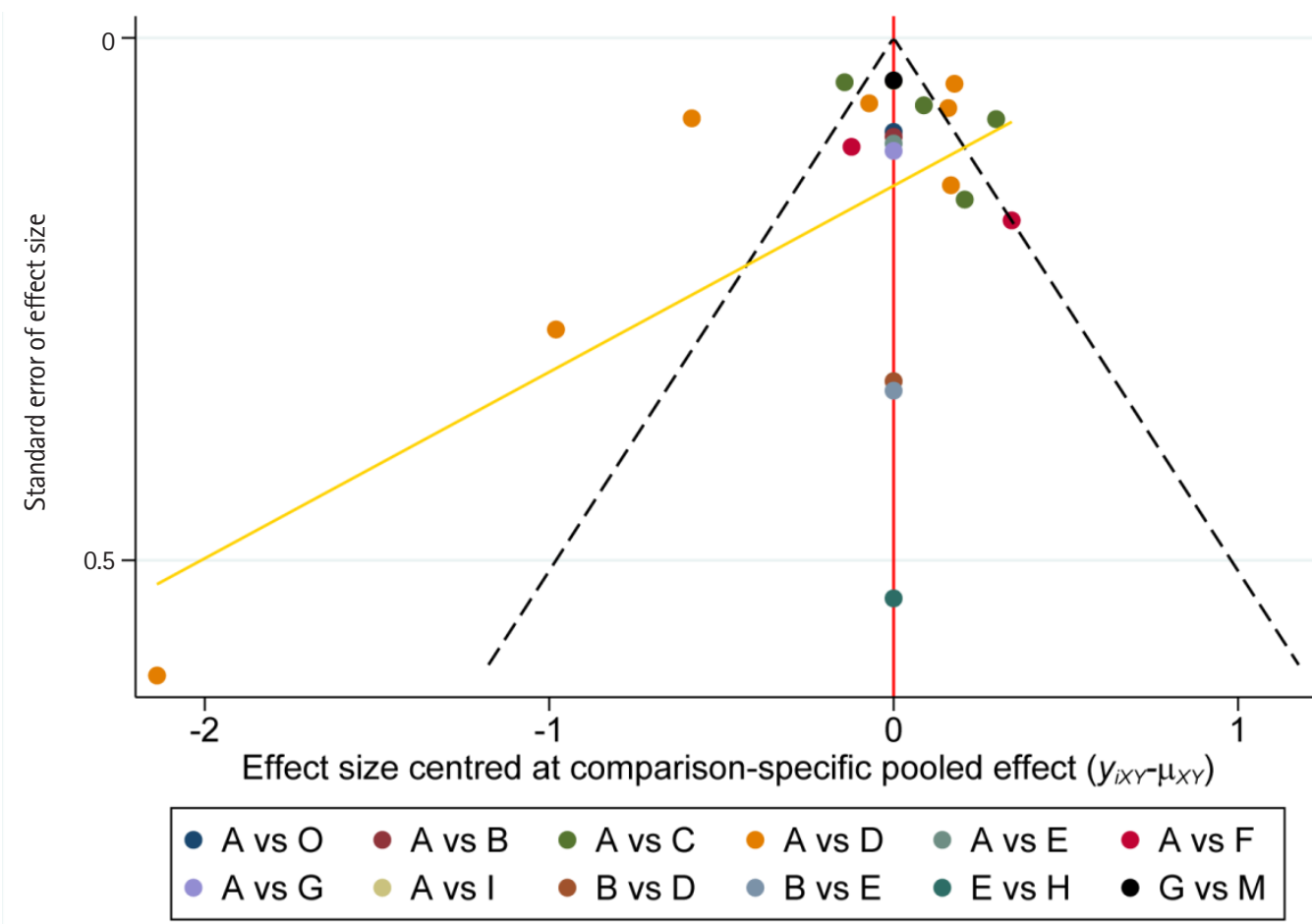

Supplementary Figure 33. Comparison-adjusted funnel plot for tolerability. A, placebo; B, calcium channel blocker (CCB); $C$, angiotensin II receptor blocker $(A R B) ; D$, angiotensin-converting enzyme inhibitor (ACEi); $E$, diuretic; $F$, beta-blocker (BB); $G$, ACEi+diuretic; $H, C C B+$ diuretic; I, ARB+diuretic; $M, A C E i+C C B ; 0$, renin inhibitor. This is drawn only for comparisons with two or more studies. 

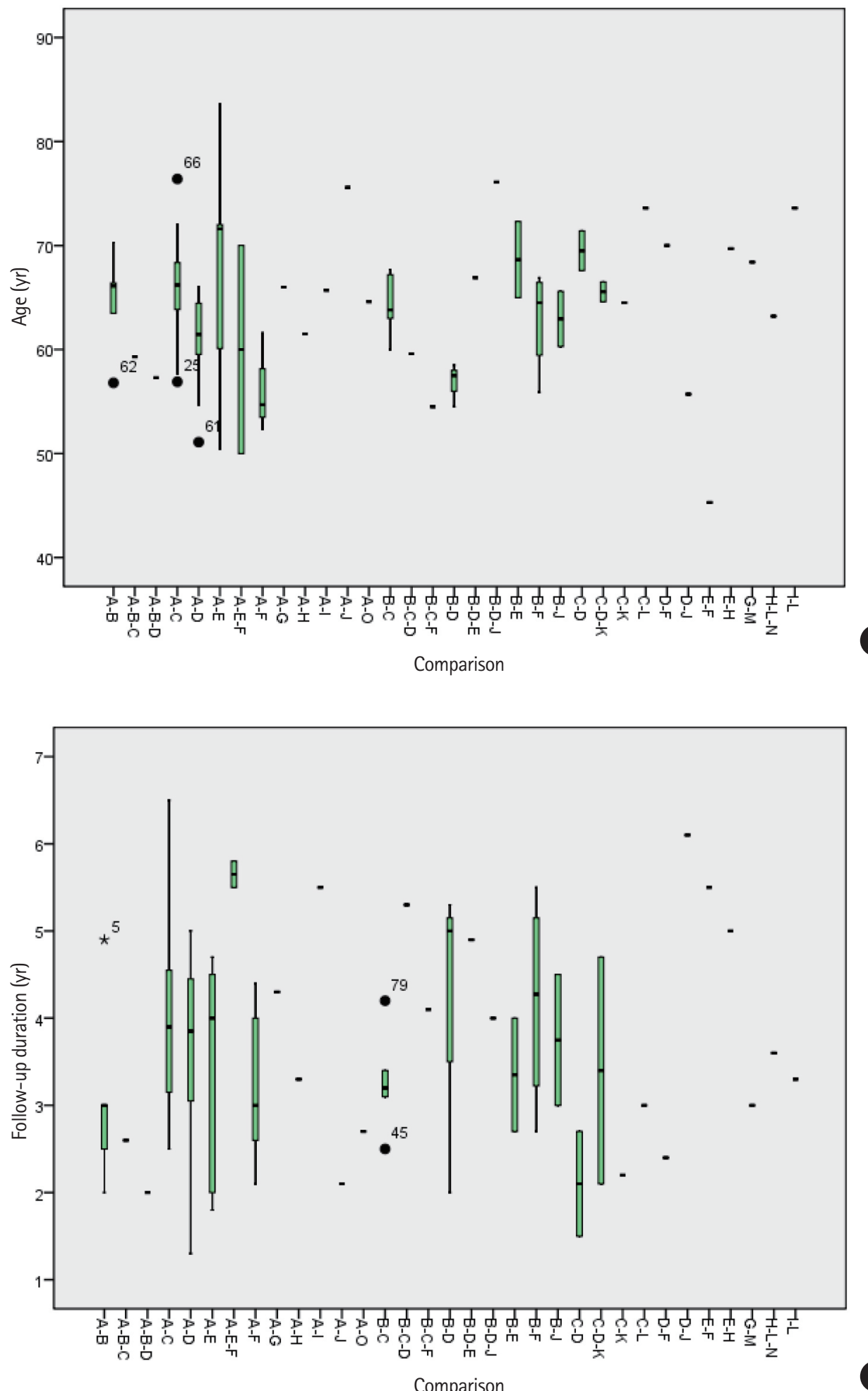

Supplementary Figure 34. Assessment of transitivity. (A) Age. (B) Follow-up duration. A, placebo; B, calcium channel blocker (CCB); $C$, angiotensin II receptor blocker (ARB); D, angiotensin-converting enzyme inhibitor (ACEi); E, diuretic; F, beta-blocker (BB); G, ACEi+diuretic; H, CCB+diuretic; I, ARB+diuretic; J, diuretic/BB; $K, A R B+A C E i ; L, A R B+C C B ; M, A C E i+C C B ; N, B B+C C B ; 0$, renin inhibitor. 


\section{Supplementary references}

1. Pfeffer MA, McMurray JJ, Velazquez EJ, Rouleau JL, Koøber $\mathrm{L}$, Maggioni AP, et al. Valsartan, captopril, or both in myocardial infarction complicated by heart failure, left ventricular dysfunction, or both. N Engl J Med 2003;349:18931906.

2. ONTARGET Investigators, Yusuf $\mathrm{S}$, Teo KK, Pogue J, Dyal L, Copland I, et al. Telmisartan, ramipril, or both in patients at high risk for vascular events. N Engl J Med 2008;358:15471559.

3. Berl T, Hunsicker LG, Lewis JB, Pfeffer MA, Porush JG, Rouleau JL, et al. Collaborative Study Group. Cardiovascular outcomes in the Irbesartan Diabetic Nephropathy Trial of patients with type 2 diabetes and overt nephropathy. Ann Intern Med 2003;138:542-549.

4. Nissen SE, Tuzcu EM, Libby P, Thompson PD, Ghali M, Garza $D$, et al. Effect of antihypertensive agents on cardiovascular events in patients with coronary disease and normal blood pressure: the CAMELOT study: a randomized controlled trial. JAMA 2004;292:2217-2225.

5. Hansson L, Zanchetti A, Carruthers SG, Dahlöf B, Elmfeldt D, Julius $S$, et al. Effects of intensive blood-pressure lowering and low-dose aspirin in patients with hypertension: principal results of the Hypertension Optimal Treatment (HOT) randomised trial. HOT Study Group. Lancet 1998;351:17551762.

6. Higgins JP, Thompson SG, Deeks JJ, Altman DG. Measuring inconsistency in meta-analyses. BMJ 2003;327:557-560.

7. Egger M, Davey Smith G, Schneider M, Minder C. Bias in meta-analysis detected by a simple, graphical test. BMJ 1997;315:629-634.

8. Dias S, Welton NJ, Sutton AJ, Ades AE. NICE DSU Technical Support Document 2: A Generalised Linear Modelling Framework for Pairwise and Network Meta-Analysis of Randomized Controlled Trials. National Institute for Health and Care Excellence. National Institute for Health and Care Excellence. http://nicedsu.org.uk/wp-content/uploads/2016/ 03/A-general-linear-modelling-framework-for-pair-wiseand-network-meta-analysis-of-randomised-controlled-trials.pdf 2011. Accessed December 23, 2020.

9. Lambert PC, Sutton AJ, Burton PR, Abrams KR, Jones DR. How vague is vague?: a simulation study of the impact of the use of vague prior distributions in MCMC using WinBUGS. Stat Med 2005;24:2401-2428.

10. Dias S, Welton NJ, Sutton AJ, Caldwell DM, Lu G, Ades AE. Evidence synthesis for decision making 4: inconsistency in networks of evidence based on randomized controlled tri- als. Med Decis Making 2013;33:641-656.

11. Biondi-Zoccai G, Abbate A, Benedetto U, Palmerini T, D'Ascenzo F, Frati G. Network meta-analysis for evidence synthesis: what is it and why is it posed to dominate cardiovascular decision making? Int J Cardiol 2015;182:309-314.

12. Gelman A, Rubin DB. Inference from iterative simulation using multiple sequences. Stat Sci 1992;7:457-472.

13. Lu G, Ades AE. Assessing evidence inconsistency in mixed treatment comparisons. J Am Stat Assoc 2006;101:447-459.

14. Dias S, Welton NJ, Caldwell DM, Ades AE. Checking consistency in mixed treatment comparison meta-analysis. Stat Med 2010;29:932-944.

15. Higgins JP, Jackson D, Barrett JK, Lu G, Ades AE, White IR. Consistency and inconsistency in network meta-analysis: concepts and models for multi-arm studies. Res Synth Methods 2012;3:98-110.

16. Salanti $G$, Ades AE, loannidis JP. Graphical methods and numerical summaries for presenting results from multiple-treatment meta-analysis: an overview and tutorial. J Clin Epidemiol 2011;64:163-171.

17. Chaimani A, Higgins JP, Mavridis D, Spyridonos P, Salanti G. Graphical tools for network meta-analysis in STATA. PLoS One 2013;8:e76654.

18. Poole-Wilson PA, Lubsen J, Kirwan BA, van Dalen FJ, Wagener $G$, Danchin $N$, et al. Effect of long-acting nifedipine on mortality and cardiovascular morbidity in patients with stable angina requiring treatment (ACTION trial): randomised controlled trial. Lancet 2004;364:849-857.

19. ACTIVE I Investigators, Yusuf S, Healey JS, Pogue J, Chrolavicius $\mathrm{S}$, Flather $\mathrm{M}$, et al. Irbesartan in patients with atrial fibrillation. N Engl J Med 2011;364:928-938.

20. Patel A; ADVANCE Collaborative Group, MacMahon $S$, Chalmers J, Neal B, Woodward M, et al. Effects of a fixed combination of perindopril and indapamide on macrovascular and microvascular outcomes in patients with type 2 diabetes mellitus (the ADVANCE trial): a randomised controlled trial. Lancet 2007;370:829-840.

21. Parving HH, Brenner BM, McMurray JJ, de Zeeuw D, Haffner $\mathrm{SM}$, Solomon SD, et al. Cardiorenal end points in a trial of aliskiren for type 2 diabetes. N Engl J Med 2012;367:22042213.

22. The Acute Infarction Ramipril Efficacy (AIRE) Study Investigators. Effect of ramipril on mortality and morbidity of survivors of acute myocardial infarction with clinical evidence of heart failure. Lancet 1993;342:821-828.

23. The Australian therapeutic trial in mild hypertension. Report by the Management Committee. Lancet 1980;1:1261-1267.

24. Hedblad B, Wikstrand J, Janzon L, Wedel H, Berglund G. 
Low-dose metoprolol $\mathrm{CR} / \mathrm{XL}$ and fluvastatin slow progression of carotid intima-media thickness: main results from the Beta-Blocker Cholesterol-Lowering Asymptomatic Plaque Study (BCAPS). Circulation 2001;103:1721-1726.

25. A randomized trial of propranolol in patients with acute myocardial infarction. II. Morbidity results. JAMA 1983;250:2814-2819.

26. Yusuf $S$, Pfeffer MA, Swedberg K, Granger CB, Held P, McMurray JJ, et al. Effects of candesartan in patients with chronic heart failure and preserved left-ventricular ejection fraction: the CHARM-Preserved Trial. Lancet 2003;362:777781.

27. McMurray JJ, Ostergren J, Swedberg $K$, Granger CB, Held $P_{1}$ Michelson EL, et al. Effects of candesartan in patients with chronic heart failure and reduced left-ventricular systolic function taking angiotensin-converting-enzyme inhibitors: the CHARM-Added trial. Lancet 2003;362:767-771.

28. Granger CB, McMurray JJ, Yusuf S, Held P, Michelson EL, Olofsson B, et al. Effects of candesartan in patients with chronic heart failure and reduced left-ventricular systolic function intolerant to angiotensin-converting-enzyme inhibitors: the CHARM-Alternative trial. Lancet 2003;362: 772-776.

29. Marre M, Lievre M, Chatellier G, Mann JF, Passa P, Ménard J, et al. Effects of low dose ramipril on cardiovascular and renal outcomes in patients with type 2 diabetes and raised excretion of urinary albumin: randomised, double blind, placebo controlled trial (the DIABHYCAR study). BMJ 2004;328:495.

30. Sjølie AK, Klein $R$, Porta $M$, Orchard T, Fuller J, Parving $H H_{\text {, }}$ et al. Effect of candesartan on progression and regression of retinopathy in type 2 diabetes (DIRECT-Protect 2): a randomised placebo-controlled trial. Lancet 2008;372:13851393.

31. DREAM Trial Investigators, Bosch J, Yusuf S, Gerstein HC, Pogue J, Sheridan $P_{1}$ et al. Effect of ramipril on the incidence of diabetes. N Engl J Med 2006;355:1551-1562.

32. The Dutch TIA Trial Study Group. Trial of secondary prevention with atenolol after transient ischemic attack or nondisabling ischemic stroke. Stroke 1993;24:543-548.

33. Fox KM; EURopean trial On reduction of cardiac events with Perindopril in stable coronary Artery disease Investigators. Efficacy of perindopril in reduction of cardiovascular events among patients with stable coronary artery disease: randomised, double-blind, placebo-controlled, multicentre trial (the EUROPA study). Lancet 2003;362:782-788.

34. Amery $A$, Birkenhäger $W$, Brixko $P$, Bulpitt $C$, Clement $D_{1}$ Deruyttere $\mathrm{M}$, et al. Mortality and morbidity results from the European Working Party on High Blood Pressure in the Elderly trial. Lancet 1985;1:1349-1354.

35. Liu L, Zhang Y, Liu G, Li W, Zhang X, Zanchetti A, et al. The Felodipine Event Reduction (FEVER) Study: a randomized long-term placebo-controlled trial in Chinese hypertensive patients. J Hypertens 2005;23:2157-2172.

36. Coope J, Warrender TS. Randomised trial of treatment of hypertension in elderly patients in primary care. $\mathrm{Br} \mathrm{Med} \mathrm{J}$ (Clin Res Ed) 1986;293:1145-1151.

37. Heart Outcomes Prevention Evaluation Study Investigators, Yusuf S, Sleight P, Pogue J, Bosch J, Davies R, et al. Effects of an angiotensin-converting-enzyme inhibitor, ramipril, on cardiovascular events in high-risk patients. $N$ Engl J Med 2000;342:145-153.

38. Lonn EM, Bosch J, López-Jaramillo P, Zhu J, Liu L, Pais P, et al. Blood-pressure lowering in intermediate-risk persons without cardiovascular disease. N Engl J Med 2016;374: 2009-2020.

39. Sun $M$, Zhou $H_{1}$ Jia Z. Prevention and treatment of stroke after hypertension for ten years in Hunan Province. Zhonghua Nei Ke Za Zhi 1997;36:312-314.

40. Beckett NS, Peters R, Fletcher AE, Staessen JA, Liu L, Dumitrascu $D$, et al. Treatment of hypertension in patients 80 years of age or older. N Engl J Med 2008;358:1887-1898.

41. Massie BM, Carson PE, McMurray JJ, Komajda M, McKelvie $\mathrm{R}$, Zile $M R$, et al. Irbesartan in patients with heart failure and preserved ejection fraction. N Engl J Med 2008;359: 2456-2467.

42. Ogawa $H$, Kim-Mitsuyama $S$, Matsui $K$, Jinnouchi T, Jinnouchi $H_{1}$ Arakawa K, et al. Angiotensin II receptor blocker-based therapy in Japanese elderly, high-risk, hypertensive patients. Am J Med 2012;125:981-990.

43. Helgeland A. Treatment of mild hypertension: a five year controlled drug trial. The Oslo study. Am J Med 1980;69: 725-732.

44. MacMahon S, Sharpe N, Gamble G, Clague A, Mhurchu CN, Clark T, et al. Randomized, placebo-controlled trial of the angiotensin-converting enzyme inhibitor, ramipril, in patients with coronary or other occlusive arterial disease. PART-2 Collaborative Research Group. Prevention of Atherosclerosis with Ramipril. J Am Coll Cardiol 2000;36:438443.

45. Liu L, Wang Z, Gong L, Zhang Y, Thijs L, Staessen JA, et al. Blood pressure reduction for the secondary prevention of stroke: a Chinese trial and a systematic review of the literature. Hypertens Res 2009;32:1032-1040.

46. Braunwald E, Domanski MJ, Fowler SE, Geller NL, Gersh BJ, Hsia J, et al. Angiotensin-converting-enzyme inhibition in 
stable coronary artery disease. N Engl J Med 2004;351:20582068.

47. Lüders S, Schrader J, Berger J, Unger T, Zidek W, Böhm M, et al. The PHARAO study: prevention of hypertension with the angiotensin-converting enzyme inhibitor ramipril in patients with high-normal blood pressure: a prospective, randomized, controlled prevention trial of the German Hypertension League. J Hypertens 2008;26:1487-1496.

48. Asselbergs FW, Diercks GF, Hillege $H L$, van Boven $A$, Janssen WM, Voors AA, et al. Effects of fosinopril and pravastatin on cardiovascular events in subjects with microalbuminuria. Circulation 2004;110:2809-2816.

49. Pitt $B$, Byington RP, Furberg CD, Hunninghake DB, Mancini $\mathrm{GB}$, Miller ME, et al. Effect of amlodipine on the progression of atherosclerosis and the occurrence of clinical events. PREVENT Investigators. Circulation 2000;102:1503-1510.

50. Yusuf S, Diener HC, Sacco RL, Cotton D, Ounpuu S, Lawton $W A$, et al. Telmisartan to prevent recurrent stroke and cardiovascular events. N Engl J Med 2008;359:1225-1237.

51. PROGRESS Collaborative Group. Randomised trial of a perindopril-based blood-pressure-lowering regimen among 6,105 individuals with previous stroke or transient ischaemic attack. Lancet 2001;358:1033-1041.

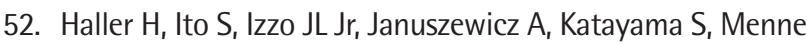
$J$, et al. Olmesartan for the delay or prevention of microalbuminuria in type 2 diabetes. N Engl J Med 2011;364:907917.

53. Lithell H, Hansson L, Skoog I, Elmfeldt D, Hofman A, Olofsson $B$, et al. The Study on Cognition and Prognosis in the Elderly (SCOPE): principal results of a randomized double-blind intervention trial. J Hypertens 2003;21:875-886.

54. SHEP Cooperative Research Group. Prevention of stroke by antihypertensive drug treatment in older persons with isolated systolic hypertension: final results of the Systolic Hypertension in the Elderly Program (SHEP). JAMA 1991; 265:3255-3264.

55. SOLVD Investigators, Yusuf $\mathrm{S}$, Pitt B, Davis CE, Hood WB, Cohn JN. Effect of enalapril on survival in patients with reduced left ventricular ejection fractions and congestive heart failure. N Engl J Med 1991;325:293-302.

56. SOLVD Investigators, Yusuf $S_{1}$ Pitt B, Davis CE, Hood WB Jr, Cohn JN. Effect of enalapril on mortality and the development of heart failure in asymptomatic patients with reduced left ventricular ejection fractions. N Engl J Med 1992; 327:685-691.

57. Sakata Y, Shiba N, Takahashi J, Miyata S, Nochioka K, Miura $M$, et al. Clinical impacts of additive use of olmesartan in hypertensive patients with chronic heart failure: the sup- plemental benefit of an angiotensin receptor blocker in hypertensive patients with stable heart failure using olmesar$\tan$ (SUPPORT) trial. Eur Heart J 2015;36:915-923.

58. Gong L, Zhang W, Zhu Y, Zhu J, Kong D, Pagé V, et al. Shanghai trial of nifedipine in the elderly (STONE). J Hypertens 1996;14:1237-1245.

59. Dahlöf $B$, Lindholm LH, Hansson L, Scherstén B, Ekbom $T$, Wester PO. Morbidity and mortality in the Swedish Trial in Old Patients with Hypertension (STOP-Hypertension). Lancet 1991;338:1281-1285.

60. Liu L, Wang JG, Gong L, Liu G, Staessen JA. Comparison of active treatment and placebo in older Chinese patients with isolated systolic hypertension. Systolic Hypertension in China (Syst-China) Collaborative Group. J Hypertens 1998; 16(12 Pt 1):1823-1829.

61. Staessen JA, Fagard R, Thijs L, Celis H, Arabidze GG, Birkenhäger WH, et al. Randomised double-blind comparison of placebo and active treatment for older patients with isolated systolic hypertension. The Systolic Hypertension in Europe (Syst-Eur) Trial Investigators. Lancet 1997;350:757764.

62. Telmisartan Randomised AssessmeNt Study in ACE iNtolerant subjects with cardiovascular Disease (TRANSCEND) Investigators, Yusuf S, Teo K, Anderson C, Pogue J, Dyal L, et al. Effects of the angiotensin-receptor blocker telmisartan on cardiovascular events in high-risk patients intolerant to angiotensin-converting enzyme inhibitors: a randomized controlled trial. Lancet 2008;372:1174-1183.

63. Fried LF, Emanuele N, Zhang JH, Brophy M, Conner TA,

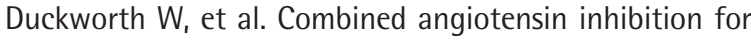
the treatment of diabetic nephropathy. N Engl J Med 2013;369:1892-1903.

64. Appel $\amalg$, Wright JT Jr, Greene T, Agodoa LY, Astor BC, Bakris $\mathrm{GL}$, et al. Intensive blood-pressure control in hypertensive chronic kidney disease. N Engl J Med 2010;363:918-929.

65. Estacio RO, Jeffers BW, Hiatt WR, Biggerstaff SL, Gifford N, Schrier RW. The effect of nisoldipine as compared with enalapril on cardiovascular outcomes in patients with non-insulin-dependent diabetes and hypertension. $N$ Engl J Med 1998;338:645-652.

66. Schrier RW, Estacio RO, Esler A, Mehler P. Effects of aggressive blood pressure control in normotensive type 2 diabetic patients on albuminuria, retinopathy and strokes. Kidney Int 2002;61:1086-1097.

67. ACCORD Study Group, Cushman WC, Evans GW, Byington RP, Goff DC Jr, Grimm RH Jr, et al. Effects of intensive blood-pressure control in type 2 diabetes mellitus. $N$ Engl J Med 2010;362:1575-1585. 
68. Hannson L. The BBB Study: the effect of intensified antihypertensive treatment on the level of blood pressure, side-effects, morbidity and mortality in "well-treated" hypertensive patients. Behandla Blodtryck Bättre. Blood Press 1994;3:248-254.

69. Verdecchia P, Staessen JA, Angeli F, de Simone G, Achilli A, Ganau $A$, et al. Usual versus tight control of systolic blood pressure in non-diabetic patients with hypertension (Cardio-Sis): an open-label randomised trial. Lancet 2009;374: 525-533.

70. Hypertension Detection and Follow-up Program Cooperative Group. Five-year findings of the hypertension detection and follow-up program. III. Reduction in stroke incidence among persons with high blood pressure. JAMA 1982;247: 633-638.

71. Asayama K, Ohkubo T, Metoki H, Obara T, Inoue R, Kikuya $M$, et al. Cardiovascular outcomes in the first trial of antihypertensive therapy guided by self-measured home blood pressure. Hypertens Res 2012;35:1102-1110.

72. JATOS Study Group. Principal results of the Japanese trial to assess optimal systolic blood pressure in elderly hypertensive patients (JATOS). Hypertens Res 2008;31:2115-2127.

73. SPRINT Research Group, Wright JT Jr, Williamson JD, Whelton PK, Snyder JK, Sink KM, et al. A randomized trial of intensive versus standard blood-pressure control. N Engl J Med 2015;373:2103-2116.

74. SPS3 Study Group, Benavente OR, Coffey CS, Conwit R, Hart RG, McClure LA, et al. Blood-pressure targets in patients with recent lacunar stroke: the SPS3 randomised trial. Lancet 2013;382:507-515.

75. UK Prospective Diabetes Study Group. Tight blood pressure control and risk of macrovascular and microvascular complications in type 2 diabetes: UKPDS 38. BMJ 1998;317:703713.

76. Ogihara $T$, Saruta $T$, Rakugi $H_{1}$ Matsuoka $H_{1}$ Shimamoto $K_{1}$ Shimada $K_{1}$ et al. Target blood pressure for treatment of isolated systolic hypertension in the elderly: valsartan in elderly isolated systolic hypertension study. Hypertension 2010;56:196-202.

77. Hansson L, Lindholm LH, Niskanen L, Lanke J, Hedner T, Niklason $A$, et al. Effect of angiotensin-converting-enzyme inhibition compared with conventional therapy on cardiovascular morbidity and mortality in hypertension: the Captopril Prevention Project (CAPPP) randomised trial. Lancet 1999;353:611-616.

78. Cardiovascular risk and risk factors in a randomized trial of treatment based on the beta-blocker oxprenolol: the International Prospective Primary Prevention Study in Hyperten- sion (IPPPSH). The IPPPSH Collaborative Group. J Hypertens 1985:3:379-392.

79. Hansson L, Hedner T, Lund-Johansen P, Kjeldsen SE, Lindholm LH, Syvertsen JO, et al. Randomised trial of effects of calcium antagonists compared with diuretics and beta-blockers on cardiovascular morbidity and mortality in hypertension: the Nordic Diltiazem (NORDIL) study. Lancet 2000;356:359-365.

80. Jamerson K, Weber MA, Bakris GL, Dahlöf B, Pitt B, Shi V, et al. Benazepril plus amlodipine or hydrochlorothiazide for hypertension in high-risk patients. N Engl J Med 2008;359: 2417-2428.

81. ALLHAT Officers and Coordinators for the ALLHAT Collaborative Research Group. The Antihypertensive and Lipid-Lowering Treatment to Prevent Heart Attack Trial. Major outcomes in high-risk hypertensive patients randomized to angiotensin-converting enzyme inhibitor or calcium channel blocker vs diuretic: the Antihypertensive and Lipid-Lowering Treatment to Prevent Heart Attack Trial (ALLHAT). JAMA 2002;288:2981-2997.

82. Dahlöf B, Sever PS, Poulter NR, Wedel H, Beevers DG, Caulfield $\mathrm{M}$, et al. Prevention of cardiovascular events with an antihypertensive regimen of amlodipine adding perindopril as required versus atenolol adding bendroflumethiazide as required, in the Anglo-Scandinavian Cardiac Outcomes Trial-Blood Pressure Lowering Arm (ASCOT-BPLA): a multicentre randomised controlled trial. Lancet 2005;366:895906.

83. Ogihara T, Nakao K, Fukui T, Fukiyama K, Ueshima K, Oba K, et al. Effects of candesartan compared with amlodipine in hypertensive patients with high cardiovascular risks: candesartan antihypertensive survival evaluation in Japan trial. Hypertension 2008;51:393-398.

84. Ogihara T, Saruta T, Rakugi H, Saito I, Shimamoto K, Matsuoka $\mathrm{H}$, et al. Combinations of olmesartan and a calcium channel blocker or a diuretic in elderly hypertensive patients: a randomized, controlled trial. J Hypertens 2014;32: 2054-2063.

85. Black HR, Elliott WJ, Grandits G, Grambsch P, Lucente T, White WB, et al. Principal results of the Controlled Onset Verapamil Investigation of Cardiovascular End Points (CONVINCE) trial. JAMA 2003;289:2073-2082.

86. Matsuzaki M, Ogihara $T$, Umemoto $S$, Rakugi $H$, Matsuoka $H$, Shimada $K$, et al. Prevention of cardiovascular events with calcium channel blocker-based combination therapies in patients with hypertension: a randomized controlled trial. J Hypertens 2011;29:1649-1659.

87. Suzuki H, Kanno Y; Efficacy of Candesartan on Outcome in 
Saitama Trial (E-COST) Group. Effects of candesartan on cardiovascular outcomes in Japanese hypertensive patients. Hypertens Res 2005;28:307-314.

88. Zanchetti A, Bond MG, Hennig M, Neiss A, Mancia G, Dal Palù $C$, et al. Calcium antagonist lacidipine slows down progression of asymptomatic carotid atherosclerosis: principal results of the European Lacidipine Study on Atherosclerosis (ELSA), a randomized, double-blind, long-term trial. Circulation 2002;106:2422-2427.

89. Brown MJ, Palmer CR, Castaigne A, de Leeuw PW, Mancia G, Rosenthal T, et al. Morbidity and mortality in patients randomised to double-blind treatment with a long-acting calcium-channel blocker or diuretic in the International Nifedipine GITS study: Intervention as a Goal in Hypertension Treatment (INSIGHT). Lancet 2000;356:366-372.

90. Pepine CJ, Handberg EM, Cooper-DeHoff RM, Marks RG, Kowey $\mathrm{P}$, Messerli FH, et al. A calcium antagonist vs a non-calcium antagonist hypertension treatment strategy for patients with coronary artery disease. The International Verapamil-Trandolapril Study (INVEST): a randomized controlled trial. JAMA 2003;290:2805-2816.

91. Dahlöf B, Devereux RB, Kjeldsen $S E$, Julius $S$, Beevers $G$, de Faire $U$, et al. Cardiovascular morbidity and mortality in the Losartan Intervention For Endpoint reduction in hypertension study (LIFE): a randomised trial against atenolol. Lancet 2002;359:995-1003.

92. Schrader J, Lüders $S$, Kulschewski A, Hammersen F, Plate $K_{\text {, }}$ Berger J, et al. Morbidity and mortality after stroke, eprosartan compared with nitrendipine for secondary prevention: principal results of a prospective randomized controlled study (MOSES). Stroke 2005;36:1218-1226.

93. Medical Research Council Working Party. MRC trial of treatment of mild hypertension: principal results. Br Med J (Clin Res Ed) 1985;291:97-104.

94. MRC Working Party. Medical Research Council trial of treatment of hypertension in older adults: principal results. BMJ 1992;304:405-412.

95. Muramatsu T, Matsushita K, Yamashita K, Kondo T, Maeda K, Shintani S, et al. Comparison between valsartan and amlodipine regarding cardiovascular morbidity and mortality in hypertensive patients with glucose intolerance: NAGOYA HEART Study. Hypertension 2012;59:580-586.

96. National Intervention Cooperative Study in Elderly Hypertensives Study Group. Randomized double-blind compari- son of a calcium antagonist and a diuretic in elderly hypertensives. Hypertension 1999;34:1129-1133.

97. Ogihara T. Practitioner's Trial on the Efficacy of Antihypertensive Treatment in the Elderly Hypertension (The PATE-Hypertension Study) in Japan. Am J Hypertens 2000; 13(5 Pt 1):461-467.

98. Malacco E, Mancia G, Rappelli A, Menotti A, Zuccaro MS, Coppini $A$, et al. Treatment of isolated systolic hypertension: the SHELL study results. Blood Press 2003;12:160-167.

99. Hansson L, Lindholm LH, Ekbom T, Dahlöf B, Lanke J, Scherstén $B$, et al. Randomised trial of old and new antihypertensive drugs in elderly patients: cardiovascular mortality and morbidity the Swedish Trial in Old Patients with Hypertension-2 study. Lancet 1999;354:1751-1756.

100. Julius S, Kjeldsen SE, Weber M, Brunner HR, Ekman S, Hans-

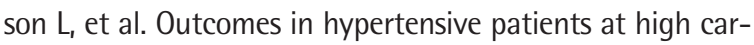
diovascular risk treated with regimens based on valsartan or amlodipine: the VALUE randomized trial. Lancet 2004;363:2022-2031.

101. Narumi H, Takano H, Shindo S, Fujita M, Mizuma H, Kuwabara $Y$, et al. Effects of valsartan and amlodipine on cardiorenal protection in Japanese hypertensive patients: the Valsartan Amlodipine Randomized Trial. Hypertens Res 2011;34:62-69.

102. Rosei $E A$, Dal Palù $C$, Leonetti $G$, Magnani $B$, Pessina $A$, Zanchetti A. Clinical results of the Verapamil in Hypertension and Atherosclerosis Study. VHAS Investigators. J Hypertens 1997; 15:1337-1344.

103. Dickstein K, Kjekshus J; OPTIMAAL Steering Committee of the OPTIMAAL Study Group. Effects of losartan and captopril on mortality and morbidity in high-risk patients after acute myocardial infarction: the OPTIMAAL randomised trial. Optimal Trial in Myocardial Infarction with Angiotensin II Antagonist Losartan. Lancet 2002;360:752-760.

104. Pitt B, Poole-Wilson PA, Segal R, Martinez FA, Dickstein $K_{1}$ Camm AJ, et al. Effect of losartan compared with captopril on mortality in patients with symptomatic heart failure: randomised trial: the Losartan Heart Failure Survival Study ELITE II. Lancet 2000;355:1582-1587.

105. NAVIGATOR Study Group, McMurray JJ, Holman RR, Haffner SM, Bethel MA, Holzhauer B, et al. Effect of valsartan on the incidence of diabetes and cardiovascular events. $N$ Engl J Med 2010;362:1477-1490. 